DOMENICA PALOMARIS MARIANO DE SOUZA

AVALIAÇÃO DOS EFEITOS TÓXICOS DA Senna occidentalis EM RATOS. PARÂMETROS: BIOQUÍMICOS,HEMATOLÓGICOS, ANATOMOPATOLÓGICOS E INFLAMATÓRIOS. 


\section{AVALIAÇÃO DOS EFEITOS TÓXICOS DA Senna occidentalis EM RATOS. PARÂMETROS: BIOQUÍMICOS, HEMATOLÓGICOS, ANATOMOPATOLÓGICOS E INFLAMATÓRIOS.}

Dissertação apresentada ao Programa de Pós-Graduação em Patologia Experimental e Comparada da Faculdade de Medicina Veterinária e Zootecnia da Universidade de São Paulo para obtenção do título de Mestre em Ciências

Departamento:

Palologia

Área de Concentração:

Patologia Experimental e Comparada

Orientador:

Profa. Dra. Silvana Lima Górniak 
Autorizo a reproducăo parcial ou total desta obra, para fins académicos, desde que citada a fonte.

DADOS INTERNACIONAIS DE CATALOGAÇĀO-NA-PUBLICAÇÃO

(Biblioteca da Faculdade de Medicina Veterinsria e Zootecnia da Universidede de Sto Paulo)

\section{T.1462 Mariano-Souza, Domenica Palomaris}

FMVZ Avaliaçăa dos efeitos tóxicos da Senne occidentelis em ratos. Parámetros: bioquímicos, hematológicos, anatomopatológicos e inflamatórios / Domenica Palomaris Mariano-Souzz. - Săo Paulo: D. P. Mariano-Souza, 2005.

159 f. : il.

Dissertaçåo (mestrado) - Universidade de Săo Paulo. Faculdade de Medicina Veterinária e Zootecnia. Departamento de Patologia, 2005.

Programa de Pós-graduaçăo: Patologia Experimental e Comparada.

Area de concentraça: Patologia Experimental e Comparada.

Orientador, Profa. Dra. Silvana Lima Gómiak.

1. Ratos. 2. Senna occidentelis. 3. Plantas tóxicas. 4. Patologia animal. I. Titulo. 


\section{UNIVERSIDADE DE SÃO PAULO \\ Faculdade de Medicina Veterinária e Zootecnia \\ Cidade Universitária "Armando de Salles Oliveira" \\ Comissão Bioética \\ CERTIFICADO}

Certificamos que o Projeto intitulado "Estudo da resposta inflamatória e da atividade de macrófagos em ratas tratadas prolongadamente com sementes de Senna occidentalis.", Protocolo $n^{0} 28 / 2002$, sob a responsabilidade da Prof ${ }^{\mathrm{a}} \mathrm{Dr}^{\mathrm{a}}$ Silvana Lima Górniak, está de acordo com os princípios éticos de experimentação animal da Comissão de Bioética da Faculdade de Medicina Veterinária e Zootecnia da Universidade de São Paulo e foi aprovado em reunião de $20 / 03 / 2002$.

(We certify that the Research "Inflammatory study and macrophage activity of rats treated chronically with $\mathrm{S}$. occidentalis seeds" protocol number 28/2002, under the responsability of $\operatorname{Prof}^{\mathrm{a}} \mathrm{Dr}^{\mathrm{a}}$ Silvana Lima Górniak, agree with Ethical Principles in Animal Research adopted by Bioethic Commision of the Faculty of Veterinary Medicine and Zootechny of University of São Paulo and was approved in 20/03/2002 meeting.)

São Paulo, 22 de março de 2002

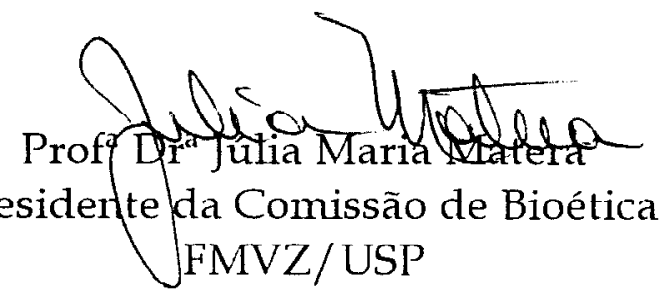


FOLHA DE AVALIAÇÃO

Nome do autor: MARIANO-SOUZA, Domenica Palomaris

Título: Avaliação dos efeitos tóxicos da Senna occidentalis em ratos. Parâmetros: bioquímicos, hematológicos, anatomopatológicos e inflamatórios.

Data:

Dissertação apresentada ao programa de Patologia Experimental e Comparada da Faculdade de Medicina Veterinária e Zootecnia da Universidade de São Paulo para obtenção do título de Mestre em Ciências

Banca Examinadora

Prof.Dr.

Instituição:

Assinatura:

Julgamento:

Prof.Dr.

Instituição:

Assinatura:

Julgamento:

Prof.Dr.

Instituição:

Assinatura: Julgamento: 
* A energia mantenedora de todo universo, por me proporcionar ao longo desta caminhada, sentimentos únicos dentro deste incessante processo de criação e doação que a é vida.

* A minha mãe Marise e a minha avó Cynira, que pelas águas sagradas de seus úteros geraram o amor incondicional, este que se faz presente todos os dias, seja nas noites em claro, nos dias de incerteza e em cada etapa vivida.

* Ao meu pai Dionísio (in memoriam), pelos doces e inesquecíveis momentos que se tornaram únicos em minha vida e por todo amor dedicado durante sua vida.

* À minha amada família Mariano-Souza, por todo amor e carinho, e por fornecerem todo subsídio espiritual e familiar.

* Ao meu amigo e irmão Altamir por toda amizade, convivência e auxílio ao longo desta etapa da minha vida.

* Aos animais de laboratório utilizados em meus experimentos.

"Sim todo amor é sagrado, e o fruto do trabalho é mais que sagrado, meu amor"... 
Á Profa. Dra. Silvana Lima Górniak, por toda sua dedicação, por me acolher desde o início, por todas oportunidades oferecidas, pela confiança, orientação e atenção dedicados. $E$ por ter me feito acreditar que tudo é possível, a partir do momento em que se acredita muito no que se faz. Obrigada por tudo! 
Á Profa. Dra. Célia Aparecida Paulino, por toda sua dedicação, paciência, amizade e por toda confiança depositada em mim desde de os tempos de graduação. Pelo incentivo, preocupação e atenção dispensadas em todos os momentos vividos. Obrigada por tudo! 
Meus mais sinceros agradecimentos, a todos que de alguma forma, contribuíram durante o período de execução e realização desta dissertação.

*à Profa. Dra. Maria Lúcia Zaidan Dagli, pela paciência, contribuição e auxílio nas leituras do material histopatológico;

*à Profa. Dra. Mitsue Haraguchi pela contribuição e ajuda na coleta de sementes de Senna occidentalis,

* Ao Prof. Dr. Luciano Freitas Felicío por toda carisma e auxílio para finalização da presente dissertação;

* Ao Prof. Dr. Paulo Maiorka, por toda sua amizade, contribuição e pelo seu auxílio durante as leituras do material histopatológico;

* À Profa. Dra. Primavera Borelli da Faculdade de Ciências Farmacêuticas - USP pela orientação a respeito das técnicas de hematologia e por toda sua solicitude para com nosso grupo de pesquisa;

* Ao Instituto Butantã de São Paulo, pela concessão de todas as vacinas de Onco-BCG utilizadas neste trabalho;

*as funcionários do Centro de Pesquisa Toxicológico (CEPTOX): Paulo César, Éster, Dona Mary, Marquinhos, Estevão e Adilson, por toda receptividade e colaboração na preparação dos comedouros adaptados e na coleta de Senna occidentalis.

* A bibliotecária da FMVZ/USP, Elza Maria R. B. Faquim e aos funcionários Ana Cristina, Cristiane, Elena, Maria Inês e Rose por todo auxílio na confecção desta dissertação, carinho e simpatia;

*aos técnicos de laboratório Magali, Priscila e Ricardo pelo apoio técnico prestado;

*aos funcionários do Biotério do VPT: Claudia, Idalina, Herculano, Nelsinho, Seu Luiz e Rosires, pelo fornecimento e cuidado com os animais utilizados neste trabalho, pela prontidão e simpatia; 
* Aos funcionários do laboratório de histopatologia Cláudio Arroyo, Luciano e Marguite, pela confecção dos cortes histológicos e auxílio prestado neste trabalho;

* As secretárias de pós-graduação Cláudia, Dayse e Sandra, por toda presteza e simpatia;

* As secretárias de Departamento Cristina, Cláudia, Romeika e Silvia, por toda paciência e carinho dedicados;

* Aos meus irmãos científicos: Altamir, Andréia, Benito, Breno, Helena, Isis, Marcos e Stella por todo companheirismo e ajuda para a realização deste e de futuros trabalhos e pelos bons momentos de descontração;

Aos meus "amigos-irmãos", Alexandra Nicolau, Adriana Valera, Fabiana Godoy, Helena Manzano, Paulo Maiorka e Milena Soares, por toda solidariedade, paciência e amizade irrestrita;

* Aos colegas de pós-graduação: Aline, Ana Paula, Cristina Massoco, Daniel, Dario, Eduardo, Elaine, Evelise, Fabiana Xavier, Fábio, Glaucie, Kátia Kimura, Letícia, Luciana Neves, Luciana Moura, Lílian, Marcela, Maria Isabel, Mônica, Renata, Renato, Sílvia Oloris, Soraia, Ricardo Lazarini e Tereza, por todo apoio e companheirismo;

* Aos meus amigos de prontidão, por toda choradeira, reclamação e constante ausência ao longo da graduação e pós-graduação. Amo vocês!

* Ao Conselho Nacional de Desenvolvimento Científico e Tecnologia (CNPq) pelo financiamento desta pesquisa. 


\section{RESUMO}

MARIANO-SOUZA, D. P. Avaliação dos efeitos tóxicos da Senna occidentalis em ratos. Parâmetros: bioquímicos, hematológicos, anatomopatológicos e inflamatórios. [Evaluation of toxic effects of Senna occidentalis in rats. Biochemical, hematological, anatomopatological and inflammatory parameters]. 2005. $159 \mathrm{f}$. Dissertação (Mestrado em Ciências) - Faculdade de Medicina Veterinária e Zootecnia, Universidade de São Paulo, São Paulo, 2005.

Tanto no Brasil como em vários outros países, a Senna occidentalis é uma planta de interesse agropecuário, pois é encontrada em pastos ou como contaminante de cereais, podendo, causar intoxicação na criação animal. Além disto, vem sendo utilizada, empiricamente, na Medicina Humana, para o tratamento de várias afecções. Em estudo recente, verificou-se que frangos tratados com sementes de S. occidentalis apresentavam, além das lesões musculares, alterações em órgãos linfóides. Assim, o presente trabalho procurou verificar se as sementes de S. occidentalis poderiam produzir efeitos tóxicos nos órgãos linfóides de mamíferos, utilizando, para tal, ratos como modelo experimental. As sementes de S. occidentalis foram administradas, durante 14 dias, a ratos Wistar (150-200g), em diferentes concentrações de sementes desta planta na ração: 1\% (So1), 2\% (So2) e 4\%(So4). Os animais do grupo peer-feeding (PF) receberam a mesma quantidade de ração consumida pelos animais tratados com So4, porém isentas da planta. Foram avaliados os seguintes parâmetros: consumo de água e ração e ganho de peso, avaliação hematológica e bioquímica, além da histopatologia, morfometria e de ensaios preconizados para o estudo da resposta imunológica não específica. Todos os ratos pertencentes aos diferentes grupos experimentais apresentaram diminuição no consumo de ração e água e no ganho de peso. A avaliação hematológica revelou anemia microcítica e hipocrômica nos animais que receberam $4 \%$ da planta. Além 
disso, todos os animais dos grupos So2 e So4 apresentaram depleção de células linfóides e redução da polpa branca do baço. Os ratos pertencentes ao grupo So4 apresentaram redução significante no peso relativo do timo e diminuição significante na região cortical e também no diâmetro dos folículos medulares deste órgão. Estes mesmos animais apresentaram diminuição da produção de água oxigenada e óxido nítrico. Em relação à resposta inflamatória, todos os animais dos grupos experimentais, apresentaram redução na evolução do edema inflamatório agudo e crônico. Assim, a presente pesquisa mostrou que, também em mamíferos, a S. occidentalis pode comprometer o sistema imunológico, haja vista as alterações encontradas no timo e baço dos ratos expostos à planta. Além disso, verificou-se que as sementes desta planta também promovem efeitos tóxicos sobre eritrócitos e alterações na resposta inflamatória. A inclusão do grupo PF permitiu verificar que os efeitos aqui encontrados não são devidos a possíveis alterações nutricionais promovidas pela queda do consumo de alimento e sim relacionados ao efeito tóxico direto da S. occidentalis.

Palavras-chaves: Ratos. Senna occidentalis. Plantas tóxicas. Patologia animal. 


\begin{abstract}
MARIANO-SOUZA, D. P. Evaluation of toxic effects of Senna occidentalis in rats. Biochemical, hematological, anatomopatological and inflammatory parameters. [Avaliação dos efeitos tóxicos da Senna occidentalis em ratos. Parâmetros: bioquímicos, hematológicos, anatomopatológicos e inflamatórios]. 2005. 159 f. Dissertação (Mestrado em Ciências) - Faculdade de Medicina Veterinária e Zootecnia, Universidade de São Paulo, São Paulo, 2005.
\end{abstract}

Senna occidentalis is a weed which grows in pasture along fences and fields cultivated with cereals as corn and soybean and many reports have been showing intoxication with this plant in different animal species. The effects of daily administration of $S$. occidentalis seeds in different concentrations 1\% (So1), $2 \%$ (So2) and 4\% (So4) in ration was investigated in rats. It was also evaluated the effects of rats that received the same amount of ration to those of So4-group, however free of S. occidentalis seeds, (PF-rats). The experimental period lasted 14 days and the effects were evaluated on the basis of food consumption, weight gain, hematological and biochemical parameters, inflammatory and immunological responses, as well as histopathology, relative organ weight and morphometric analysis. All experimental animals, showed significant decrease in ration and water consumption and body weight gain. The hematological parameters revealed microcytic and hypochromic anemia in those animals treated with the higher concentration S. occidentalis seeds. Morphometric analysis of the spleen from So2 and So4-animals displayed a significant decrease in the cortical thickness. The thymus from So4-rats showed reduction in the organ size, and the morphometry revealed thickness and reduction of the diameter of the follicles at the cortical area. The same animals presented reduction in hydrogen peroxide and nitric oxide 
production. In inflammatory response all experimental animals, showed significant decrease in the evolution of acute and chronic edema. These results showed that the alterations found in this present study are related to the poisonous effects of the S. occidentalis and not to the malnutrition.

Key words: Rats. Senna occidentalis. Poisonous Plants. Animal Pathology. 


\section{LISTA DE TABELAS}

Tabela 1- Consumo médio e total de água (em $\mathrm{ml}$ ) pelos ratos tratados durante 14 dias com diferentes concentrações (0\%, 1\%, 2\% e 4\%) de sementes de $S$. occidentalis, na ração e seu grupo peer-feeding. Foram utilizados 10 animais por grupo. São apresentados as medias e os respectivos erros padrões.

Tabela 2- Consumo médio e total de ração (em g) pelos ratos tratados durante 14 dias com diferentes concentrações (0\%, 1\%, 2\% e 4\%) de sementes de $S$. occidentalis, na ração. Foram utilizados 10 animais por grupo. São apresentados as medias e os respectivos erros padrões.

Tabela 3- Peso médio (em g), de ratos tratados durante 14 dias com diferentes concentrações $(0 \%, 1 \%, 2 \%$ e $4 \%)$ de sementes de S. occidentalis, na ração e seu grupo peer-feeding. Foram utilizados 10 animais por grupo. São apresentados as medias e os respectivos erros padrões

Tabela 4- Peso semanal e total (em g), de ratos tratados durante 14 dias com diferentes concentrações $(0 \%, 1 \%, 2 \%$ e $4 \%)$ de sementes de S. occidentalis, na ração e seu grupo peer-feeding. Foram utilizados 10 animais por grupo. São apresentados as medias e os respectivos erros padrões.

Tabela 5- Número médio de eritrócitos $\left(\times 10^{6} / \mathrm{mm}^{3}\right)$ e leucócitos $\left(\times 10^{6} / \mathrm{mm}^{3}\right)$ e os valores médios do hematócrito - HCT (\%) e hemoglobina - HGB $(\mathrm{g} / \mathrm{dL})$, volume corpuscular médio - VCM $\left(\mu^{3}\right)$, hemoglobina corpuscular média - HCM $(\mu \mu \mathrm{g})$ e concentração de hemoglobina corpuscular média - CHCM (\%), de ratos tratados durante 14 dias com diferentes concentrações $(0 \%, 1 \%, 2 \%$ e $4 \%)$ de sementes de S. occidentalis, na ração e seu grupo peer-feding. Foram utilizados 10 animais por grupo. São apresentados as medias e os respectivos erros padrões. 
Tabela 6- Média do número de linfócitos (em \%), neutrófilos segmentados (em\%), eosinófilos (em \%), bastonete (em \%) e monócitos (em \%), de ratos tratados durante 14 dias com diferentes concentrações $(0 \%, 1 \%, 2 \%$ e $4 \%)$ de sementes de $S$. occidentalis, na ração e seu grupo peer-feding. Foram utilizados 10 animais por grupo. São apresentados as medias e os respectivos erros padrões.

Tabela 7- Níveis séricos de proteínas totais $(\mathrm{g} / \mathrm{L})$, glicose $(\mathrm{mg} / \mathrm{dL})$ e albumina $(\mathrm{g} / \mathrm{L})$, de ratos tratados durante 14 dias com diferentes concentrações $(0 \%, 1 \%, 2 \%$ e $4 \%)$ de sementes de $S$. occidentalis, na ração e seu grupo peer-feding. Foram utilizados 10 animais por grupo. São apresentados as medias e os respectivos erros padrões

Tabela 8- Peso relativo do baço e timo $(\mathrm{g})$, de ratos tratados durante 14 dias com diferentes concentrações $(0 \%, 1 \%, 2 \%$ e $4 \%)$ de sementes de S. occidentalis, na ração e seu grupo peer-feeding. Foram utilizados 10 animais por grupo. São apresentados as medias e os respectivos erros padrões.

Tabela 9- Celularidade do baço, timo e da medula óssea (x 10\% $/$ cel), de ratos tratados durante 14 dias com diferentes concentrações $(0 \%, 1 \%$, $2 \%$ e $4 \%$ ) de sementes de S. occidentalis, na ração e seu grupo peer-feeding. Foram utilizados 10 animais por grupo. São apresentados as medias e os respectivos erros padrões.

Tabela 10- Análise morfométrica da região cortical e medular do baço e timo, de ratos tratados durante 14 dias com diferentes concentrações $(0 \%, 1 \%, 2 \%$ e $4 \%)$ de sementes de $S$. occidentalis, na ração e seu grupo peer-feeding. Foram utilizados 5 animais por grupo

Tabela 11- Consumo médio e total de água (em $\mathrm{ml}$ ) pelos ratos tratados durante 14 dias com diferentes concentrações ( $0 \%, 1 \%, 2 \%$ e $4 \%)$ de sementes de $S$. occidentalis, na ração e seu grupo peer-feeding. Foram utilizados 10 animais por grupo. São apresentados as medias e os respectivos erros padrões 
Tabela 12- Consumo médio e total de ração (em g) pelos ratos tratados durante 14 dias com diferentes concentrações $(0 \%, 1 \%, 2 \%$ e $4 \%)$ de sementes de $S$. occidentalis, na ração. Foram utilizados 10 animais por grupo. São apresentados as medias e os respectivos erros padrões.

Tabela 13- Peso médio (em g), de ratos tratados durante 14 dias com diferentes concentrações $(0 \%, 1 \%, 2 \%$ e $4 \%)$ de sementes de S. occidentalis, na ração e seu grupo peer-feeding. Foram utilizados 10 animais por grupo. São apresentados as medias e os respectivos erros padrões

Tabela 14- Peso semanal e total (em g), de ratos tratados durante 14 dias com diferentes concentrações $(0 \%, 1 \%, 2 \%$ e $4 \%)$ de sementes de $S$. occidentalis, na ração e seu grupo peer-feeding. Foram utilizados 10 animais por grupo. São apresentados as medias e os respectivos erros padrões.

Tabela 15 Avaliação na atividade de espraiamento e fagocitose de macrófagos peritoneais (\%), de ratos tratados durante 14 dias com diferentes concentrações $(0 \%, 1 \%, 2 \%$ e $4 \%)$ de sementes de S. occidentalis na ração e seu grupo peer-feeding. Foram utilizados 10 animais por grupo. São apresentados as medias e os respectivos erros padrões

Tabela 16- Liberação por macrófagos peritoneais de água oxigenada $\left(\mathrm{H}_{2} \mathrm{O}_{2}\right)$ espontânea ou induzida por PMA, de ratos tratados durante 14 dias com diferentes concentrações $(0 \%, 1 \%, 2 \%$ e $4 \%)$ de sementes de S. occidentalis, na ração e seu grupo peer-feeding. São apresentados as medias e os respectivos erros padrões.

Tabela 17- Determinação indireta de óxido nítrico via dosagem de seu metabólito (nitrito), por macrófagos peritoneais de ratos tratados durante 14 dias com diferentes concentrações ( $0 \%, 1 \%, 2 \%$ e $4 \%)$ de sementes de $S$. occidentalis, na ração e seu grupo peer-feeding. São apresentados as medias e os respectivos erros padrões 
Tabela 18- Consumo médio e total de água (em $\mathrm{ml}$ ) pelos ratos tratados durante 14 dias com diferentes concentrações (0\%, 1\%, 2\% e 4\%) de sementes de $S$. occidentalis, na ração e seu grupo peer-feeding. Foram utilizados 10 animais por grupo. São apresentados as medias e os respectivos erros padrões

Tabela 19- Consumo médio e total de ração (em g) pelos ratos tratados durante 14 dias com diferentes concentrações (0\%, 1\%, 2\% e 4\%) de sementes de $S$. occidentalis, na ração. Foram utilizados 10 animais por grupo. São apresentados as medias e os respectivos erros padrões

Tabela 20- Peso médio (em g), de ratos tratados durante 14 dias com diferentes concentrações $(0 \%, 1 \%, 2 \%$ e $4 \%)$ de sementes de S. occidentalis na ração e seu grupo peer feeding. Foram utilizados 10 animais por grupo. São apresentados as medias e os respectivos erros padrões

Tabela 21- Peso semanal e total (em g), de ratos tratados durante 14 dias com diferentes concentrações $(0 \%, 1 \%, 2 \%$ e $4 \%)$ de sementes de S. occidentalis, na ração e seu grupo peer-feeding. Foram utilizados 10 animais por grupo. São apresentados as medias e os respectivos erros padrões

Tabela 22- Volume do edema inflamatório agudo (em $\mu \mathrm{L}$ ) medido através de pletismografia em diferentes momentos após a inoculação de carragenina $1 \%$ no coxim plantar da pata posterior esquerda de ratos, tratados durante 14 dias com diferentes concentrações $(0 \%$, $1 \%, 2 \%$ e $4 \%$ ) de sementes de $S$. occidentalis, na ração e seu grupo peer-feeding. Foram utilizados 10 animais por grupo. São apresentados as medias e os respectivos erros padrões 
Tabela 23- Consumo médio e total de água (em $\mathrm{ml}$ ) pelos ratos tratados durante 14 dias com diferentes concentrações $(0 \%, 1 \%, 2 \%$ e $4 \%)$ de sementes de $S$. occidentalis, na ração e seu grupo peer-feeding. Foram utilizados 10 animais por grupo. São apresentados as medias e os respectivos erros padrões

Tabela 24- Consumo médio e total de ração (em g) pelos ratos tratados durante 14 dias com diferentes concentrações ( $0 \%, 1 \%, 2 \%$ e $4 \%$ ) de sementes de $S$. occidentalis, na ração. Foram utilizados 10 animais por grupo. São apresentados as medias e os respectivos erros padrões.

Tabela 25- Peso médio (em g), de ratos tratados durante 14 dias com diferentes concentrações $(0 \%, 1 \%, 2 \%$ e $4 \%)$ de sementes de S. occidentalis na ração e seu grupo peer-feeding. Foram utilizados 10 animais por grupo. São apresentados as medias e os respectivos erros padrões.

Tabela 26- Peso semanal e total (em g), de ratos tratados durante 14 dias com diferentes concentrações $(0 \%, 1 \%, 2 \%$ e $4 \%)$ de sementes de $S$. occidentalis, na ração e seu grupo peer-feeding. Foram utilizados 10 animais por grupo. São apresentados as medias e os respectivos erros padrões

Tabela 27- Volume do edema inflamatório agudo (em $\mu \mathrm{L}$ ) e do granuloma experimental induzido pela inoculação de Onco-BCG no coxim plantar da pata posterior esquerda de ratos, tratados durante 14 dias com diferentes concentrações $(0 \%, 1 \%, 2 \%$ e $4 \%)$ de sementes de $S$. occidentalis, na ração e seu grupo peer-feeding. Foram utilizados 10 animais por grupo. São apresentados as medias e os respectivos erros padrões

Tabela 28- Número médio de bacilos álcool-ácido resistentes presentes na lesão granulomatosa podal após 21 dias de inoculação de OncoBCG (22 dia) no coxim plantar da pata posterior esquerda, de ratos tratados durante 14 dias com diferentes concentrações $(0 \%$, $1 \%, 2 \%$ e $4 \%$ ) de sementes de $S$. occidentalis, na ração e seu grupo peer-feeding. Foram utilizados 10 animais por grupo. 


\section{LISTA DE FIGURAS}

Figura 1 - Senna occidentalis (KISSMANN, K. G; GROTH, D. Plantas infestantes e nocivas, tomo II, BASF, 1995).

Figura 2 - Desenho esquemático do comedouro adaptado

Figura 3 - Consumo médio e total de água (em $\mathrm{ml}$ ) pelos ratos tratados durante 14 dias com diferentes concentrações (0\%, 1\%, 2\% e 4\%) de sementes de $S$. occidentalis, na ração e seu grupo peer-feeding. Foram utilizados 10 animais por grupo.

Figura 4 - Consumo médio e total de ração (em g) pelos ratos tratados durante 14 dias com diferentes concentrações (0\%, 1\%, 2\% e 4\%) de sementes de $S$. occidentalis, na ração. Foram utilizados 10 animais por grupo

Figura 5 - Peso médio (em g), de ratos tratados durante 14 dias com diferentes concentrações $(0 \%, 1 \%, 2 \%$ e $4 \%)$ de sementes de S. occidentalis, na ração e seu grupo peer-feeding. Foram utilizados 10 animais por grupo

Figura 6 - Peso semanal e total (em g), de ratos tratados durante 14 dias com diferentes concentrações $(0 \%, 1 \%, 2 \%$ e $4 \%)$ de sementes de $S$. occidentalis, na ração e seu grupo peer-feeding. Foram utilizados 10 animais por grupo

Figura 7 - Valor médio do hematócrito - HCT (\%), volume corpuscular médio $\operatorname{VCM}\left(\mu^{3}\right)$ e concentração de hemoglobina corpuscular média CHCM (\%), de ratos tratados durante 14 dias com diferentes concentrações $(0 \%, 1 \%, 2 \%$ e $4 \%)$ de sementes de $S$. occidentalis, na ração e seu grupo peer-feding. Foram utilizados 10 animais por grupo.

Figura 8 - Peso relativo timo $(\mathrm{g} / 100 \mathrm{~g} \mathrm{pv})$, de ratos tratados durante 14 dias com diferentes concentrações $(0 \%, 1 \%, 2 \%$ e $4 \%)$ de sementes de S. occidentalis, na ração e seu grupo peer-feeding. Foram utilizados 10 animais por grupo. 
Figura 9 - Celularidade da medula óssea $\left(\times 10^{6} / \mathrm{cel}\right)$, de ratos tratados durante 14 dias com diferentes concentrações $(0 \%, 1 \%, 2 \%$ e $4 \%)$ de sementes de $S$. occidentalis, na ração e seu grupo peer-feeding. Foram utilizados 10 animais por grupo.

Figura 10- Análise morfométrica da região cortical e medular do baço e timo, de ratos tratados durante 14 dias com diferentes concentrações $(0 \%, 1 \%, 2 \%$ e $4 \%)$ de sementes de $S$. occidentalis, na ração e seu grupo peer-feeding. Foram utilizados 5 animais por grupo.

Figura 11 - Consumo médio e total de água (em $\mathrm{ml}$ ) pelos ratos tratados durante 14 dias com diferentes concentrações (0\%, 1\%, 2\% e 4\%) de sementes de $S$. occidentalis, na ração e seu grupo peer-feeding. Foram utilizados 10 animais por grupo.

Figura 12 - Consumo médio e total de ração (em g) pelos ratos tratados durante 14 dias com diferentes concentrações $(0 \%, 1 \%, 2 \%$ e $4 \%)$ de sementes de $S$. occidentalis, na ração. Foram utilizados 10 animais por grupo. São apresentados às médias e os respectivos erros padrões.

Figura 13 - Peso médio (em g), de ratos tratados durante 14 dias com diferentes concentrações $(0 \%, 1 \%, 2 \%$ e $4 \%)$ de sementes de S. occidentalis, na ração e seu grupo peer-feeding. Foram utilizados 10 animais por grupo. São apresentados às médias e os respectivos erros padrões.

Figura 14 - Peso semanal e total (em g), de ratos tratados durante 14 dias com diferentes concentrações $(0 \%, 1 \%, 2 \%$ e $4 \%)$ de sementes de S. occidentalis, na ração e seu grupo peer-feeding. Foram utilizados 10 animais por grupo.

Figura 15 - Liberação por macrófagos peritoneais de água oxigenada $\left(\mathrm{H}_{2} \mathrm{O}_{2}\right)$ espontânea ou induzida por PMA, de ratos tratados durante 14 dias com diferentes concentrações $(0 \%, 1 \%, 2 \%$ e $4 \%)$ de sementes de S. occidentalis, na ração e seu grupo peer-feeding. Foram utilizados 10 animais por grupo. 
Figura 16 - Determinação indireta de óxido nítrico via dosagem de seu metabólito (nitrito), por macrófagos peritoneais de ratos tratados durante 14 dias com diferentes concentrações ( $0 \%, 1 \%, 2 \%$ e $4 \%)$ de sementes de $S$. occidentalis, na ração e seu grupo peer-feeding. São apresentados às médias e os respectivos erros padrões

Figura 17 - Consumo médio e total de água (em $\mathrm{ml}$ ) pelos ratos tratados durante 14 dias com diferentes concentrações $(0 \%, 1 \%, 2 \%$ e $4 \%)$ de sementes de $S$. occidentalis, na ração e seu grupo peer-feeding. Foram utilizados 10 animais por grupo.

Figura 18 - Consumo médio e total de ração (em g) pelos ratos tratados durante 14 dias com diferentes concentrações $(0 \%, 1 \%, 2 \%$ e $4 \%)$ de sementes de $S$. occidentalis, na ração. Foram utilizados 10 animais por grupo. São apresentados às médias e os respectivos erros padrões.

Figura 19 - Peso médio (em g), de ratos tratados durante 14 dias com diferentes concentrações $(0 \%, 1 \%, 2 \%$ e $4 \%)$ de sementes de S. occidentalis, na ração e seu grupo peer-feeding. Foram utilizados 10 animais por grupo.

Figura 20 - Peso semanal e total (em g), de ratos tratados durante 14 dias com diferentes concentrações $(0 \%, 1 \%, 2 \%$ e $4 \%)$ de sementes de S. occidentalis, na ração e seu grupo peer-feeding. Foram utilizados 10 animais por grupo.

Figura 21 - Volume do edema inflamatório agudo (em $\mu \mathrm{L}$ ) medido através de pletismografia em diferentes momentos após a inoculação de carragenina $1 \%$ no coxim plantar da pata posterior esquerda de ratos, tratados durante 14 dias com diferentes concentrações $(0 \%$, $1 \%, 2 \%$ e $4 \%$ ) de sementes de $S$. occidentalis, na ração e seu grupo peer-feeding. Foram utilizados 10 animais por grupo. 
Figura 22 - Consumo médio e total de água (em $\mathrm{ml}$ ) pelos ratos tratados durante 14 dias com diferentes concentrações $(0 \%, 1 \%, 2 \%$ e $4 \%)$ de sementes de $S$. occidentalis, na ração e seu grupo peer-feeding. Foram utilizados 10 animais por grupo.

Figura 23 - Consumo médio e total de ração (em g) pelos ratos tratados durante 14 dias com diferentes concentrações $(0 \%, 1 \%, 2 \%$ e $4 \%)$ de sementes de $S$. occidentalis, na ração. Foram utilizados 10 animais por grupo

Figura 24 - Peso médio (em g), de ratos tratados durante 14 dias com diferentes concentrações $(0 \%, 1 \%, 2 \%$ e $4 \%)$ de sementes de $S$. occidentalis, na ração e seu grupo peer-feeding. Foram utilizados 10 animais por grupo.

Figura 25 - Peso semanal e total (em g), de ratos tratados durante 14 dias com diferentes concentrações $(0 \%, 1 \%, 2 \%$ e $4 \%)$ de sementes de S. occidentalis, na ração e seu grupo peer-feeding. Foram utilizados 10 animais por grupo

Figura 26 - Volume do edema inflamatório agudo (em $\mu \mathrm{L})$ e do granuloma experimental induzido pela inoculação de Onco-BCG no coxim plantar da pata posterior esquerda de ratos, tratados durante 14 dias com diferentes concentrações $(0 \%, 1 \%, 2 \%$ e $4 \%)$ de sementes de $S$. occidentalis, na ração. São apresentados às médias e os respectivos erros padrões 


\section{SUMÁRIO}

1.1 SOBRE A Senna occidentalis.

23

1.2 SOBRE A AÇÃO DE XENOBIÓTICOS SOBRE O SISTEMA HEMATOPOÉTICO E ÓRGÃOS LINFÓIDES

2.2 OBJETIVOS ESPECÍFICOS 35

3 MATERIAL E MÉTODOS. 37

3.1

ANIMAIS 38

3.3.1 Soluções e Reagentes.......................................................... 39

"Kits” para bioquímica sérica.............................................. 44

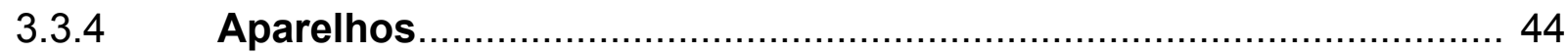

PROCEDIMENTOS $\quad$ P...

3.4.1 Preparo e administração da ração............................................ 46

3.4.1.1 Administração de ração ao grupo peer-feeding ............................... 47

3.4.2 Avaliação do consumo de ração e água, ganho de peso e observações clínicas

Avaliação do hemograma $\quad$.................................................... 48

Avaliação bioquímica............................................................ 49 
3.4.5 Avaliação da atividade de macrófagos espraiamento e fagocitose.. 49

3.4.5.1 Elicitação de células peritoneais pelo tioglicolato e LPS......................... 50

3.4.5.2 Coleta das células peritoneais estimuladas pelo LPS.......................... 50

3.4.5.3 Execução da técnica para avaliação do espraiamento de macrófagos peritoneais

3.4.5.4 Execução da técnica para avaliação da fagocitose de macrófagos peritoneais de ratos

3.4.5.5 Contagem de células aderidas de ratos com capacidade de espraiamento e de fagocitose.

3.4.6 Medida da liberação de peróxido de hidrogênio das células peritoneais de ratos.

3.4.7 Medida do óxido nítrico através da produção de nitrito.................... 54

3.4.8 Indução da resposta inflamatória aguda ...................................... 55

3.4.8.1 Medida do volume do edema inflamatório agudo induzido pela carragenina na pata de ratos.

3.4.9 Indução da resposta inflamatória crônica......................................... 56

3.4.10 Estudo Anatomo e Histopatológico................................................... 57

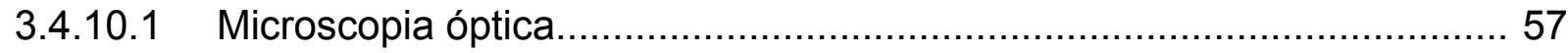

3.4.10.2 Avaliação morfométrica esplênica e tímica.......................................... 58

3.4.10.3 Avaliação da celularidade do timo, baço e medula óssea........................ 58

3.5 DELINEAMENTO EXPERIMENTAL ........................................... 58

3.5.1 Experimento 1: Efeitos da administração prolongada das sementes de Senna occidentalis a ratos: avaliação do consumo de ração, ganho de peso, hemograma, componentes sangüíneos e celularidade de timo, baço e medula óssea. 
3.5.2 Experimento 2: Avaliação dos possíveis efeitos da administração prolongada de sementes de Senna occidentalis sobre a atividade de macrófagos peritoneais em ratos.

3.5.3 Experimento 3: Avaliação dos efeitos da administração prolongada de sementes de Senna occidentalis sobre a produção de água oxigenada e óxido nítrico em ratos

3.5.4 Experimento 4: Avaliação dos efeitos da administração prolongada de sementes de Senna occidentalis sobre as respostas inflamatórias, aguda e crônica, em ratos.

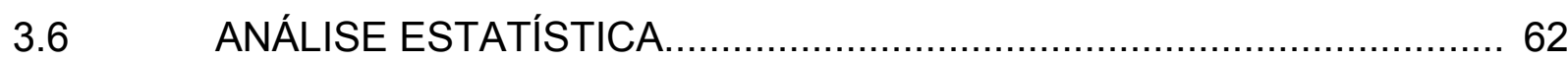

$4 \quad$ RESULTADOS

4.1 EXPERIMENTO 1: AVALIAÇÃO DOS POSSÍVEIS EFEITOS TÓXICOS DA ADMINISTRAÇÃO PROLONGADA DE SEMENTES DE Senna occidentalis A RATOS.

4.2 EXPERIMENTO 2: AVALIAÇÃO DOS POSSÍVEIS EFEITOS DA ADMINISTRAÇÃO PROLONGADA DE SEMENTES DE Senna occidentalis SOBRE A ATIVIDADE DE MACRÓFAGOS PERITONEAIS E A PRODUÇÃO DE ÁGUA OXIGENADA E ÓXIDO NÍTRICO

4.3 EXPERIMENTO 3: AVALIAÇÃO DOS EFEITOS DA ADMINISTRAÇÃO PROLONGADA DE SEMENTES DE Senna occidentalis SOBRE A REPOSTA INFLAMATÓRIA AGUDA.

4.4 EXPERIMENTO 4: AVALIAÇÃO DOS EFEITOS DA ADMINISTRAÇÃO PROLONGADA DE SEMENTES DE Senna occidentalis SOBRE A RESPOSTA INFLAMATÓRIA CRÔNICA E DO GRANULOMA EXPERIMENTAL EM RATOS.

5. DISCUSSÃO. 
Introdução 22

1 INTRODUÇÃO 


\section{INTRODUÇÃO}

A importância econômica das plantas tóxicas deve-se principalmente a fatores como as perdas por morte de animais ou por diminuição da produção e gastos com medidas de controle e profilaxia. A causa de intoxicações por estas plantas pode ser determinada por diversos fatores como a palatabilidade, fome, sede, fácil acesso às plantas tóxicas, variações de toxicidade, entre outros (TOKARNIA et al., 2000). Todavia, o impacto econômico causado por fitotoxinas é de difícil avaliação (DWYER, 1978).

Dentre as perdas estão a queda no ganho de peso e na produção animal, o aparecimento de doenças infecciosas e/ou parasitárias devido à imunodeficiência naqueles animais intoxicados, os abortos, a teratogênese e o nascimento de filhotes inviáveis, entre outras (CHEEKE, 1998; RIET-CORREA et al., 1993).

Os custos para o controle das plantas tóxicas são dispendiosos, exigindo o deslocamento dos animais de uma pastagem para outra, construção de cercas, reposição de animais no rebanho e o abandono de áreas onde seja alta a prevalência da planta tóxica em questão (CHEEKE, 1998; RIET-CORREA et al., 1993).

\subsection{SOBRE A Senna occidentalis}

A Senna occidentalis (L) Link - S. occidentalis (Figura 1), sinônimo Cassia occidentalis, é uma planta herbácea, anual, pertencente à família Leguminosae Caesalpinoideae (TOKARNIA et al., 2000), amplamente distribuída em regiões tropicais e subtropicais do mundo (BARROS et al., 1990; COLVIN et al., 1986; 
GRAZIANO et al., 1983; MARTIN et al., 1981; RODRIGUES et al., 1993; ROGERS et al., 1979).

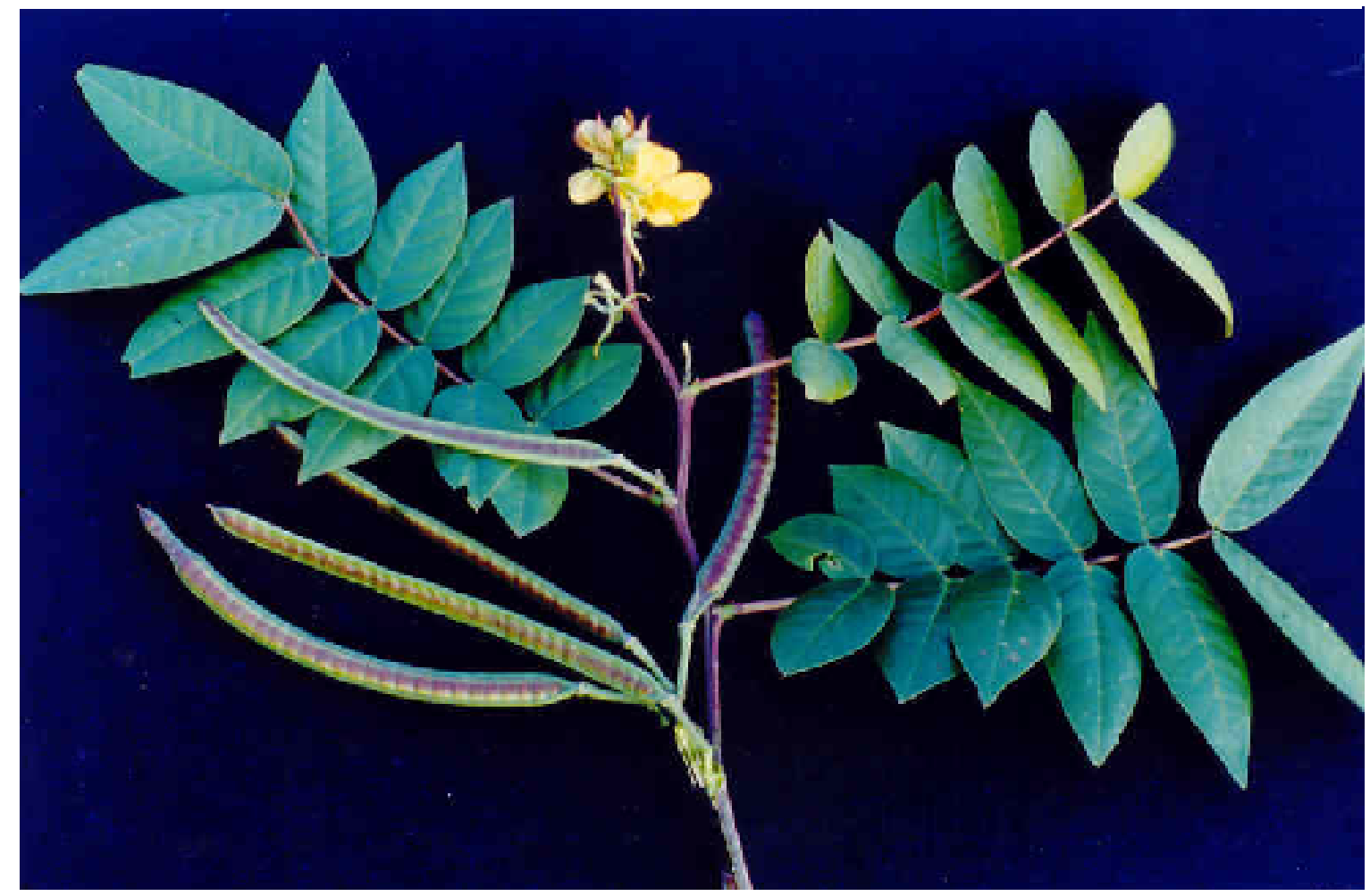

Figura 1 - Senna occidentalis (KISSMANN, K. G; GROTH, D. Plantas infestantes e nocivas, tomo II, BASF, 1995)

Apesar da ampla distribuição da S. occidentalis pelo Brasil, é na região Sul do país que esta planta tem causado problemas de intoxicação com maior freqüência (TOKARNIA et al., 2000). Este vegetal é muito comum em pastagens, beira de estradas, terrenos baldios e culturas anuais como o milho, o sorgo e a soja, por exemplo (LORENZI, 1991). A S. occidentalis possui vários nomes vulgares, tais 
como "fedegoso", "mata-pasto", "verdadeiro", "mamangá”, "sene”, "cigarreira”, "lavapratos", entre outros (HOEHNE, 1939; JOLY, 1977).

De acordo com Lorenzi (1991, p. 265),

[...] a S. occidentalis é uma planta perene, subarbustiva, lenhosa, ramificada, medindo de 1-2 metros de altura, com reprodução por sementes. As folhas são alternadas, compostas parapinadas, com 46 pares de folíolos glabros de 6-7 $\mathrm{cm}$ de comprimento. As inflorescências são axilares e terminais, em racemos com poucas flores pediceladas e de coloração amarelo ouro. Os frutos são formados dentro de vagens achatadas, mais ou menos retas, de coloração marrom, com 10-14 cm de comprimento. Esta leguminosa floresce no período de setembro a outubro e frutifica no período de fevereiro a abril. Poderá ser diferenciada das outras espécies de Senna através das características no direcionamento de crescimento das vagens, ou seja, no caso da Senna occidentalis, este ocorre de forma curva, com as pontas para cima; estas vagens, quando imaturas, são verdes, com faixas transversais marrons, tornando-se secas no outono, quando as sementes estão maduras.

A S. occidentalis cresce agregada a plantações de cereais e, além de competir com nutrientes úteis a essas culturas, pode contaminá-las com suas sementes durante a coleta mecânica (DOLLAHITE; HENSON, 1965). Caso não haja uma separação adequada dos tipos de sementes, principalmente por meio de peneiragem, separação por densidade ou ambas, as sementes de $S$. occidentalis poderão vir a compor parte do produto final destinado à alimentação humana ou animal, levando a um desbalanço nutricional e causando ainda o risco de se incluir 
nesta dieta algum componente tóxico (BARROS, 1991). Contudo, foi somente com o desenvolvimento da pecuária, e a ocorrência de importantes surtos de intoxicação em países onde a prevalência desta planta é alta, como no Sul dos Estados Unidos da América, França, Austrália e Brasil (BAILEY, 1977), é que se iniciaram estudos mais aprofundados sobre os efeitos tóxicos da S. occidentalis (TASAKA, 2000).

As espécies animais mais acometidas pela $S$. occidentalis são os bovinos (HENSON et al., 1965; MARTINS et al., 1986; MERCER et al., 1967), suínos (MARTINS et al., 1986), eqüinos (BARROS et al., 1990) e aves (PAGE et al., 1977), por serem animais freqüentemente criados de maneira extensiva.

Nas intoxicações naturais, assim como nas experimentais, os animais podem apresentar sinais clínicos por vezes semelhantes, porém, a intensidade das manifestações clínicas pode variar entre as espécies estudadas (TASAKA, 2000; WEG, 2001). Desta forma, de maneira geral, os animais intoxicados com concentrações moderadas ou elevadas (de $3 \%$ a $20 \%$ ) de sementes de S. occidentalis apresentam abatimento, diarréia, fraqueza muscular, incoordenação motora, tremores musculares, relutância em mover-se, períodos de decúbito esternal, decúbito lateral e morte (TOKARNIA et al., 2000). Por outro lado, a intoxicação por baixos níveis das sementes da planta pode promover como sinal clínico apenas anorexia e queda no ganho de peso (TASAKA et al., 2000).

Em relação aos achados na necropsia e histopatológicos, nas diferentes espécies animais, verificam-se como principais lesões às degenerações do músculo esquelético e cardíaco (CAVALIERI et al., 1997; HERBERT et al., 1983; O'HARA; PIERCE, 1974, a,b; ROGERS et al., 1983). Pode-se, ainda, verificar alterações hepáticas (MERCER et al., 1967; TASAKA et al., 2000), renais (BARROS et al., 
1999; EL SAYED, 1983), bem como no sistema nervoso central (BARBOSAFERREIRA et al., 2005). Entretanto, os locais onde as lesões se apresentam com maior gravidade variam de acordo com a espécie animal; assim, a miopatia degenerativa da musculatura esquelética e cardíaca prevalece na espécie bovina e suína (MERCER et al., 1967; RODRIGUES et al., 1993), enquanto que em leporinos foi observada lesão mais severa na musculatura cardíaca (TASAKA et al., 2000)

O diagnóstico das intoxicações por $S$. occidentalis deve ser baseado nos dados clínicos e epidemiológicos, nos achados de necropsia e na histopatologia. A fonte da planta tóxica, nas pastagens ou como sementes contaminando grãos usados na ração dos animais, deve ser pesquisada e confirmada (RIET-CORREA et al., 1993).

O princípio ativo tóxico da S. occidentalis foi identificado como sendo uma antraquinona, a diantrona (HARAGUCHI et al., 1996). No entanto, foram extraídas de várias espécies de Senna, inclusive da S. occidentalis, outras substâncias potencialmente tóxicas como: flavonóides, oxalato de cálcio, albumina tóxica, glicosídeos esteróides, glicosídeos saponínicos, glicosídeos antraquinônicos, senosídeos A, B, C e D, emodina, aloe-emodina, reína e crisofanol e $\mathrm{N}$ metilmorfolina (BOTSARIS et al., 1995; KIM et al., 1971; O'HARA et al., 1969; WITTE, 1993).

Conforme proposto por Cavaliere et al. (1997), o mecanismo de ação tóxico da S. occidentalis estaria relacionado ao desacoplamento da fosforilação oxidativa mitocondrial, produzido pela diantrona; assim estes autores teorizaram que esta antraquinona agiria diretamente sobre o metabolismo desta organela. 
Em contraposição aos efeitos tóxicos promovidos pela S. occidentalis, tem sido atribuída a esta planta propriedades medicinais. Lemli (1988) sugeriu que esta foi introduzida como planta medicinal pelos árabes no século IX. Acredita-se que as plantas da espécie Senna foram trazidas para o Brasil com a imigração destes povos (BOTSARIS et al., 1995). Embora diferentes partes da S. occidentalis venham sendo amplamente empregadas na medicina popular, estudos recentes mostram que o uso freqüente da planta pode produzir efeitos colaterais. Neste sentido, um trabalho conduzido por Joo (1998) revelou que indivíduos propensos à constipação recorrente e que usavam cronicamente laxantes contendo $S$. occidentalis, apresentavam efeitos como a dilatação do intestino grosso.

\subsection{SOBRE A AÇÃO DE XENOBIÓTICOS SOBRE O SISTEMA HEMATOPOÉTICO E ÓRGÃOS LINFÓIDES}

A imunodeficiência é uma das principais causas de perda de animais no campo (CHEEKE, 1998; RIET-CORREA et al., 1993), uma vez que a debilidade física causada pelas plantas tóxicas os deixa mais suscetíveis a outras doenças, ou seja, pode ocorrer diminuição das respostas de defesa do organismo animal.

Conforme relatado por Burn-Nass et al. (2000), a interação de xenobióticos com os vários componentes do sistema imune é uma área que surgiu recentemente e desperta grande interesse no meio científico.

Desta forma, segundo Lawrence e Kim (2000), a produção de células que participam da defesa do organismo do hospedeiro, tanto de natureza inespecífica quanto especifica, é rigorosamente controlada em dois níveis: o central, que 
compreende os sítios hemato-linfopoéticos medulares e o periférico presente no baço, linfonodos e nos tecidos linfóides associados às mucosas.

As células envolvidas nas respostas imunes encontram-se organizadas em tecidos e órgãos, a fim de realizar suas funções de forma mais eficiente. Estas estruturas são, coletivamente, denominadas de sistema linfóide. O sistema linfóide é composto por linfócitos, células acessórias como os macrófagos e células apresentadoras de antígenos e, em alguns tecidos, células epiteliais. O tecido linfóide distribui-se pelo organismo como órgãos discretamente encapsulados ou como acúmulo de tecidos linfóide difuso (LYDYARD; GROSSI, 1999).

Os órgãos linfóides primários são os principais sítios de desenvolvimento dos linfócitos no organismo e compreendem o timo e a medula óssea. Neles, os linfócitos se diferenciam a partir de células tronco linfóides, proliferam-se e amadurecem em células funcionais. Nos mamíferos, as células T amadurecem no timo, e as células B no fígado fetal e na medula óssea. As aves possuem um local especializado de geração de célula B que é a bursa de Fabricius (LAWRENCE; KIM, 2000).

Um outro aspecto a ser considerado na interação de xenobióticos com o organismo diz respeito às linhagens celulares precursoras da medula óssea e às células sangüíneas circulantes, as quais participam de funções críticas na defesa do hospedeiro (HARVEY, 1996).

De acordo com Guest e Uetrecht (2000), os xenobióticos que causam toxicidade na medula óssea pertencem a um grupo heterogêneo de compostos que agem por meio de vários mecanismos; entretanto, a etiologia destas ações tóxicas é insuficientemente compreendida. Na literatura, verifica-se que a hematotoxicidade é manifestada pela alteração do número de células maduras no sangue ou medula 
óssea, que pode ser caracterizada pela destruição excessiva ou supressão da produção destas células (LANNING, 1998).

Dentre os xenobióticos que causam supressão de células do tecido hematopoético, destacam se os agentes antineoplásicos como a ciclofosfamida e o busulfan (GALE, 1988; HOAGLAND, 1982). Entretanto, trabalhos recentes têm demonstrado a ação de alguns princípios ativos tóxicos de plantas sobre o tecido sangüíneo. Neste sentido, Pan et al. (1993) verificaram que o metabólito da monocrotalina, um alcalóide pirrolizidínico presente nas espécies de Crotalaria spp, promove o aumento de eritrócitos imaturos micronucleados na medula óssea e no sangue periférico de camundongos (SANDERSON; CLARK, 1993).

Especificamente em relação a plantas do gênero Senna, estudos conduzidos por Dugan e Gumbmann (1990) evidenciaram congestão e depleção na medula óssea de ratos tratados com $16 \%$ de Cassia obtusifolia na ração e diminuição de linfócitos e neutrófilos circulantes. Em adição, Voss e Brennecke (1991) observaram em animais tratados com esta mesma planta, aplasia mielóide com leucocitose e trombocitose periférica na medula óssea e anemia moderada seguida de neutropenia. Estes mesmos autores observaram, também, hiperplasia e presença de histiócitos em linfonodos periféricos de ratos tratados com a planta, mostrando, assim, a intrínseca relação entre os compartimentos centrais e periféricos do sistema linfóide.

Já, as respostas imunes de natureza celular e humoral ocorrem nos tecidos linfóides secundários que compreendem o baço, os linfonodos e os tecidos linfóides associados às mucosas, incluindo as amídalas e as placas de Peyer no íleo, onde também são geradas as células efetoras de memória. $O$ baço encarrega-se, 
predominantemente, dos antígenos que têm disseminação via sangüínea; os linfonodos elaboram respostas imunes contra antígenos circulantes na linfa, quer tenham sido absorvidos pela pele ou pelas vísceras internas. As tonsilas, as placas de Peyer e outros tecidos associados às mucosas respondem a antígenos que penetram as barreiras mucosas. As respostas imunes geradas nos órgãos linfóides secundários requerem macrófagos fagócitos, células apresentadoras de antígenos e células B e T maduras (KUBY, 1997).

São os macrófagos, as células essenciais para a efetivação das respostas imunológicas, tanto, inespecíficas quanto específicas (KUMAR et al., 1997), frente a ação dos xenobióticos sobre o organismo do hospedeiro (ADAMS; HALMILTON, 1984). Os macrófagos são membros do sistema fagocítico mononuclear e são derivados da medula óssea, circulando no sangue como monócitos; sua diferenciação se dá em distintos órgãos e tecidos (VAN FURTH, 1980). Os macrófagos residentes são macrófagos teciduais que não fagocitam partículas estranhas e possuem baixa atividade no que diz respeito à secreção das espécies reativas de oxigênio (REIKO; WERB, 1984).

Experimentalmente, os macrófagos inflamatórios podem ser obtidos por meio de injeções de tioglicolato estéril (HOPPER, 1986), o qual, prejudica sistematicamente a atividade antimicrobicida e diminui a ativação dos macrófagos (BAKER; CAMPBELL, 1980); como conseqüência desta ativação, estas células apresentam alta atividade fagocítica e baixa atividade citotóxica. Já os macrófagos ativados são citotóxicos para células tumorais e microrganismos e podem ser obtidos experimentalmente pela injeção de bacilo de Calmette-Guérin (BCG) (KARNOVSKY; LAZDINS, 1978). 
Os macrófagos auxiliam na resposta inflamatória aguda pela secreção de alguns mediadores como as prostaglandinas, fator ativador de plaquetas, leucotrienos e pela secreção de enzimas proteolíticas que ativam os mediadores dos precursores peptídicos (GEMSA et al., 1975). Além disso, na inflamação aguda, os macrófagos são responsáveis por outros aspectos desta resposta como a secreção de pirógenos endógenos e pela secreção de fatores que irão estimular a síntese de proteínas de fase aguda pelo fígado (REIKO; WERB, 1984). Quando o processo inflamatório persiste, na fase crônica da inflamação, os macrófagos podem contribuir para a destruição excessiva do tecido, devido à secreção de proteinases neutras que são efetivas em neutralizar o pH local, pela secreção de hidrolases ácidas que são responsáveis por acidificar o pH e também podem promover fibrose excessiva pela secreção de mitógenos, ativando os fibroblastos (MIZEL et al., 1981).

Assim, estudos que avaliam o metabolismo e a função de macrófagos aos diferentes estímulos (inespecíficos e específicos) têm sido desenvolvidos com os xenobióticos. Neste sentido, em recente pesquisa conduzida por Hueza et al. (2003) foi verificado que a administração de $3 \mathrm{~g} / \mathrm{kg}$ de Ipomoea carnea foi capaz de aumentar a atividade fagocítica de macrófagos e a secreção de peróxido de hidrogênio por estas células. Por outro lado, Dhuley (1997) mostrou que a ocratoxina A, uma micotoxina contaminante de grãos de cereais, café, leite e produtos de origem animal, foi capaz de diminuir a quimiotaxia, a produção de interleucina 1 (IL1) e fator de necrose tumoral $\alpha$ (TNF- $\alpha$ ) de macrófagos peritoneais de camundongos tratados com este contaminante.

Destarte, pode-se supor que a avaliação do comprometimento do sistema imune através da diminuição da celularidade dos órgãos linfóides, alterações nas subpopulações de linfócitos, diminuição da resistência do hospedeiro e alterações 
nas funções da resposta imune específica e inespecífica, deve fazer parte daqueles protocolos de avaliação de toxicidade (BURN-NASS et al., 2000). De fato, as áreas relacionadas à atividade imunomodulatória, no que tange ao estudo com plantas tóxicas, têm sido alvo de recentes investigações devido ao seu potencial de modificar a resposta imune inespecífica e específica (AGARWAL et al., 1999).

Particularmente no que se refere à toxicidade promovida pela S. occidentalis, um estudo recente conduzido por Silva et al. (2003) mostrou redução nos diâmetros dos folículos e na densidade das regiões cortical e medular da bursa de Fabricius e redução da polpa branca do baço, em aves tratadas com até um $1 \%$ de tegumento externo (TE) da planta. Estes dados, tomados em conjunto, sugerem um possível efeito da $S$. occidentalis sobre a resposta imunológica não-específica dos animais tratados com esta planta.

Desta forma, no presente trabalho procurou-se verificar os possíveis efeitos tóxicos produzidos pela $S$. occidentalis, em ratos, utilizando-se metodologias capazes de avaliar parâmetros da resposta inflamatória e imunológica nãoespecífica, com a finalidade de verificar se, em mamíferos, ocorrem modificações semelhantes àquelas encontradas em frangos de corte. 
Objetivos 34

2 OBJETIVOS 


\section{OBJETIVOS}

Avaliar os possíveis efeitos tóxicos da administração oral de sementes de Senna occidentalis incorporadas à ração, em ratos, durante um período de 14 dias.

\subsection{OBJETIVOS ESPECÍFICOS}

- Avaliar os possíveis efeitos tóxicos da administração de sementes de S. occidentalis no consumo de ração e água por ratos.

- Avaliar os possíveis efeitos tóxicos da administração de sementes de S. occidentalis no ganho de peso de ratos.

- Avaliar os possíveis efeitos tóxicos da administração de sementes de S. occidentalis sobre a dosagem bioquímica de albumina, glicose e proteínas totais de ratos.

- Avaliar os possíveis efeitos tóxicos da administração de sementes de S. occidentalis sobre o hemograma e medula óssea de ratos. 
- Avaliar os possíveis efeitos tóxicos da administração de sementes de S. occidentalis sobre a celularidade do timo, baço e medula óssea de ratos.

- Avaliar os possíveis efeitos tóxicos da administração de sementes de S. occidentalis sobre timo, baço, linfonodos, fígado e intestino de ratos, por meio de estudos anatomopatológicos.

- Avaliar os possíveis efeitos tóxicos da administração de sementes de S. occidentalis sobre o timo e baço de ratos, por meio de análise histomorfométrica.

- Avaliar os possíveis efeitos tóxicos da administração de sementes de S. occidentalis sobre a atividade de macrófagos peritoneais, espraiamento e fagocitose, em ratos.

- Avaliar os possíveis efeitos tóxicos da administração de sementes de S. occidentalis sobre a produção de água oxigenada e da determinação indireta de óxido nítrico via dosagem de seu metabólito (nitrito) pelos ratos.

- Avaliar os possíveis efeitos tóxicos da administração de sementes de S. occidentalis sobre o edema inflamatório agudo induzido pela carragenina em ratos.

- Avaliar os possíveis efeitos tóxicos da administração de sementes de S. occidentalis sobre o edema inflamatório e a evolução do granuloma experimental induzido pela vacina de Onco-BCG em ratos. 
Material e Métodos 37

3 MATERIAL E MÉTODOS 


\section{MATERIAL E MÉTODOS}

Para a execução desta dissertação foram utilizados os seguintes materiais e métodos

\subsection{ANIMAIS}

Foram utilizados 50 ratos Wistar, machos, jovens, com 70-75 dias de idade e com peso inicial entre 150 a 200 g, provenientes do biotério do Departamento de Patologia da Faculdade de Medicina Veterinária e Zootecnia, da Universidade de São Paulo (FMVZ/USP). Os animais foram alojados em gaiolas de polipropileno fosco com tampas metálicas, medindo $40 \times 50 \times 20 \mathrm{~cm}$. Todas as gaiolas foram mantidas em sala com temperatura ambiente aproximadamente constante $\left(21-24^{\circ} \mathrm{C}\right)$ e iluminação artificial em ciclo de claro-escuro de 12 horas, iniciando-se a fase clara às 7:00 horas. Estes animais foram utilizados em conformidade com as normas e procedimentos relativos ao uso de animais de Laboratório do Departamento de Patologia da FMVZ/USP, os quais são baseados naqueles descritos pelo Committee on Care and Use of Laboratory Animal Resources - National Research Council, EUA.

O protocolo para a realização deste estudo foi submetido à Comissão de Bioética da Faculdade de Medicina Veterinária e Zootecnia/USP, sendo aprovado pela mesma (protocolo n 26/2002) no dia 20 de Março de 2002. 


\subsection{PLANTA ${ }^{1}$}

Foram utilizadas sementes de $S$. occidentalis provenientes do Instituto Biológico de São Paulo, coletas entre o período de fevereiro á março de 2003. Após a coleta, as sementes foram alojadas em local seco, até o momento de serem moídas e adicionadas à ração.

\subsection{MATERIAL}

Para a realização dos diversos experimentos foram utilizados os materiais descritos abaixo:

\subsubsection{Soluções e Reagentes}

- Soro fetal bovino a $10 \%\left(\right.$ Merck $\left.^{\circledR}\right)$;

- Lipopolissacarídeo de Escherichia coli (LPS), Sorotipo 055:B5 100,0 mg $\left(\right.$ Sigma $\left.^{\circledR}\right)$;

- Peróxido de hidrogênio a $30 \%\left(\operatorname{Merck}^{\circledR}\right)$;

\footnotetext{
${ }^{1}$ A Senna occidentalis foi depositada no herbário Maria Eneida Fidalgo no Instituto Botânico de São Paulo na forma de exsicata sobre o número SP-363817.
} 
- Vacina Onco-BCG (Instituto Butantã de São Paulo ${ }^{\circledR}$ ) - vacina contendo Mycobacterium bovis atenuado, da cepa Moreaux, envasada na concentração de $40 \mathrm{mg} / 5 \mathrm{~mL}$;

- Tiopental sódico 10,0 mL $\left(\right.$ Abbot $\left.^{\circledR}\right)$;

- Solução de carragenina a $1 \%$ : foi diluída $0,01 \mathrm{~g}$ de carragenina lamba $\left(\right.$ Sigma $\left.^{\circledR}\right)$ em 10,0 mL de solução de Ringer $\left(\right.$ Aster $\left.^{\circledR}\right)$. A suspensão obtida foi dissolvida por cerca de 5 minutos com auxílio de um banho sonicador (Microsonic SX-20 ${ }^{\circledR}$ ), a fim de obter-se uma suspensão a mais homogênea possível. A suspensão resultante foi armazenada em frasco previamente identificado e utilizada imediatamente;

- Solução de PBS - solução salina tamponada com fosfato. Solução estoque: foram dissolvidos $82,0 \mathrm{~g}$ de cloreto de sódio $\left(\right.$ Synth $\left.^{\circledR}\right), 26,79 \mathrm{~g}$ de fosfato de sódio dibásico (Synth ${ }^{\circledR}$ ) e 4,14 $\mathrm{g}$ de fosfato de sódio monohidratado (Synth ${ }^{\circledR}$ ) em $1.000 \mathrm{~mL}$ de água filtrada em Filtro Milli-Q plus ${ }^{\circledR}$. Esta solução foi filtrada e armazenada em frasco previamente identificado, sob refrigeração $\left(2-8^{\circ} \mathrm{C}\right)$. No momento do uso, esta solução foi diluída na proporção de 1:10 de água filtrada em Filtro Milli-Q plus ${ }^{\circledR}$, mantendo-se um pH em torno de 7,2 a 7,4;

- Solução de PBS glicosado - salina tamponada com fosfato e glicose.

- Solução A: foram dissolvidos $80,0 \mathrm{~g}$ de cloreto de sódio (Synth $\left.{ }^{\circledR}\right), 2,0 \mathrm{~g}$ de cloreto de potássio $\left(\right.$ Synth $\left.^{\circledR}\right), 2,0 \mathrm{~g}$ de fosfato de potássio $\left(\right.$ Synth $\left.^{\circledR}\right)$ e $21,5 \mathrm{~g}$ de fosfato de sódio dibásico $\left(\right.$ Synth $^{\circledR}$ ) em $800,0 \mathrm{~mL}$ de água filtrada em Filtro Milli-Q plus ${ }^{\circledR}$. A solução resultante foi armazenada, em frasco previamente identificado, sob refrigeração $\left(2-8^{\circ} \mathrm{C}\right)$; 
- Solução B: foi dissolvido 1,3 g de cloreto de cálcio $\left(\right.$ Synth $\left.^{\circledR}\right)$ em 100,0 mL de água filtrada em Filtro Milli-Q plus ${ }^{\circledR}$. A solução resultante foi armazenada, em frasco previamente identificado, sob refrigeração $\left(2-8^{\circ} \mathrm{C}\right)$;

-Solução C: foi dissolvido $2,1 \mathrm{~g}$ de cloreto de magnésio $\left(\right.$ Synth $^{\circledR}$ ) em 100,0 mL de água filtrada em Filtro Milli-Q plus ${ }^{\circledR}$. A solução resultante foi armazenada em frasco previamente identificado, sob refrigeração $\left(2-8^{\circ} \mathrm{C}\right)$;

- Solução de glicose a 10\%: foi dissolvido $10,0 \mathrm{~g}$ de glicose $\left(\right.$ Sigma $\left.{ }^{\circledR}\right)$ em 100,0 mL de água filtrada em Filtro Milli-Q plus ${ }^{\circledR}$. A solução resultante foi armazenada em frasco previamente identificado, sob refrigeração $\left(2-8^{\circ} \mathrm{C}\right)$;

- No momento do uso foram diluídos $8,0 \mathrm{~mL}$ da solução $A, 1,0 \mathrm{~mL}$ da solução $\mathrm{B}, 1,0 \mathrm{~mL}$ da solução $\mathrm{C}, 1,0 \mathrm{~mL}$ da solução de glicose a $10 \%$, completandose o volume para $100,0 \mathrm{~mL}$ com água destilada mantendo-se o $\mathrm{pH}$ em torno de 7,2 a 7,4

- Solução de vermelho de fenol: foram diluídos $0,8 \mathrm{~mL}$ de solução $\mathrm{A}, 0,1 \mathrm{~mL}$ de solução $B, 0,1 \mathrm{~mL}$ de solução $C$ e $0,1 \mathrm{~mL}$ de glicose a $10 \%, 0,2 \mathrm{~mL}$ de vermelho de fenol a $0,5 \%\left(\right.$ Sigma $\left.^{\circledR}\right)$ e $0,1 \mathrm{~mL}$ de peroxidase $\left(\right.$ Sigma $\left.{ }^{\circledR}\right)$. A está solução foi adicionada $8,6 \mathrm{~mL}$ de água filtrada em Filtro Milli-Q plus ${ }^{\circledR}$. A solução resultante foi armazenada em frasco previamente identificado, sendo utilizada imediatamente após seu preparo;

- Solução de tioglicolato a $3 \%$ : foram dissolvidos $3,0 \mathrm{~g}$ de caldo tioglicolato brewer $\left(\right.$ Gibco $^{\circledR}$ ) em 100,0 mL de água filtrada em Filtro Milli-Q plus ${ }^{\circledR}$. A solução resultante foi armazenada em frasco previamente identificado e levada à autoclave (Brinkmann ${ }^{\circledR}$ modelo $\left.2340 \mathrm{E}\right)$ por 30 minutos a $21^{\circ} \mathrm{C}$. Após este procedimento a solução foi armazenada sob refrigeração $\left(2-8^{\circ} \mathrm{C}\right)$, até o momento do uso; 
- Solução de glutaraldeído: foram diluídos $2,0 \mathrm{~mL}$ de glutaraldeído a $25 \%$ em 98,0 mL de PBS. A solução resultante foi armazenada em frasco previamente identificado e imediatamente utilizada;

- Solução de azul de trypan: foi adicionado $1,0 \mathrm{~mL}$ de azul de trypan (Merck ${ }^{\circledR}$ ) em 5,0 mL de PBS. Esta solução foi armazenada em frasco previamente identificado e mantida em temperatura ambiente;

- Solução aquosa de etilenodiamino-tetracético-dissódico (EDTA) a 10\%: foi dissolvido $1,0 \mathrm{~g}$ de EDTA $\left(\right.$ Synth $^{\circledR}$ ) em 100,0 mL de solução fisiológica. A solução resultante foi armazenada em frasco previamente identificado. A proporção indicada para uso foi de $0,1 \mathrm{~mL}$ da solução para $1 \mathrm{~mL}$ de sangue;

- Solução de meio de cultura RPMI 1641 (Gibco $\left.{ }^{\circledR}\right)$ : foram diluídos em 1 L de água filtrada em Filtro Milli-Q plus ${ }^{\circledR}, 10,39 \mathrm{~g}$ de RPMI 1641 (Gibco $^{\circledR}$ ), 2,00 $\mathrm{g}$ de bicarbonato de sódio $\left(\right.$ Synth $^{\circledR}$ ), 292,0 g de glutamina (Synth ${ }^{\circledR}$ ), 5,20 g de hepes $\left(\mathrm{Gibco}^{\circledR}\right), 100,0 \mathrm{mg}$ de estreptomicina $\left(\right.$ Sigma $^{\circledR}$ ) e 60,0 mg de penicilina $\left(\right.$ Sigma $\left.^{\circledR}\right)$. Todo este procedimento foi realizado em fluxo laminar e a solução resultante foi filtrada e armazenada em frasco previamente identificado e mantida sob refrigeração $\left(2-8^{\circ} \mathrm{C}\right)$. No momento do uso o pH desta solução foi ajustado para 7,8 ;

- Solução estoque de $1 \mathrm{mM}$ de nitrito de sódio $\left(\mathrm{NaNO}_{2}\right)$ : foram diluídos $6,9 \mathrm{mg}$ de $\mathrm{NaNO}_{2}\left(\right.$ Synth $\left.^{\circledR}\right)$ em $100,0 \mathrm{~mL}$ de água filtrada em Filtro Milli-Q plus ${ }^{\circledR}$. A solução resultante foi armazenada em frasco previamente identificado e mantida sob refrigeração $\left(2-8^{\circ} \mathrm{C}\right)$ até o momento do uso.

- Solução estoque de forbol miristato acetato (PMA) (ICN Biomedicals ${ }^{\circledR}$ ):

- solução A: foram dissolvidos 10,0 mg de PMA em 1,0 mL de dimetilsulfóxido (DMSO) $\left(\right.$ Gibco $\left.^{\circledR}\right)$. Todo o procedimento foi realizado em fluxo laminar. A 
solução resultante foi armazenada em frasco previamente identificado e mantida sob refrigeração $\left(0^{\circ} \mathrm{C}\right)$ até o momento do uso;

- solução B: foram diluídos 10,0 $\mu \mathrm{L}$ da solução A em 90,0 $\mu \mathrm{L}$ de DMSO. Todo o procedimento foi realizado em fluxo laminar. A solução resultante foi armazenada em frasco previamente identificado e mantida sob refrigeração $\left(0^{\circ} \mathrm{C}\right)$ até o momento do uso;

- No momento do uso 1,0 $\mu \mathrm{L}$ da solução B foi diluído em 1000,0 $\mu \mathrm{L}$ de vermelho de fenol a $25 \%$, sendo adicionado $10,0 \mu \mathrm{L}$ desta solução nas últimas 4 linhas da placa destinadas a produção induzida de água oxigenada $\left(\mathrm{H}_{2} \mathrm{O}_{2}\right)$;

- Reagente de Griess

- solução A: foi adicionada a 45,0 mL de água filtrada em Filtro Milli-Q plus ${ }^{\circledR}$, $1,0 \mathrm{~g}$ de sulfanilamida $\left(\right.$ Synth $\left.^{\circledR}\right)$ e $2,5 \mathrm{~mL}$ de ácido ortofosfórico (Nuclear ${ }^{\circledR}$ );

- solução B: foram adicionados a $45,0 \mathrm{~mL}$ de água filtrada em Filtro Milli-Q plus $^{\circledR}, 100,0$ mg de $\alpha$-naftiletilenodiamina (Synth ${ }^{\circledR}$ );

- Todo o procedimento foi realizado em sala escura. Em seguida, partes iguais da solução A e B foram adicionadas e armazenadas em frascos previamente identificados, recobertos por papel alumínio e mantidos sob refrigeração $\left(2-8^{\circ} \mathrm{C}\right)$ até o momento do uso;

- Solução para pletismografia: foram adicionados $0,5 \mathrm{~g}$ de lauril sulfato de sódio $\left(\right.$ Synth $^{\circledR}$ ) e 0,5 g cloreto de sódio (Synth ${ }^{\circledR}$ ) em $900,0 \mathrm{~mL}$ de água destilada. A solução resultante foi armazenada em frasco previamente identificado sob refrigeração $\left(2-8^{\circ} \mathrm{C}\right)$;

- Solução de zimozan A $\left(\right.$ Sigma $\left.^{\circledR}\right)$, produto a base de Saccharomyces cerevisiae: para este preparo foi utilizado $20,0 \mathrm{mg}$ de zimosan A para cada 
1,0 mL de PBS; ferveu-se a mistura por uma hora, sob agitação em sonicador (Microsonic SX $-20^{\circledR}$ ). A suspensão obtida foi lavada com PBS e centrifugada 5 vezes a 2000 rpm, sendo sua concentração final ajustada para 50,0 mg/mL com PBS. Este material biológico foi acondicionado em frasco previamente identificado sob refrigeração;

- Solução de metacarn para coleta dos órgãos linfóides: foram diluídos $60,0 \mathrm{~mL}$ de álcool metílico $96^{\circ} \mathrm{GL}$ (Dinâmica ${ }^{\circledR}$ ), 30,0 mL de clorofórmio 99,5\% $\left(\right.$ Dinâmica $^{\circledR}$ ) e 10,0 mL de ácido acético glacial 99,5\% (Dinâmica ${ }^{\circledR}$ ). Após esta diluição a solução resultante foi armazenada em frasco previamente identificado e mantida em temperatura ambiente até o momento do uso.

\subsubsection{Kits para bioquímica sérica}

- Albumina $\left(\right.$ Celm $\left.{ }^{\circledR}\right)$.

- Glicose $\left(\right.$ Celm $\left.{ }^{\circledR}\right)$.

- Proteínas Totais (PT) $\left(\right.$ Celm $\left.^{\circledR}\right)$.

\subsubsection{Aparelhos}

- Aparelho para determinação bioquímica CELM SBA-200 ${ }^{\circledR}$, utilizado para a análise de albumina, glicose e proteínas totais;

- Aparelho para diluição celular CELM DA $500^{\circledR}$, utilizado para diluir eritrócitos e 
leucócitos para a análise hematológica;

- Aparelho para determinação do hemograma CELM CC-550 ${ }^{\circledR}$, utilizado para a análise hematológica;

- Leitor de ELISA Multiskan MCC340 Tiertek $^{\circledR}$, utilizado para medida da produção de óxido nítrico e água oxigenada;

- Pletismógrafo digital Ugo Basile ${ }^{\circledR}$, utilizado para medida do volume de edema inflamatório agudo e crônico;

- Microscópio de Contraste de Fase $\mathrm{Nikon}^{\circledR}$, para a quantificação do número de células com capacidade de espraiamento e de fagocitose;

- $\quad$ Sistema de análise de imagens computadorizado BIOSCAN/OPTIMAS ${ }^{\circledR}$, para avaliação morfométrica. 


\subsection{PROCEDIMENTOS}

Para a execução dos diversos experimentos foram realizados os seguintes procedimentos.

\subsubsection{Preparo e administração da ração}

As sementes de Senna occidentalis foram separadas dos cotilédones, congeladas em nitrogênio líquido, trituradas em liquidificador comercial (Wallita ${ }^{\circledR}$ ) e incorporadas à ração comercial $\left(\mathrm{Nuvital}^{\circledR}\right)$. Foram adicionadas diferentes concentrações de sementes $(1 \%, 2 \%$ e $4 \%)$ à ração, sendo esta mistura homogeneizada em misturador (Marconi ${ }^{\circledR}$ modelo 206).

A ração foi colocada em um comedouro adaptado (Figura 2), de tal maneira que não houvesse desperdício como o esparramamento deste alimento pelos animais e para que o cálculo do consumo de ração fosse adequado durante todo o período experimental. Assim, este comedouro consistiu de um cilindro de aproximadamente $6,2 \times 6,4 \mathrm{~cm}$, com uma tampa, provida de um orifício central com $1,2 \mathrm{~cm}$ de diâmetro, por onde o rato retirava a ração. Como esta tampa foi adaptada internamente ao cilindro, à medida que havia o esvaziamento do alimento, a tampa deslizava para baixo, evitando qualquer saída de ração que não fosse através do orifício central. 

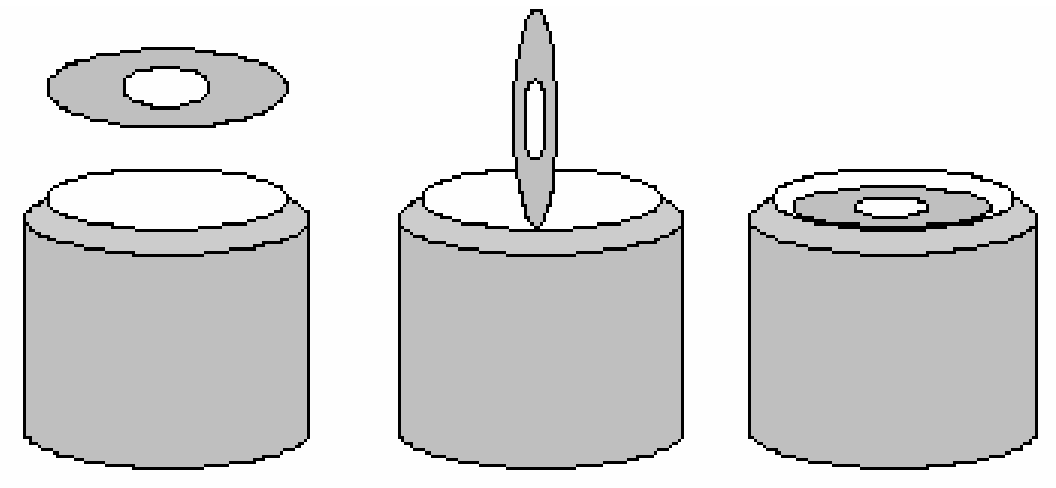

Figura 2- Esquema do comedouro para fornecimento da ração triturada para os ratos. A tampa foi encaixada dentro da lata contendo a ração. $O$ único acesso do animal ao alimento foi através do orifício central da tampa

\subsubsection{Administração de ração ao grupo peer-feeding}

O experimento no qual se realizou a administração denominada peer-feeding, teve por objetivo fornecer a mesma quantidade de ração consumida pelos animais tratados com $4 \%$ de sementes de S. occidentalis (So4\%). Para tanto, iniciou-se a administração do grupo experimental So4\%, 24 horas antes de se administrar à ração comercial para os roedores do grupo peer-feeding; este procedimento permitiu, durante 14 dias, o cálculo do consumo médio de ração pelos animais do grupo experimental So4\%; a quantidade obtida através da média consumida pelos ratos do grupo experimental foi administrada para os animais pertencentes ao grupo peer-feeding. 


\subsubsection{Avaliação do consumo de ração e água, ganho de peso e observações clínicas}

Os ratos foram pesados individualmente, logo antes do início da administração das sementes de $S$. occidentalis misturadas na ração. $O$ acompanhamento dos animais quanto ao ganho de peso, consumo de ração e de água foi realizado a cada 2 dias do tratamento. Para avaliar o consumo de ração e o ganho de peso, os animais foram pesados em balança semi-analítica (Marte ${ }^{\circledR}$ ), no período matutino entre 8:00 e 9:00 h. As observações clínicas foram realizadas a cada 2 dias e os seguintes sinais e sintomas eram avaliados: presença de fezes amolecidas, letargia, abatimento e pêlos arrepiados.

\subsubsection{Avaliação do hemograma}

O hemograma foi constituído pelo eritrograma e pelo leucograma. Ao final do período de avaliação de 14 dias, os ratos foram anestesiados com tiopental sódico $\left(\right.$ Abbot $^{\circledR}$ ) na dose de $40,0 \mathrm{mg} / \mathrm{kg}$. Imediatamente foi realizada a coleta de sangue, por punção da veia hepática, em seringas não heparinizadas. Estas coletas foram realizadas no período matutino entre ás 08:00 e 9:00h da manhã. Foram colhidos $5,00 \mathrm{~mL}$ de sangue, que foram transferidos para um frasco contendo $0,05 \mu \mathrm{l}$ de solução aquosa de etilenodiamino-tetracético-dissódico (EDTA) a 10\%, produzindose adequada homogeneização. O hemograma foi realizado segundo procedimento 
recomendado por Birgel (1982) e com o auxílio dos aparelhos hematológicos para uso veterinário, CELM DA-500 ${ }^{\circledR}$ e CELM CC-550 ${ }^{\circledR}$, respectivamente.

\subsubsection{Avaliação bioquímica}

Ao final do período de avaliação de 14 dias, os ratos foram anestesiados com tiopental sódico $\left(\right.$ Abbot $^{\circledR}$ ) na dose de 40,0 mg/kg. Em seguida, foi realizada a coleta de sangue por punção da veia hepática. Estas coletas foram realizadas no período matutino entre ás 08:00 e 9:00h da manhã. Após a retração do coágulo, as amostras sangüíneas foram centrifugadas a 2000 rpm em centrífuga (Fanem ${ }^{\circledR}$ modelo Excelsa Baby II 206 R) para obtenção do soro.

Foram determinados os níveis séricos de albumina, glicose e proteínas totais (PT), por meio de kits comerciais $\left(C E L M^{\circledR}\right)$, utilizando-se o aparelho para determinações bioquímicas CELM SBA-200 ${ }^{\circledR}$.

\subsubsection{Avaliação da atividade de macrófagos espraiamento e fagocitose}

Para a execução das técnicas de espraiamento e fagocitose de macrófagos peritoneais de ratos Wistar foram realizados os seguintes protocolos. 
3.4.5.1 Elicitação de células peritoneais pelo tioglicolato e LPS

Para a execução das técnicas de espraiamento e fagocitose de macrófagos, todos os animais tratados foram injetados através da via intraperitoneal (ip), com 5,0 $\mathrm{mL}$ de tioglicolato a $3 \%$, com o objetivo de elicitar macrófagos para cavidade peritoneal, os quais foram coletados 5 dias após este inóculo. Seis dias após a injeção do tioglicolato a $3 \%$ e um dia antes da coleta foi inoculado lipopolissacarídeo de parede bacteriana (LPS) na concentração de $1,0 \mathrm{mg} / \mathrm{mL}$, para estimular as células da cavidade peritoneal. Estas inoculações foram realizadas no período matutino entre ás 08:00 e 9:00h da manhã. Todas as injeções de LPS foram realizadas com seringas descartáveis (Becton-Dickinson ${ }^{\circledR}$ ) conectadas a agulhas de calibre $29 \mathrm{G} 1 / 2-12,7 \mathrm{~mm} \times 0,33 \mathrm{~mm}$, visando minimizar eventual agressão ao tecido alvo.

\subsubsection{Coleta das células peritoneais estimuladas pelo LPS}

Após a eutanásia destes animais, por meio de tiopental sódico $\left(\mathrm{Abbot}^{\circledR}\right)$ na dose de $60,0 \mathrm{mg} / \mathrm{kg}$, foram colhidas células peritoneais residentes e estimuladas pelo LPS. As coletas de células peritoneais foram sempre realizadas entre 08:30 e 11:30 h da manhã. Para a coleta das células peritoneais, foram injetados cerca de $10,0 \mathrm{~mL}$ de PBS a $4^{\circ} \mathrm{C}$ na cavidade peritoneal de cada animal e, após massagem abdominal, foi colhida uma suspensão de células de cada rato, por meio de punção 
neste local. Estas células foram mantidas em banho de gelo, em tubos de ensaio de polipropileno, até serem quantificadas em câmara de Neubauer, sendo a viabilidade celular das mesmas observadas pela coloração com azul de trypan, aceitando-se no mínimo 95\% de viabilidade. As suspensões de células devidamente conservadas em banho de gelo foram ajustadas para uma concentração de aproximadamente 2,0 x $10^{6}$ células $/ \mathrm{mL}$.

3.4.5.3 Execução da técnica para avaliação do espraiamento de macrófagos peritoneais

Das amostras de suspensão celulares colhidas do peritônio de cada animal, um volume aproximado de $200 \mu$ foi distribuído, em duplicata, sobre lamínulas de vidro $(20 \times 20 \mathrm{~cm})$ acondicionadas, uma a uma, dentro dos poços com $16 \mathrm{~mm}$ de diâmetro de placas especiais de plástico (Costar $\left.{ }^{\circledR} n^{\circ} 3424\right)$, as quais foram mantidas por 20 minutos em temperatura ambiente. As células sobre as lamínulas foram, a seguir, lavadas com PBS a $4^{\circ} \mathrm{C}$, recobertas com o meio de cultura RPMI 1641 , fechadas e incubadas em estufa a $37^{\circ} \mathrm{C}$ por 1 hora. Após este período, as células foram lavadas com PBS a $4^{\circ} \mathrm{C}$ e fixadas com solução de glutaraldeído $0,5 \%$ em PBS por 10 minutos. Em seguida, as lamínulas foram lavadas vigorosamente com PBS a $4^{\circ} \mathrm{C}$, sendo fixadas com glutaraldeído a $0,5 \%$ por 10 minutos. Para armazenar as placas em geladeira, o glutaraldeído foi diluído com a adição de 1,0 mL de água filtrada em Filtro Milli-Q plus ${ }^{\circledR}$, dentro de cada poço da placa. 
3.4.5.4 Execução da técnica para avaliação da fagocitose de macrófagos peritoneais de ratos

Todos os procedimentos descritos para a técnica de espraiamento foram também adotados para a técnica da fagocitose. Porém, após a aderência à lamínula de vidro, as células coletadas da cavidade peritoneal foram incubadas com meio de cultura RPMI 1641 , em estufa a $37^{\circ} \mathrm{C}$ por 1 hora, na presença de $1,0 \mathrm{mg}$ de zymosan A diluído em PBS para a concentração de $50 \mathrm{mg} / \mathrm{mL}$, acrescentado em cada poço das placas $10 \mu \mathrm{L}$ da suspensão. Para armazenar as placas em geladeira, o glutaraldeído foi diluído com $1,0 \mathrm{~mL}$ de água filtrada em Filtro Milli-Q plus ${ }^{\circledR}$, dentro de cada poço da placa.

3.4.5.5 Contagem de células aderidas de ratos com capacidade de espraiamento e de fagocitose

Ao final do período de incubação e de conservação das células aderidas à lamínula, foram realizadas a quantificação microscópica do número de células com capacidade de espraiamento e de fagocitose por meio de um microscópio de contraste de fase $\left(\mathrm{Nikon}^{\circledR}\right)$. O cálculo final foi realizado contando-se o número de células que espraiaram ou que fagocitaram / 200 células aderidas à lamínula. No caso da fagocitose, os resultados expressaram o número de células espraiadas que fagocitaram uma ou mais partículas de zymosan A. O índice de espraiamento e de 
fagocitose, em porcentagem, foi definido multiplicando-se por 100 o valor deste cálculo final. As técnicas de espraiamento e fagocitose foram executadas conforme descrição de Rabinovitch (1973); Rabinovitch e De Stefano (1973) e adaptação de Passeti (1993).

\subsubsection{Medida da liberação de peróxido de hidrogênio das células peritoneais de ratos}

Esta técnica consiste na utilização de uma placa de 96 poços de fundo chato $\left(\right.$ Costar $\left.^{\circledR}\right)$, composta por 12 colunas e 8 linhas, com a mesma medida de circunferência e profundidade para todos os poços. A primeira coluna da placa foi preenchida com $100 \mu \mathrm{l}$ de vermelho de fenol por poço e foi chamada de branco. Nas $2^{a}$ e $3^{a}$ colunas foram colocadas em quadruplicatas, concentrações molares previamente conhecidas de $\mathrm{H}_{2} \mathrm{O}_{2}$, a saber: 0,5 , 1,0, 2,0, 4,0 e 8,0 nmoles de $\mathrm{H}_{2} \mathrm{O}_{2}$ em $100 \mu$ l de vermelho de fenol, de modo a permitir a obtenção de uma curva padrão. Após o procedimento descrito no item 3.4.5.2, as células foram centrifugadas e ressuspendidas em $1,0 \mathrm{~mL}$ da solução de vermelho de fenol para a detecção de $\mathrm{H}_{2} \mathrm{O}_{2}$. Cem $\mu \mathrm{l}$ desta suspensão foram adicionadas no restante da placa e incubadas a $37^{\circ} \mathrm{C}$ com $5 \%$ de $\mathrm{CO}_{2}$, por uma hora. Após este período, todos os poços receberam $10,0 \mu \mathrm{l}$ de $\mathrm{NaOH} 1 \mathrm{~N}$ para interromper a reação. A oxidação do vermelho de fenol dependente de $\mathrm{H}_{2} \mathrm{O}_{2}$ foi medida em um leitor de ELISA, no comprimento de onda de $620 \mathrm{~nm}$. O mesmo procedimento foi aplicado para determinar a liberação de $\mathrm{H}_{2} \mathrm{O}_{2}$ induzida por forbol miristato de acetato (PMA), e para 
isso, 10,0 $\mu$ l de PMA (10 ng/mL) foram adicionados aos poços da placa antes da incubação.

Os resultados foram obtidos em densidade óptica (DO), sendo transformados em nmoles de $\mathrm{H}_{2} \mathrm{O}_{2}$ liberados por $2 \times 10^{6}$ células peritoneais, mediante equação de regressão linear e com base na curva padrão. A liberação espontânea e induzida por PMA, de $\mathrm{H}_{2} \mathrm{O}_{2}$ foi medida em quadruplicata para cada animal, e a média dos valores encontrados foi utilizada como medida desta concentração. A técnica utilizada foi aquela descrita por Pick e Keisari (1980), adaptada para microensaio por Pick e Mizel (1981) e modificada por Russo (1989).

\subsubsection{Medida do óxido nítrico através da produção de nitrito}

O peróxido de hidrogênio $\left(\mathrm{H}_{2} \mathrm{O}_{2}\right)$, o nitrito $\left(\mathrm{NO}_{2}{ }^{-}\right)$e outras espécies de radicais livres de $\mathrm{O}_{2}$, como o óxido nítrico (NO), são produtos inorgânicos secretados pelos macrófagos; embora a produção destes dois últimos ainda não tenha sido padronizada, elas podem ser, teoricamente, inferidas através da medida de níveis de $\mathrm{NO}_{2}^{-}$. Assim, a técnica utilizada para medir a produção de óxido nítrico neste trabalho foi aquela descrita por Ding et al. (1988). Esta técnica consiste na determinação indireta do $\mathrm{NO}$, via dosagem de seu metabólito $\mathrm{NO}_{2}^{-}$, que é um ânion estável nas condições em que foram realizados os experimentos. Após o procedimento descrito no item 3.4.5.2, as células foram centrifugadas e ressuspendidas em 1,0 mL de meio de cultura RPMI 1641 (Gibco ${ }^{\circledR}$ ), enriquecido com soro fetal bovino estéril a 10\%. Então, 100,0 $\mu$ l desta suspensão foram adicionados 
aos poços das placas de forma semelhante à descrita no item 3.4.6 e incubadas por $24 \mathrm{~h}$ a $37^{\circ} \mathrm{C}$ com $5 \%$ de $\mathrm{CO}_{2}$. Após a retirada da placa da estufa transferiu-se $50,0 \mu \mathrm{l}$ do sobrenadante de células para outra placa. Nesta nova placa, a primeira coluna foi chamada de branco. Nas $2^{a}$ e $3^{a}$ colunas colocou-se em quadruplicata, 50,0 $\mu$ de concentrações molares previamente conhecidas de nitrito de sódio, a saber: 0,05, 1,0, 3,0 e 6,0 nmoles de $\mathrm{NO}_{2}{ }^{-}$diluídos em meio RPMI-1641, de modo a permitir a obtenção de uma curva padrão. Após a transferência do sobrenadante das células, $50,0 \mu \mathrm{l}$ do reagente de Griess foi adicionado a todos os poços da nova placa. A produção de $\mathrm{NO}_{2}{ }^{-}$foi determinada em um leitor de Elisa no comprimento de onda de $540 \mathrm{~nm}$. Os resultados foram obtidos em densidade óptica (DO), sendo transformados em nmoles de nitrito liberados por $2 \times 10^{6}$ células peritoneais mediante equação de regressão linear com base na curva padrão. A produção de $\mathrm{NO}_{2}^{-}$foi medida em triplicata para cada animal. A média dos valores encontrados foi utilizada como medida da concentração de NO.

\subsubsection{Indução da resposta inflamatória aguda}

A resposta inflamatória aguda foi induzida pela injeção de uma suspensão de carragenina, tipo lambda, na concentração de 1,0\%, diluída em solução de Ringer. Este irritante foi sempre preparado imediatamente antes das injeções e a suspensão obtida foi dissolvida por cerca de 5 minutos com auxílio de um banho sonicador (Microsonic SX-20 ${ }^{\circledR}$ ), a fim de obter-se uma suspensão homogênea deste xenobiótico. O irritante foi injetado no volume de $0,1 \mathrm{~mL}$, por animal, no tecido celular 
subcutâneo do coxim plantar da pata posterior esquerda de cada rato. Todas as injeções de carragenina foram realizadas com seringas descartáveis (BectonDickinson $^{\circledR}$ ) conectadas a agulhas de calibre $29 \mathrm{G} 1 / 2-12,7 \mathrm{~mm} \times 0,33 \mathrm{~mm}$, visando-se minimizar uma eventual agressão física ao tecido alvo.

3.4.8.1 Medida do volume do edema inflamatório agudo induzido pela carragenina na pata de ratos

O volume do edema inflamatório agudo foi medido através do método da pletismografia, utilizando-se para tanto um pletismógrafo digital (Plethysmometer Ugo Basile ${ }^{\circledR}$ ), antes e 1 - 2 - 4 - 6 - 8 e 24 horas após a injeção da carragenina. A avaliação cinética do volume do edema inflamatório agudo induzido pela carragenina tinha início sempre no intervalo compreendido entre 09:00 e 10:00 horas da manhã.

Os resultados finais obtidos, ou seja, as diferenças entre os volumes medidos antes e depois da injeção foram expressas diretamente em microlitros $(\mu \mathrm{l})$.

\subsubsection{Indução da resposta inflamatória crônica}

A resposta inflamatória crônica foi induzida pela vacina Onco-BCG, contendo o bacilo de Calmette-Guérin, cepa Moreaux, na concentração de 40,0 mg/mL, obtidas do Instituto Butantã de São Paulo. O Onco-BCG, devidamente 
acondicionado em gelo, foi inoculado no tecido celular subcutâneo do coxim plantar da pata posterior esquerda dos ratos $(0,1 \mathrm{~mL}$ correspondendo a $10 \mathrm{mg}$ de bacilos/animal). A avaliação cinética do volume do edema inflamatório e da evolução do granuloma induzidos pelo Onco-BCG teve início sempre no intervalo compreendido entre 09:00 e 10:00 horas da manhã.

O volume do edema inflamatório e a evolução do granuloma experimental induzidos pelo Onco-BCG foram medidos através do método da pletismografia como descrito no item 3.4.8.1, antes e 1 - 2 - 4 - 6 - 8 e 24 horas e 1 - 2 - 3 - 4 - 5 - 6 - 7 11 - 13 - 15 - 17 - 19 e 21 dias após a injeção do BCG.

\subsubsection{Estudo Anátomo e Histopatológico}

Para a execução do estudo anátomo e histopatológico foram realizados os seguintes protocolos.

\subsubsection{Microscopia óptica}

Após a eutanásia dos animais com tiopental sódico $\left(\right.$ Abbot $\left.^{\circledR}\right)$ na dose de 60,0 $\mathrm{mg} / \mathrm{kg}$, estes foram necropsiados e procedeu-se à coleta de fragmentos representativos do baço, timo, linfonodos fígado e intestino. Estes fragmentos foram fixados em metacarn durante 24 h, após este período, esta solução foi substituída 
por álcool a 70\%; posteriormente, o material foi incluído em parafina, cortado e corado com hematoxilina-eosina $(\mathrm{HE})$, para observação de possíveis alterações à microscopia óptica.

\subsubsection{Avaliação morfométrica esplênica e tímica}

A avaliação morfométrica foi realizada com a utilização do sistema de análise de imagens computadorizado (BIOSCAN/OPTIMAS ${ }^{\circledR}$ ), composto por um microscópio óptico acoplado a uma câmera de vídeo e um computador, que possui uma placa digitalizadora e o programa Optimas ${ }^{\circledR}$. As imagens observadas ao microscópio foram transmitidas ao monitor, permitindo a sua análise. A avaliação morfométrica foi realizada utilizando-se cortes histológicos de baço e timo. A mensuração foi feita com régua utilizando-se uma objetiva de 40x. O território de interesse foi localizado, procedendo-se, em seqüência, o congelamento da imagem e a sua mensuração.

3.4.10.3 Avaliação da celularidade do timo, baço e medula óssea

A celularidade do timo e do baço foi determinada após a dissociação destes órgãos em meio RPMI-1640 com auxílio de lâminas para microscopia Perfecta ${ }^{\circledR}$. Estas células foram mantidas em banho de gelo, dentro de placas especiais de plástico $\left(\right.$ Costar $\left.^{\circledR} n^{\circ} 3424\right)$, até serem quantificadas em câmara de Neubauer, sendo 
a viabilidade celular das mesmas observadas pela coloração com azul de trypan $6 \%$, aceitando-se no mínimo 95\% de viabilidade.

Para determinar a celularidade da medula óssea, foi utilizado o fêmur esquerdo de cada animal. O conteúdo da medula óssea foi lavado com $10,0 \mathrm{~mL}$ de meio RPMI-1640 e a suspensão resultante foi acondicionada em tubos de polipropileno de 50,0 mL, dentro de um banho de gelo. Imediatamente, as células da medula óssea foram contadas, utilizando-se a técnica descrita por Raissuddin et al. (1990).

\subsection{DELINEAMENTO EXPERIMENTAL}

Para a realização dos diversos experimentos, estes foram delineados conforme descrição abaixo.

3.5.1 Experimento 1: Efeitos da administração prolongada das sementes de Senna occidentalis a ratos: avaliação do consumo de ração, ganho de peso, hemograma, componentes sangüíneos, celularidade de timo baço e medula óssea

Foram utilizados 50 ratos divididos em 5 grupos iguais, 3 experimentais e 2 controles. Os ratos dos grupos experimentais receberam, diariamente, por um 
período de 14 dias ração contendo 1\% (So1\%), 2\% (So2\%) e 4\% (So4\%) de S. occidentalis na ração ${ }^{2}$, conforme descrito no item 3.4.1. Aqueles animais do grupo controle e peer-feeding receberam apenas a ração comercial, durante todo o período experimental. O consumo de ração e o ganho de peso dos animais foram anotados conforme descrito no item 3.4.2. Após o último dia de administração das sementes da planta, os animais foram anestesiados e procedeu-se à coleta de sangue para determinação do hemograma e da avaliação bioquímica, como descrito nos itens 3.4.3 e 3.4.4, respectivamente. A seguir, estes animais foram submetidos à eutanásia para a realização de necropsia e coleta de material para exame histopatológico e morfométrico, conforme descrito nos itens 3.4.10.1 e 3.4.10.2, respectivamente.

\subsubsection{Experimento 2: Avaliação dos possíveis efeitos da administração prolongada de sementes de Senna occidentalis sobre a atividade de macrófagos peritoneais em ratos}

Foram utilizados 50 ratos divididos em 5 grupos iguais, 3 experimentais e 2 controles. Os ratos dos grupos experimentais receberam, diariamente, por um período de 14 dias ração contendo 1\% (So1\%), 2\% (So2\%) e 4\% (So4\%) de S. occidentalis na ração, conforme descrito no item 3.4.1. Aqueles animais do grupo controle e peer-feeding receberam apenas a ração comercial, durante todo o período experimental. No décimo dia de tratamento todos os animais receberam uma injeção

\footnotetext{
${ }^{2}$ Um estudo prévio mostrou que concentrações superiores a 4\% promovem diarréia nos ratos, o que produziria diminuição no ganho de peso, devido a quantidades expressivas de antranóides presente nesta planta.
} 
intraperitoneal de $5 \mathrm{~mL}$ de tioglicolato e 24 horas antes da eutanásia estes foram inoculados com 1,0 mg/mL de LPS, então procedeu-se à avaliação da atividade de macrófagos peritoneais (espraiamento e fagocitose), conforme descrita nos itens 3.4.5.1 e 3.4.5.2 respectivamente. A atividade de macrófagos foi determinada de acordo com os itens 3.4.5.3, 3.4.5.4 e 3.4.5.5, respectivamente.

\subsubsection{Experimento 3: Avaliação dos efeitos da administração prolongada de sementes de Senna occidentalis sobre a produção de água oxigenada e óxido nítrico em ratos}

Foram utilizados 50 ratos divididos em 5 grupos iguais, 3 experimentais e 2 controles. Os ratos dos grupos experimentais receberam, diariamente, por um período de 14 dias ração contendo 1\% (So1\%), 2\% (So2\%) e 4\% (So4\%) de S. occidentalis na ração, conforme descrito no item 3.4.1. Aqueles animais do grupo controle e peer-feeding receberam apenas a ração comercial, durante todo o período experimental. $\mathrm{O}$ consumo de ração e o ganho de peso dos animais foram anotados conforme descrito no item 3.4.2. Após o último dia de administração das sementes da planta, os animais foram anestesiados e procedeu-se à avaliação das espécies reativas de oxigênio e de nitrogênio, conforme descritos nos itens 3.4.6 e 3.4.7, respectivamente. 


\subsubsection{Experimento 4: Avaliação dos efeitos da administração prolongada de sementes de Senna occidentalis sobre as respostas inflamatórias, aguda e crônica, em ratos}

Foram utilizados 50 ratos divididos em 5 grupos iguais, 3 experimentais e 2 controles. Os ratos dos grupos experimentais receberam, diariamente, por um período de 14 dias, ração contendo $1 \%, 2 \%$ e $4 \%$ de S. occidentalis, conforme descrito no item 3.4.1. Os animais do grupo controle, assim como aqueles do grupo peer-feeding receberam a ração sem adição das sementes da planta, durante todo o período experimental. Após este período, realizou-se o estudo das respostas inflamatória aguda e crônica, conforme descrito nos itens 3.4.8.1 e 3.4.9, respectivamente.

\subsection{ANÁLISE ESTATÍSTICA}

A avaliação da homocedasticidade dos dados, entre os diferentes grupos foi realizada pelo teste de Bartlett, diferenciando os dados paramétricos daqueles não paramétricos (GAD; WEIL, 1989).

Para os dados paramétricos, empregou-se a análise de variância ANOVA, proposta por Snedecor (1946), seguido pelo teste de Dunnett para comparação entre os diversos grupos experimentais e o grupo controle. 
A análise de variância (ANOVA) não-paramétrica de Kruskal-Wallis foi aplicada para a detecção de possíveis diferenças entre os grupos de animais, quando da contagem do número de bacilos na lesão granulomatosa induzida pelo BCG na pata dos ratos tratados com as diferentes concentrações de S. occidentalis durante 14 dias.

O teste "t" de Student (PIMENTEL, 1981) foi empregado para a comparação dos dados obtidos entre os grupos de ratos que receberam $4 \%$ de sementes de S. occidentalis na ração (grupos experimentais) ou não (grupos controles).

A probabilidade de $p<0,05$ foi considerada capaz de revelar diferenças significantes entre os grupos. Para a análise estatística, foi empregado o software GraphPad Instat v 3.00 para Windows $95^{\circledR}$ (GRAPHPAD INSTAT, 1998). Os gráficos obtidos após a análise dos dados foram confeccionados por meio do programa GraphPad Prisma v 3.00 para Windows $95^{\circledR}$ (GRAPHPAD PRISM, 1999).

Para a estatística descritiva são apresentados as médias e os respectivos erros-padrão para os dados paramétricos. 
Resultados 64

4 RESULTADOS 


\section{RESULTADOS}

\subsection{EXPERIMENTO 1: AVALIAÇÃO DOS POSSÍVEIS EFEITOS TÓXICOS DA ADMINISTRAÇÃO PROLONGADA DE SEMENTES DE Senna occidentalis A RATOS}

A tabela 1 mostra e a figura 3 ilustra o consumo médio e total de água pelos ratos durante o experimento. Assim, a análise estatística realizada revelou haver diferença significante entre os grupos nos $4^{\circ}, 6^{\circ}$ e $14^{\circ}$ dias do experimento $\left(F_{4}=2,764\right.$; $F_{6}=3,113$ e $F_{14}=4,596 ; d f=4 / 45$, respectivamente, $\left.p<0,05\right)$, bem como no período total $(F=135,97$ e df=4/45). A aplicação do teste de Dunnett apontou diminuição significante $(p<0,05)$ no consumo de água dos animais tratados com So $4 \%$ no $4^{\circ}, 6^{\circ}$ e $14^{\circ}$ dias do experimento, quando comparado aos animais do grupo controle. $\mathrm{Na}$ avaliação no consumo total de água, o teste de Dunnett revelou haver diminuição significante $(p<0,05)$ neste parâmetro nos animais pertencentes aos grupos experimentais So2\%, So4\% e peer-feeding (PF), quando comparado aos animais do grupo controle.

Em relação ao consumo de ração destes animais (Tabela 2 e Figura 4), as análises de variância realizadas revelaram haver diferença significante entre os grupos nos $2^{\circ}, 6^{\circ}, 8^{\circ}, 10^{\circ}, 12^{\circ}$ e $14^{\circ}$ dias do experimento $\left(F_{2}=109,11 ; F_{6}=3,625\right.$; $F_{8}=5,683 ; F_{10}=16,103 ; F_{12}=17,790 ; F_{14}=13,610 ; d f=3 / 36$, respectivamente, $\left.p<0,05\right)$, bem como no período total $(\mathrm{F}=1063,2$ e $\mathrm{df}=3 / 36)$, quando comparado aos resultados 
obtidos dos animais pertencentes ao grupo controle, sendo que o consumo dos animais do grupo PF foi idêntico àquele dos ratos submetidos à administração de ração contendo $4 \%$ de sementes de S. occidentalis (dados não apresentados). A aplicação do teste de Dunnett mostrou redução significante $(p<0,05)$ deste parâmetro apenas no $2^{\circ}$ dia de tratamento pelos animais pertencentes ao grupo So1\%, em relação aos animais do grupo controle. Este mesmo teste apontou ainda, diminuição significante $(p<0,05)$ no consumo de ração daqueles ratos pertencentes ao grupo So $2 \%$ no $2^{\circ}$ e $14^{\circ}$ dias do experimento, em relação aos animais do grupo controle. Já os animais pertencentes ao grupo So4\% apresentaram diminuição significante $(p<0,05)$ deste parâmetro no $2^{\circ}, 6^{\circ}, 8^{\circ}, 10^{\circ}, 12^{\circ}$ e $14^{\circ}$ dias de avaliação, quando comparado aos animais pertencentes ao grupo controle. Na avaliação no consumo total de ração, o teste de Dunnett revelou haver diminuição significante $(p<0,05)$ em todos os animais dos grupos experimentais, em relação aos animais pertencentes ao grupo controle.

A tabela 3 mostra e a figura 5 ilustra o peso médio destes animais, as análises de variância realizadas revelaram haver diferença significante entre os grupos nos $4^{\circ}, 6^{\circ}, 8^{\circ}, 10^{\circ}, 12^{\circ}$ e $14^{\circ}$ dias do experimento $\left(F_{4}=2,460 ; F_{6}=4,992\right.$; $F_{8}=4,272 ; \quad F_{10}=6,113 ; \quad F_{12}=7,982 ; \quad F_{14}=8,017 ; d f=4 / 45$, respectivamente, $\left.p<0,05\right) . A$ aplicação do teste de Dunnett demonstrou haver diminuição significante $(p<0,05)$ no peso médio dos animais tratados com So $\%$ em relação àqueles animais pertencentes ao grupo controle nos $6^{\circ}, 8^{\circ}, 10^{\circ}$ e $14^{\circ}$ dias de tratamento. Além disso, este mesmo teste apontou redução significante $(p<0,05)$ no peso médio dos animais tratados com So $4 \%$ nos $4^{\circ}, 6^{\circ}, 8^{\circ}, 10^{\circ}, 12^{\circ}$ e $14^{\circ}$ dias de tratamento, quando comparado aos animais pertencentes ao grupo controle. 
Os ganhos de peso médios semanais e totais destes ratos são apresentados na tabela 4 e figura 6 . A análise de variância realizada revelou haver diferença significante entre os grupos na $1^{\mathrm{a}}$ e $2^{\mathrm{a}}$ semanas $\left(F_{1}=3992,6 ; F_{2}=175,93 ; \mathrm{df}=4 / 45\right.$, respectivamente, $p<0,05)$, bem como no período total $(F=590,33$ e df=4/45) do experimento. A aplicação do teste de Dunnett mostrou diminuição significante $(p<0,05)$ no ganho de peso semanal dos animais tratados com So $2 \%$ e So $4 \%$ na primeira semana de avaliação. Este mesmo teste apontou, ainda, redução significante $(p<0,05)$ de peso na $2^{a}$ semana de tratamento por todos os grupos experimentais incluindo o grupo PF, bem com no período total de tratamento, em relação aos animais pertencentes ao grupo controle.

Em relação às observações clínicas, os seguintes sinais e sintomas, foram observados: letargia, abatimento, prostração, pêlos arrepiados e fezes amolecidas, a partir da segunda semana de tratamento em todos os animais pertencentes ao grupo So4\%.

Os resultados dos efeitos da administração de ração contendo diferentes concentrações de sementes de S. occidentalis sobre os parâmetros hematológicos de ratos são apresentados na tabela 5 e ilustrados na figura 7 . O número médio de eritrócitos (RBC) e leucócitos (WBC) e os valores médios de hemoglobina (HB), hematócrito (HCT), volume corpuscular médio (VCM), hemoglobina corpuscular média $(\mathrm{HCM})$ e concentração de hemoglobina corpuscular média ( $\mathrm{CHCM})$ são apresentados. A análise estatística revelou haver diferença significante $(p<0,05)$ no HCT, no VCM e na CHCM $\left(F_{H C T}=3,093 ; F_{V C M}=25,529 ; F_{C H C M}=16,404 ; d f=4 / 45\right)$. A aplicação do teste de Dunnett apontou diminuição significante $(p<0,05)$ no VCM nos animais tratados com So2\%, quando comparado àqueles animais pertencentes ao grupo controle. Este mesmo teste apontou diminuição significante $(p<0,05)$ no HCT, 
no $\mathrm{VCM}$ e na $\mathrm{CHCM}$ dos ratos tratados com So4\% em relação aos animais do grupo controle. Na contagem diferencial de leucócitos (Tabela 6) nenhuma alteração significante $(p>0,05)$ foi observada entre os animais tratados quando comparados aos controles.

Os resultados relativos à bioquímica (albumina, glicose e proteínas totais) são apresentados na tabela 7. A análise estatística revelou não haver diferença significante $(p>0,05)$ neste parâmetro entre os valores obtidos nos diferentes grupos experimentais e aqueles obtidos dos animais do grupo controle.

Os resultados obtidos na avaliação do peso relativo do baço e timo dos animais tratados com as diferentes concentrações de S. occidentalis na ração, são apresentados na tabela 8. A análise estatística revelou haver diferença significante $(p<0,05)$ no peso relativo do timo $(F=11,009 ; d f=4 / 45)$. A aplicação do teste de Dunnett apontou diminuição significante $(p<0,05)$ no peso relativo do timo dos animais pertencentes ao grupo So $4 \%$, quando comparado aos animais do grupo controle (Figura 8).

A tabela 9 mostra a celularidade do baço, timo e medula óssea, e a figura 9 ilustra, respectivamente a celularidade da medula óssea de ratos tratados com as diferentes concentrações de $S$. occidentalis na ração. A análise estatística apontou diferença significante $(p<0,05)$ na celularidade da medula óssea $(M O)\left(F_{M O}=4,433\right.$; $d f=4 / 45)$. A aplicação do teste de Dunnett apontou aumento significante $(p<0,05)$ na celularidade da medula óssea dos animais tratados com So1\% e So2\%, em relação aos animais pertencentes ao grupo controle.

A análise morfométrica em microscopia de luz foi realizada a partir de lâminas contendo cortes transversais de baço e timo de ratos tratados com diferentes concentrações de sementes de $S$. occidentalis na ração durante 14 dias 
(Tabela 10 e Figura 10). A análise estática revelou haver diferença significante $(p<0,05)$ nas regiões cortical $(K W=10,451)$ e medular do timo $(K W=46,666)$, bem como na região cortical do baço $(K W=29,423)$. A aplicação do teste de Dunn mostrou diminuição significante $(p<0,05)$ nas densidades das regiões corticais e no diâmetro medular dos folículos do timo, dos animais tratados com So4\% em relação aos animais pertencentes ao grupo controle. Este mesmo teste apontou, ainda, redução significante $(p<0,05)$ na região cortical do baço dos animais tratados com So2\% e So $4 \%$, quando comparado aos resultados obtidos dos ratos pertencentes ao grupo controle.

Em relação ao estudo histopatológico de fragmentos histológicos provenientes do baço, timo, linfonodos, fígado e de diferentes porções do intestino, nenhuma alteração morfológica digna de nota foi observada em qualquer das amostras colhidas, de animais pertencentes aos diferentes grupos experimentais. 
Tabela 1 - Consumo médio e total de água (em $\mathrm{ml})$ pelos ratos tratados durante 14 dias com diferentes concentrações $(0 \%$, $1 \%$, $2 \%$ e $4 \%$ ) de sementes de S. occidentalis, na ração e seu grupo peer-feeding. Foram utilizados 10 animais por grupo. São apresentados as médias e os respectivos erros padrões

\begin{tabular}{|c|c|c|c|c|c|}
\hline \multirow{2}{*}{$\begin{array}{l}\text { Dias de } \\
\text { tratamento }\end{array}$} & \multicolumn{5}{|c|}{ Senna occidentalis (\%) } \\
\hline & 0 & 1 & 2 & 4 & PF \\
\hline $2^{\circ}$ & $68,0 \pm 3,1$ & $67,5 \pm 3,7$ & $68,5 \pm 2,2$ & $65,0 \pm 4,1$ & $68,5 \pm 2,5$ \\
\hline $4^{\circ}$ & $71,7 \pm 4,6$ & $73,8 \pm 1,9$ & $68,2 \pm 2,5$ & $61,3 \pm 4,3^{a b}$ & $75,2 \pm 2,5$ \\
\hline $6^{\circ}$ & $84,7 \pm 2,0$ & $82,1 \pm 3,3$ & $75,8 \pm 3,5$ & $71,8 \pm 2,7^{a b}$ & $81,0 \pm 3,0$ \\
\hline $8^{\circ}$ & $73,8 \pm 3,7$ & $73,3 \pm 4,2$ & $78,0 \pm 3,3$ & $69,3 \pm 2,8$ & $69,1 \pm 2,2$ \\
\hline $10^{\circ}$ & $73,1 \pm 4,4$ & $70,1 \pm 1,9$ & $70,1 \pm 2,7$ & $70,2 \pm 2,8$ & $68,5 \pm 2,6$ \\
\hline $12^{\circ}$ & $77,5 \pm 3,1$ & $77,5 \pm 3,4$ & $78,4 \pm 3,3$ & $76,0 \pm 3,7$ & $73,7 \pm 2,8$ \\
\hline $14^{\circ}$ & $71,4 \pm 2,9$ & $82,0 \pm 3,0$ & $80,0 \pm 3,0$ & $67,3 \pm 3,0^{a b}$ & $74,2 \pm 4,0$ \\
\hline Total & $523,0 \pm 4,0$ & $526,3 \pm 4,0$ & $484,0 \pm 4,0^{a}$ & $411,1 \pm 3,7^{\mathrm{ab}}$ & $500,0 \pm 3,9^{a}$ \\
\hline
\end{tabular}

\footnotetext{
${ }^{a}$ difere significantemente $(p<0,05)$ em relação ao controle (ANOVA, seguida de Dunnett).

${ }^{\mathrm{b}}$ difere significantemente $(\mathrm{p}<0,05)$ do grupo PF (Teste "t" Student).
} 

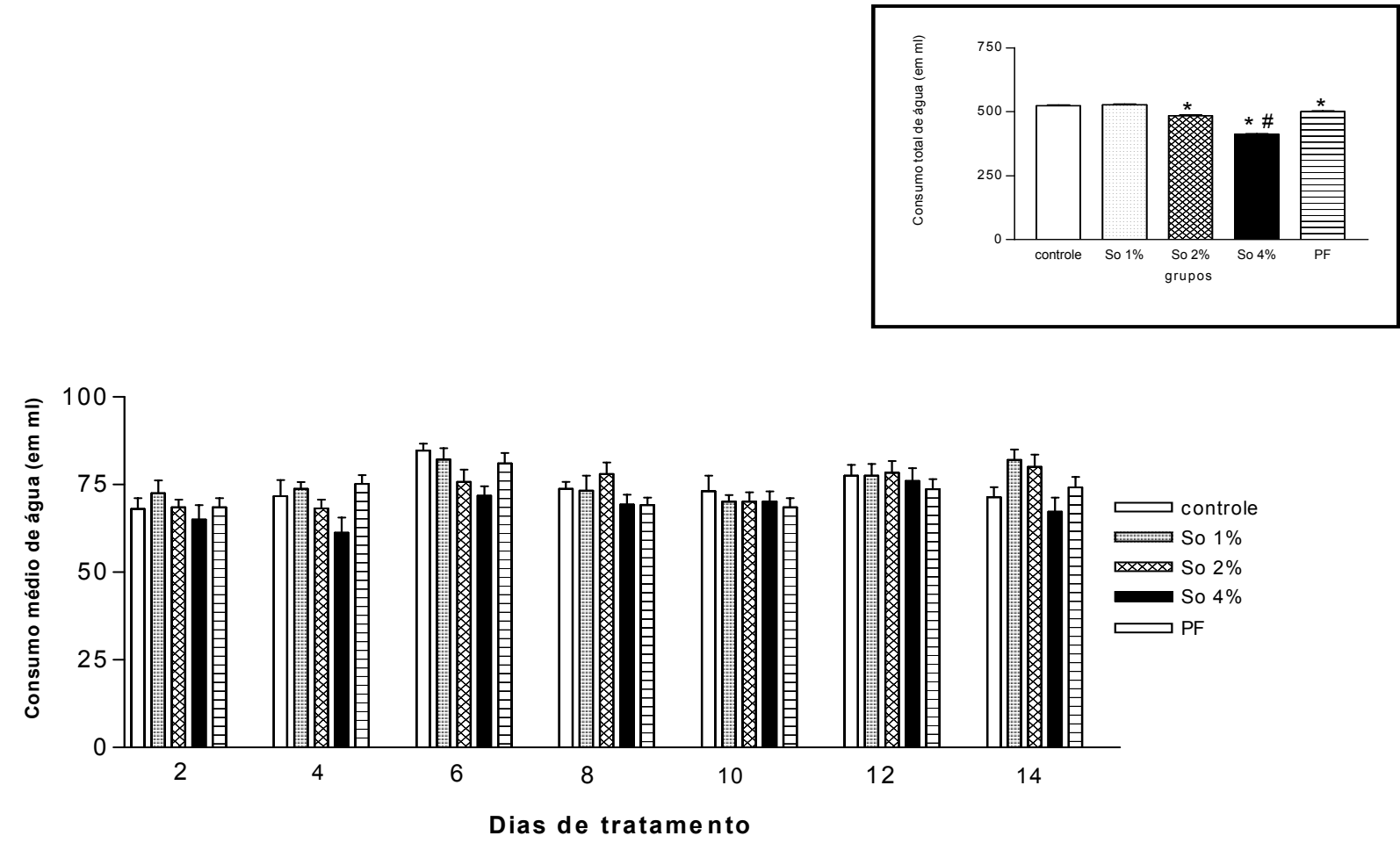

* difere significantemente $(p<0,05)$ em relação ao controle (ANOVA, seguida de Dunnett).

\# difere significantemente $(p<0,05)$ do grupo PF (Teste "t" Student).

OBS: as diferenças estatisticamente significantes no consumo médio estão identificadas na Tabela 1.

Figura 3 - Consumo médio e total de água (em $\mathrm{ml}$ ) pelos ratos tratados durante 14 dias com diferentes concentrações $(0 \%$, $1 \%, 2 \%$ e $4 \%$ ) de sementes de $S$. occidentalis, na ração e seu grupo peer-feeding. Foram utilizados 10 animais por grupo. São apresentados as médias e os respectivos erros padrões 
Tabela 2 - Consumo médio e total de ração (em g) pelos ratos tratados durante 14 dias com diferentes concentrações $(0 \%$, $1 \%$, $2 \%$ e $4 \%$ ) de sementes de $S$. occidentalis, na ração. Foram utilizados 10 animais por grupo. São apresentados as médias e os respectivos erros padrões

\begin{tabular}{|c|c|c|c|c|}
\hline \multirow{2}{*}{$\begin{array}{c}\text { Dias de } \\
\text { tratamento }\end{array}$} & \multicolumn{4}{|c|}{ Senna occidentalis (\%) } \\
\hline & 0 & 1 & 2 & 4 \\
\hline $2^{\circ}$ & $47,2 \pm 1,2$ & $41,7 \pm 0,5^{a}$ & $36,5 \pm 0,6^{a}$ & $17,8 \pm 1,9^{a}$ \\
\hline $4^{\circ}$ & $47,2 \pm 1,6$ & $44,4 \pm 3,2$ & $44,3 \pm 4,5$ & $45,5 \pm 4,4$ \\
\hline $6^{\circ}$ & $50,0 \pm 3,1$ & $50,7 \pm 3,1$ & $39,6 \pm 3,7$ & $31,5 \pm 6,9^{a}$ \\
\hline $8^{\circ}$ & $43,5 \pm 0,7$ & $38,8 \pm 0,9$ & $37,8 \pm 4,6$ & $27,8 \pm 2,9^{a}$ \\
\hline $10^{\circ}$ & $50,0 \pm 3,1$ & $40,2 \pm 2,2$ & $38,2 \pm 7,4$ & $8,60 \pm 3,0^{a}$ \\
\hline $12^{\circ}$ & $38,9 \pm 4,3$ & $39,5 \pm 2,1$ & $36,6 \pm 2,5$ & $12,0 \pm 3,0^{a}$ \\
\hline $14^{\circ}$ & $39,1 \pm 4,5$ & $38,4 \pm 2,4$ & $17,0 \pm 4,8^{a}$ & $11,6 \pm 2,9^{a}$ \\
\hline Total & $315,9 \pm 1,1$ & $293,7 \pm 0,6^{a}$ & $250,0 \pm 3,4^{a}$ & $144,8 \pm 2,1^{a}$ \\
\hline
\end{tabular}

${ }^{a}$ difere significantemente $(p<0,05)$ em relação ao controle (ANOVA, seguida de Dunnett). 

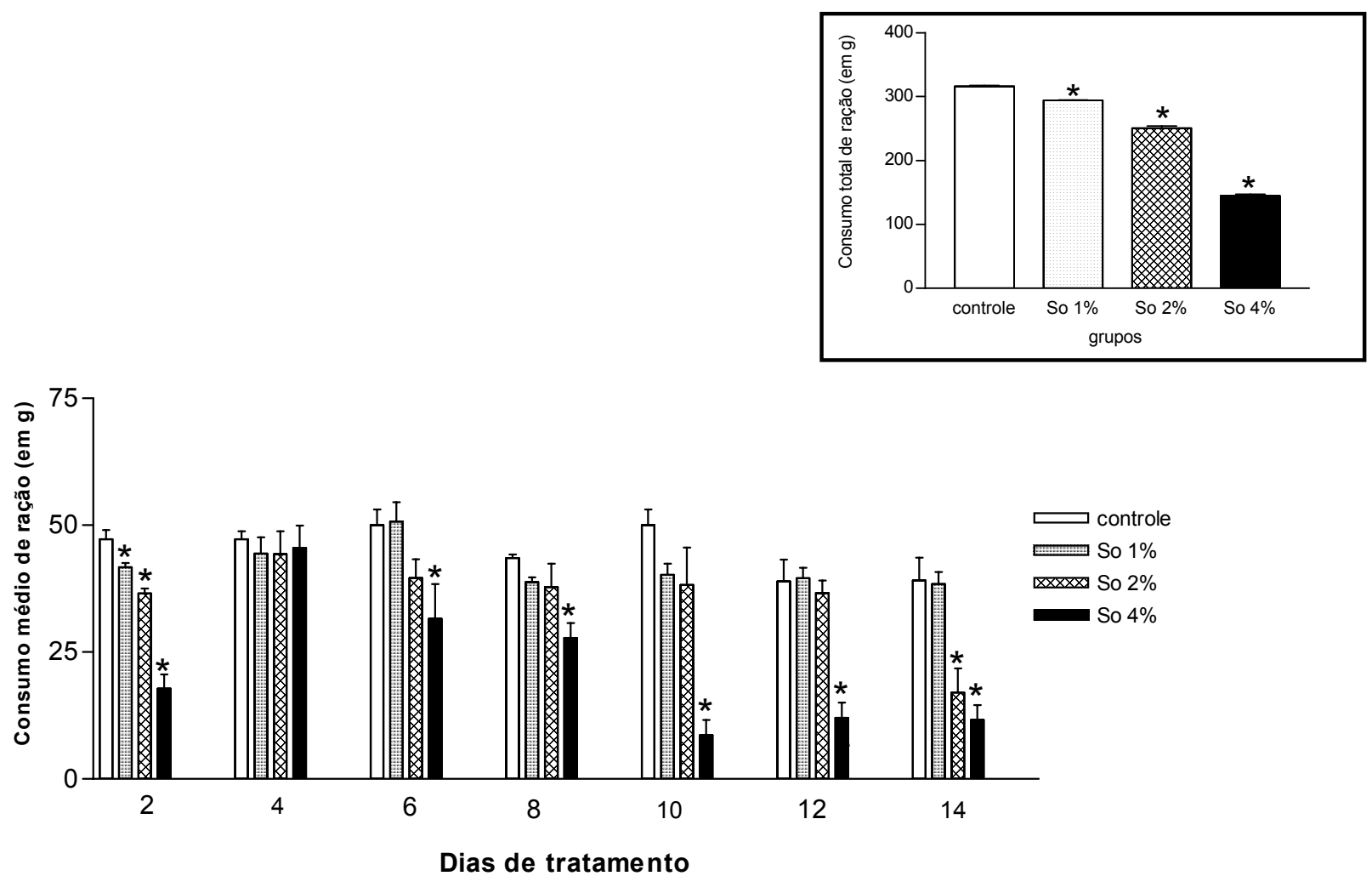

*difere significantemente $(p<0,05)$ em relação ao controle (ANOVA, seguida de Dunnett).

Figura 4 - Consumo médio e total de ração (em g) pelos ratos tratados durante 14 dias com diferentes concentrações $(0 \%$, $1 \%, 2 \%$ e $4 \%$ ) de sementes de S. occidentalis, na ração. Foram utilizados 10 animais por grupo. São apresentados as médias e os respectivos erros padrões 
Tabela 3 - Peso médio (em g), de ratos tratados durante 14 dias com diferentes concentrações (0\%, 1\%, 2\% e 4\%) de sementes de S. occidentalis, na ração e seu grupo peer-feeding. Foram utilizados 10 animais por grupo. São apresentados as médias e os respectivos erros padrões

\begin{tabular}{cccccc}
\hline $\begin{array}{c}\text { Dias de } \\
\text { tratamento }\end{array}$ & \multicolumn{4}{c}{ Senna occidentalis (\%) } & \multicolumn{4}{c}{$\mathbf{4}$} & PF \\
\hline $\mathbf{2}^{\mathbf{0}}$ & $173,4 \pm 3,7$ & $170,9 \pm 4,5$ & $168,0 \pm 4,0$ & $161,0 \pm 4,1$ & $168,4 \pm 4,0$ \\
$\mathbf{4}^{\mathbf{0}}$ & $176,8 \pm 3,6$ & $174,7 \pm 4,7$ & $165,3 \pm 5,2$ & $159,5 \pm 4,2^{\mathrm{ab}}$ & $169,8 \pm 4,3$ \\
$\mathbf{6}^{\mathbf{0}}$ & $182,2 \pm 3,4$ & $176,0 \pm 5,1$ & $162,2 \pm 4,9^{\mathrm{a}}$ & $156,9 \pm 4,8^{\mathrm{ab}}$ & $173,6 \pm 4,6$ \\
$\mathbf{8}^{\mathbf{0}}$ & $182,0 \pm 4,9$ & $179,5 \pm 5,2$ & $165,2 \pm 6,5^{\mathrm{a}}$ & $159,7 \pm 1,2^{\mathrm{ab}}$ & $171,2 \pm 4,7$ \\
$\mathbf{1 0}^{\mathbf{0}}$ & $184,4 \pm 4,9$ & $179,8 \pm 5,2$ & $164,9 \pm 6,9^{\mathrm{a}}$ & $151,6 \pm 4,5^{\mathrm{ab}}$ & $175,5 \pm 5,3$ \\
$\mathbf{1 2}^{\mathbf{0}}$ & $184,1 \pm 4,9$ & $187,8 \pm 4,6$ & $165,9 \pm 7,5$ & $148,5 \pm 4,6^{\mathrm{ab}}$ & $176,6 \pm 5,9$ \\
$\mathbf{1 4}^{\mathbf{0}}$ & $189,5 \pm 4,3$ & $182,9 \pm 4,9$ & $166,3 \pm 8,4^{\mathrm{a}}$ & $146,6 \pm 4,6^{\mathrm{ab}}$ & $178,0 \pm 6,4$
\end{tabular}

\footnotetext{
a difere significantemente $(p<0,05)$ em relação ao controle (ANOVA,seguida de Dunnett).
}

${ }^{b}$ difere significantemente $(p<0,05)$ em relação ao PF (Teste "t" Student). 


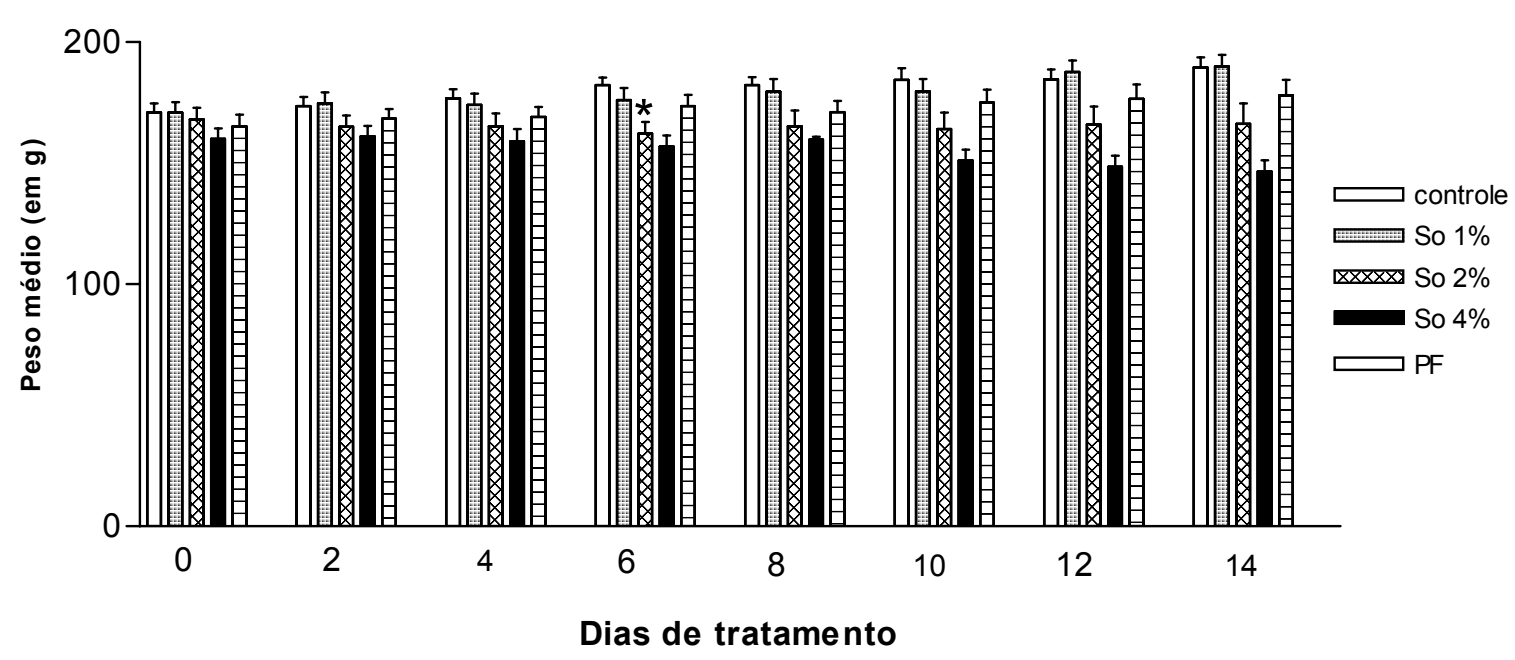

OBS: as diferenças estatisticamente significantes no consumo médio estão identificadas na Tabela 3.

Figura 5 - Peso médio (em g), de ratos tratados durante 14 dias com diferentes concentrações $(0 \%, 1 \%, 2 \%$ e $4 \%)$ de sementes de $S$. occidentalis, na ração e seu grupo peer-feeding. Foram utilizados 10 animais por grupo. São apresentados as médias e os respectivos erros padrões 
Tabela 4 - Peso semanal e total (em g), de ratos tratados durante 14 dias com diferentes concentrações (0\%, 1\%, 2\% e 4\%) de sementes de $S$. occidentalis, na ração e seu grupo peer-feeding. Foram utilizados 10 animais por grupo. São apresentados as médias e os respectivos erros padrões

\begin{tabular}{cccccc}
\hline $\begin{array}{c}\text { Semanas de } \\
\text { tratamento }\end{array}$ & $\mathbf{0}$ & $\mathbf{1}$ & $\mathbf{S e n n a}$ occidentalis (\%) & $\mathbf{4}$ & $\mathbf{2}$ \\
\hline $\mathbf{S 1}$ & $9,0 \pm 0,1$ & $8,6 \pm 0,6$ & $-2,6 \pm 0,7^{\mathrm{a}}$ & $-1,3 \pm 0,4^{\mathrm{ab}}$ & $8,0 \pm 0,1$ \\
$\mathbf{S 2}$ & $7,0 \pm 0,2$ & $3,4 \pm 0,7^{\mathrm{a}}$ & $1,7 \pm 0,9^{\mathrm{a}}$ & $-13,1 \pm 0,6^{\mathrm{ab}}$ & $3,3 \pm 0,2^{\mathrm{a}}$ \\
Total & $16,8 \pm 0,1$ & $12,0 \pm 0,6^{\mathrm{a}}$ & $4,3 \pm 0,8^{\mathrm{a}}$ & $-14,4 \pm 0,5^{\mathrm{ab}}$ & $11,3 \pm 0,1^{\mathrm{a}}$ \\
\end{tabular}

a difere significantemente $(p<0,05)$ em relação ao controle (ANOVA, seguida de Dunnett).

${ }^{b}$ difere significantemente $(p<0,05)$ em relação ao PF (Teste "t" Student). 


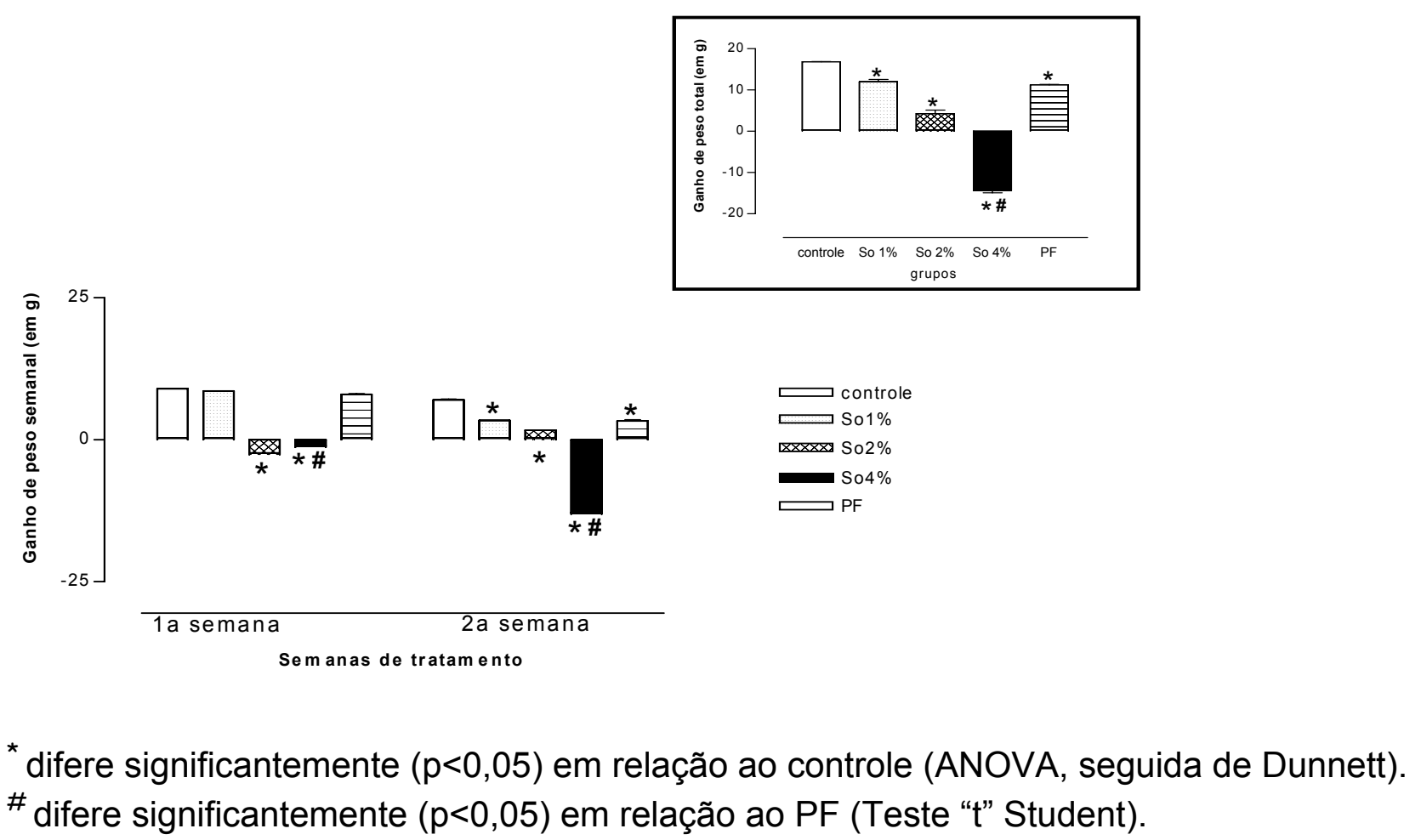

Figura 6 - Peso semanal e total (em g), de ratos tratados durante 14 dias com diferentes concentrações $(0 \%, 1 \%, 2 \%$ e $4 \%)$ de sementes de $S$. occidentalis, na ração e seu grupo peer-feeding. Foram utilizados 10 animais por grupo. São apresentados as médias e os respectivos erros padrões 
Tabela 5 - Número médio de eritrócitos $\left(\times 10^{6} / \mathrm{mm}^{3}\right)$ e leucócitos $\left(\times 10^{6} / \mathrm{mm}^{3}\right)$ e os valores médios do hematócrito - HCT (\%) e hemoglobina - HGB $(\mathrm{g} / \mathrm{dL})$, volume corpuscular médio - VCM $\left(\mu^{3}\right)$, hemoglobina corpuscular média - HCM ( $\left.\mu \mu \mathrm{g}\right)$ e concentração de hemoglobina corpuscular média - CHCM (\%), de ratos tratados durante 14 dias com diferentes concentrações $(0 \%, 1 \%, 2 \%$ e $4 \%)$ de sementes de S. occidentalis, na ração e seu grupo peer-feeding. Foram utilizados 10 animais por grupo. São apresentados as médias e os respectivos erros padrões

\section{Parâmetros Hematológicos}

\begin{tabular}{|c|c|c|c|c|c|c|c|}
\hline Grupos & $\begin{array}{l}\text { Eritrócitos } \\
\left(\times 10^{6} / \mathrm{mm}^{3}\right)\end{array}$ & $\begin{array}{l}\text { Leucócitos } \\
\left(\times 10^{6} / \mathrm{mm}^{3}\right)\end{array}$ & $\begin{array}{l}\text { HCT } \\
(\%)\end{array}$ & $\begin{array}{l}\text { HGB } \\
\text { (g/dL) }\end{array}$ & $\begin{array}{l}\text { VCM } \\
\left(\mu^{3}\right)\end{array}$ & $\begin{array}{l}\mathrm{HCM} \\
(\mu \mu \mathrm{g})\end{array}$ & $\begin{array}{c}\text { CHCM } \\
(\%)\end{array}$ \\
\hline So1\% & $6,6 \pm 0,1$ & $5,6 \pm 0,4$ & $42,5 \pm 2,6$ & $14,4 \pm 0,9$ & $74,1 \pm 0,7$ & $25,2 \pm 0,5$ & $33,6 \pm 1,3$ \\
\hline So4\% & $6,5 \pm 0,5$ & $5,7 \pm 0,3$ & $36,9 \pm 2,5^{a b}$ & $15,2 \pm 0,7$ & $67,5 \pm 1,5^{a b}$ & $24,6 \pm 0,9$ & $23,8 \pm 1,5^{a b}$ \\
\hline PF & $6,8 \pm 0,5$ & $5,8 \pm 0,7$ & $44,5 \pm 2,8$ & $16,5 \pm 0,7$ & $77,4 \pm 1,0$ & $25,7 \pm 1,3$ & $35,7 \pm 1,6$ \\
\hline
\end{tabular}

a difere significantemente $(p<0,05)$ em relação ao controle (ANOVA, seguida de Dunnett).

${ }^{b}$ difere significantemente $(p<0,05)$ em relação ao PF (Teste "t" Student 

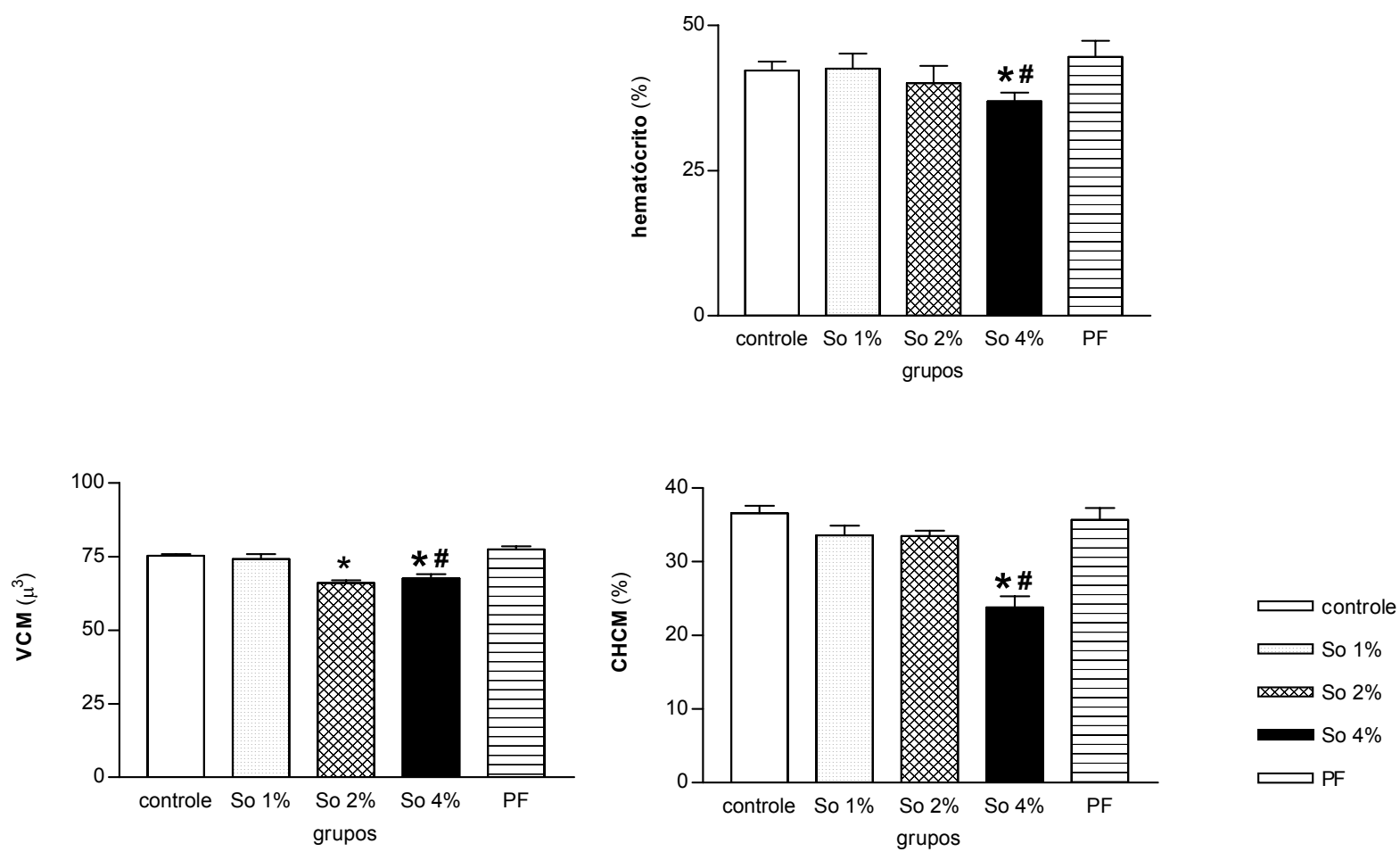

* difere significantemente $(p<0,05)$ em relação ao controle (ANOVA, seguida de Dunnett).

\# difere significantemente $(p<0,05)$ em relação ao PF (Teste "t" Student).

Figura 7 - Valor médio do hematócrito - HCT (\%), volume corpuscular médio - VCM $\left(\mu^{3}\right)$ e concentração de hemoglobina corpuscular média - CHCM (\%), de ratos tratados durante 14 dias com diferentes concentrações $(0 \%, 1 \%, 2 \%$ e $4 \%$ ) de sementes de S. occidentalis, na ração e seu grupo peer-feeding. Foram utilizados 10 animais por grupo. São apresentados as médias e os respectivos erros padrões 
Tabela 6 - Média do número de linfócitos (em \%), neutrófilos segmentados (em\%), eosinófilos (em \%), bastonete (em \%) e monócitos (em \%), de ratos tratados durante 14 dias com diferentes concentrações $(0 \%, 1 \%, 2 \%$ e $4 \%)$ de sementes de $S$. occidentalis, na ração e seu grupo peer-feding. Foram utilizados 10 animais por grupo. São apresentados as médias e os respectivos erros padrões

\section{Parâmetros Hematológicos}

\begin{tabular}{|c|c|c|c|c|c|}
\hline Grupos & Linfócitos (\%) & Neutrófilos (\%) & Eosinófilos (\%) & Bastonetes (\%) & Monócitos (\%) \\
\hline $\begin{array}{c}\text { Control } \\
e\end{array}$ & $78,0 \pm 0,9$ & $16,0 \pm 0,6$ & $1,0 \pm 0,1$ & $3,0 \pm 0,2$ & $3,0 \pm 0,5$ \\
\hline So1\% & $79,0 \pm 1,0$ & $15,0 \pm 0,6$ & $1,0 \pm 0,1$ & $2,0 \pm 0,4$ & $3,0 \pm 0,4$ \\
\hline So2\% & $80,0 \pm 1,0$ & $15,0 \pm 0,8$ & $1,0 \pm 0,1$ & $2,0 \pm 0,6$ & $2,0 \pm 0,4$ \\
\hline So4\% & $78,0 \pm 0,5$ & $16,0 \pm 0,5$ & $1,0 \pm 0,1$ & $3,0 \pm 0,7$ & $2,0 \pm 0,3$ \\
\hline PF & $77,0 \pm 1,0$ & $16,0 \pm 0,7$ & $1,0 \pm 0,1$ & $2,0 \pm 0,5$ & $4,0 \pm 1,0$ \\
\hline
\end{tabular}

Não houve diferença $(p>0,05)$ entre os grupos. 
Tabela 7 - Níveis séricos de proteínas totais $(\mathrm{g} / \mathrm{L})$, glicose $(\mathrm{mg} / \mathrm{dL})$ e albumina $(\mathrm{g} / \mathrm{L})$, de ratos tratados durante 14 dias com diferentes concentrações $(0 \%, 1 \%, 2 \%$ e $4 \%)$ de sementes de $S$. occidentalis, na ração e seu grupo peer-feding. Foram utilizados 10 animais por grupo. São apresentados as médias e os respectivos erros padrões

\begin{tabular}{|c|c|c|c|}
\hline \multirow[b]{2}{*}{ Grupos } & \multicolumn{3}{|c|}{ Enzimas séricas } \\
\hline & $\begin{array}{c}\text { Proteínas Totais } \\
(\mathrm{g} / \mathrm{L})\end{array}$ & $\begin{array}{l}\text { Glicose } \\
\text { (mg/dL) }\end{array}$ & $\begin{array}{l}\text { Albumina } \\
(g / L)\end{array}$ \\
\hline Controle & $7,3 \pm 0,3$ & $66,6 \pm 9,7$ & $3,9 \pm 0,2$ \\
\hline So1\% & $7,5 \pm 0,4$ & $49,6 \pm 12,5$ & $3,5 \pm 0,1$ \\
\hline So2\% & $8,3 \pm 0,7$ & $58,6 \pm 10,8$ & $3,9 \pm 0,2$ \\
\hline PF & $7,4 \pm 0,5$ & $40,0 \pm 3,7$ & $3,6 \pm 0,2$ \\
\hline
\end{tabular}

Não houve diferença significante $(p>0,05)$ entre os grupos. 
Tabela 8 - Peso relativo do baço e timo (g/ $100 \mathrm{~g} \mathrm{pv})$, de ratos tratados durante 14 dias com diferentes concentrações $(0 \%$, $1 \%, 2 \%$ e $4 \%$ ) de sementes de $S$. occidentalis, na ração e seu grupo peer-feeding. Foram utilizados 10 animais por grupo. São apresentados as médias e os respectivos erros padrões

\begin{tabular}{cccccc}
\hline \multirow{2}{*}{ órgãos } & $\mathbf{0}$ & $\mathbf{4}$ & $\mathbf{2}$ & $\mathbf{4}$ & Senna occidentalis (\%) \\
\cline { 2 - 6 } & $0,300 \pm 0,019$ & $0,289 \pm 0,025$ & $0,310 \pm 0,034$ & $0,340 \pm 0,063$ & $0,319 \pm 0,031$ \\
baço & & & & $0,081 \pm 0,014$ \\
& $0,142 \pm 0,006$ & $0,119 \pm 0,008$ & $0,104 \pm 0,005$ & ab & $0,134 \pm 0,008$
\end{tabular}

Não houve diferença significante $(p>0,05)$ entre os grupos. 


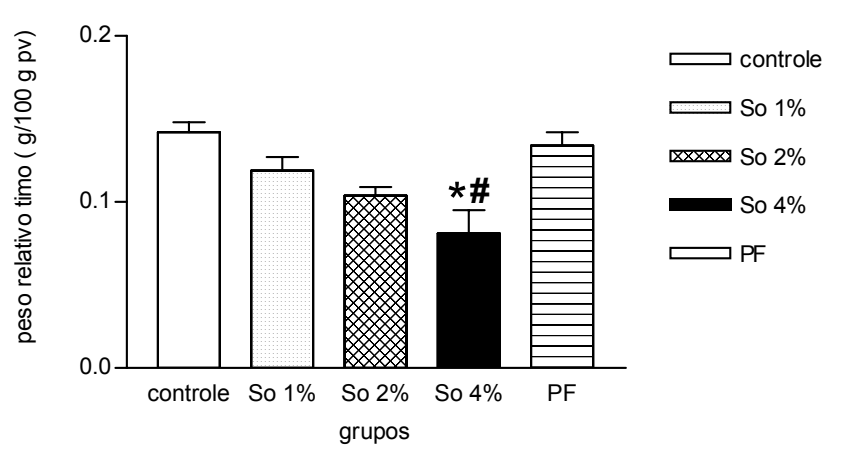

*difere significantemente $(p<0,05)$ em relação ao controle (ANOVA, seguida de Dunnett).

${ }^{\#}$ difere significantemente $(p<0,05)$ do grupo PF (Teste "t" Student).

Figura 8 - Peso relativo timo (g/ 100g pv), de ratos tratados durante 14 dias com diferentes concentrações (0\%, 1\%, 2\% e 4\%) de sementes de $S$. occidentalis, na ração e seu grupo peer-feeding. Foram utilizados 10 animais por grupo. São apresentados as médias e os respectivos erros padrões 
Tabela 9 - Celularidade do baço, timo e da medula óssea (x 10\% concentrações $(0 \%, 1 \%, 2 \%$ e $4 \%)$ de sementes de $S$. occidentalis, na ração e seu grupo peer-feeding. Foram utilizados 10 animais por grupo. São apresentados as médias e os respectivos erros padrões

\begin{tabular}{cccccc}
\hline Órgão & \multicolumn{5}{c}{ Senna occidentalis (\%) } \\
\cline { 2 - 6 } & $\mathbf{0}$ & $\mathbf{1}$ & $\mathbf{2}$ & $\mathbf{4}$ & $\mathbf{P F}$ \\
\hline baço & $2,02 \pm 0,92$ & $1,50 \pm 1,00$ & $1,36 \pm 0,80$ & $1,72 \pm 0,45$ & $2,37 \pm 1,30$ \\
timo & $1,78 \pm 0,90$ & $1,40 \pm 1,36$ & $1,51 \pm 1,37$ & $1,52 \pm 1,07$ & $1,48 \pm 1,62$ \\
medula óssea & $191,4 \pm 14,2$ & $237,7 \pm 8,00^{a}$ & $233,6 \pm 3,40^{a}$ & $206,4 \pm 8,80$ & $187,6 \pm 11,0$ \\
\hline
\end{tabular}

\footnotetext{
a difere significantemente $(p<0,05)$ em relação ao controle (ANOVA, seguida de Dunnett).
}

${ }^{b}$ difere significantemente $(p<0,05)$ em relação ao PF (Teste "t" Student). 


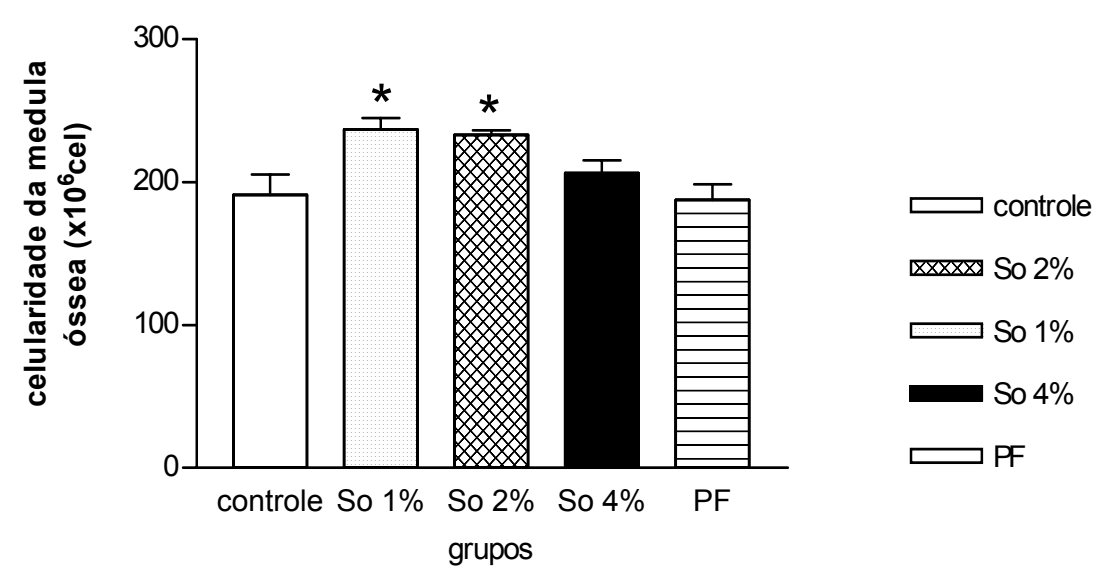

*difere significantemente $(p<0,05)$ em relação ao controle (ANOVA, seguida de Dunnett).

\# difere significantemente $(p<0,05)$ do grupo PF (Teste "t" Student).

Figura 9 - Celularidade da medula óssea (x 10\% cel), de ratos tratados durante 14 dias com diferentes concentrações $(0 \%$, $1 \%$, $2 \%$ e $4 \%$ ) de sementes de S. occidentalis, na ração e seu grupo peer-feeding. Foram utilizados 10 animais por grupo. São apresentados as médias e os respectivos erros padrões 
Tabela 10 - Análise morfométrica da região cortical e medular do baço e timo, de ratos tratados durante 14 dias com diferentes concentrações $(0 \%, 1 \%, 2 \%$ e $4 \%)$ de sementes de $S$. occidentalis, na ração e seu grupo peerfeeding. Foram utilizados 5 animais por grupo. São apresentados as médias e os respectivos erros padrões

\begin{tabular}{|c|c|c|c|c|c|}
\hline \multirow{2}{*}{ Histomorfometria } & \multicolumn{5}{|c|}{ Senna occidentalis (\%) } \\
\hline & 0 & 1 & 2 & 4 & PF \\
\hline $\begin{array}{l}\text { Região cortical do baço } \\
\left(\mathrm{mm}^{2}\right)\end{array}$ & $224,4 \pm 18,0$ & $181,4 \pm 18,0$ & $117,8 \pm 5,0^{a}$ & $118,4 \pm 5,0^{a b}$ & $186,1 \pm 10,0$ \\
\hline Região medular baço $\left(\mathrm{mm}^{2}\right)$ & $199,7 \pm 11,4$ & $195,8 \pm 10,8$ & $171,9 \pm 11,7$ & $170,5 \pm 11,0$ & $171,2 \pm 11,0$ \\
\hline Região cortical do timo $\left(\mathrm{mm}^{2}\right)$ & $570,1 \pm 45,9$ & $472,9 \pm 34,2$ & $477,0 \pm 37,5$ & $237,7 \pm 28,6^{a b}$ & $536,6 \pm 62,2$ \\
\hline Região medular timo $\left(\mathrm{mm}^{2}\right)$ & $274,6 \pm 21,9$ & $240,6 \pm 19,5$ & $252,0 \pm 16,5$ & $122,5 \pm 31,6^{a b}$ & $\begin{array}{l}234,3 \pm \\
17,2\end{array}$ \\
\hline
\end{tabular}

a difere significantemente $(p<0,05)$ em relação ao controle (teste de Kruskal-Wallis, seguido por Dunn).

${ }^{b}$ difere significantemente $(p<0,05)$ em relação ao PF (Teste "t" Student). 

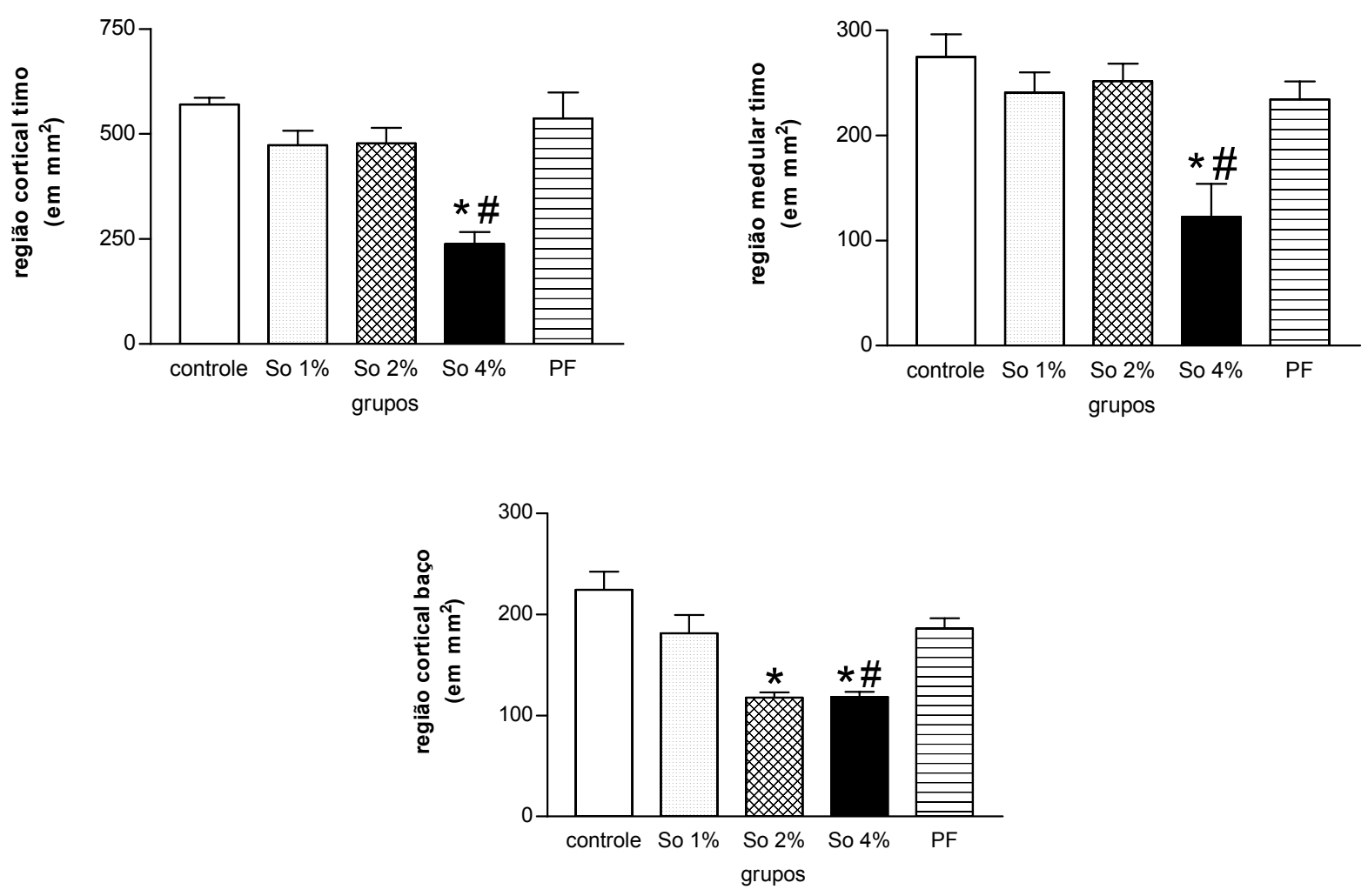

* difere significantemente $(p<0,05)$ em relação ao controle (ANOVA, seguida de Dunnett).

\# difere significantemente $(p<0,05)$ do grupo PF (Teste "t" Student).

Figura 10 - Análise morfométrica da região cortical e medular do baço e timo, de ratos tratados durante 14 dias com diferentes concentrações $(0 \%, 1 \%, 2 \%$ e $4 \%)$ de sementes de S. occidentalis, na ração e seu grupo peer-feeding. Foram utilizados 5 animais por grupo. São apresentados as médias e os respectivos erros padrões 


\subsection{EXPERIMENTO 2: AVALIAÇÃO DOS POSSÍVEIS EFEITOS DA} ADMINISTRAÇÃO PROLONGADA DE SEMENTES DE Senna occidentalis SOBRE A ATIVIDADE DE MACRÓFAGOS PERITONEAIS E A PRODUÇÃO DE ÁGUA OXIGENADA E ÓXIDO NÍTRICO EM RATOS

A tabela 11 mostra e a figura 11 ilustra o consumo médio e total de água pelos ratos tratados com diferentes concentrações de $S$. occidentalis na ração. Assim, a análise estatística realizada revelou haver diferença significante entre os grupos nos $2^{\circ}, 6^{\circ}$ e $10^{\circ}$ dias do experimento $\left(F_{2}=5,582 ; F_{6}=2,955\right.$ e $F_{10}=7,206$; $d f=4 / 45$, respectivamente, $p<0,05)$, bem como no período total $(F=66,276$ e $d f=4 / 45)$. A aplicação do teste de Dunnett apontou diminuição significante $(p<0,05)$ no consumo de água daqueles animais pertencentes ao grupo So $2 \%$ apenas no $10^{\circ}$ dia de experimento quando comparados aos animais do grupo controle. Este mesmo teste apontou diminuição significante $(p<0,05)$ deste parâmetro nos ratos pertencentes ao grupo So $4 \%$ nos $2^{\circ}, 6^{\circ}$ e $10^{\circ}$ dias do experimento, quando comparado com os resultados obtidos pelos animais pertencentes ao grupo controle. Na avaliação no consumo total de água, o teste de Dunnett revelou haver diminuição significante $(p<0,05)$ neste parâmetro em todos os animais pertencentes aos grupos experimentais, quando comparado aos animais do grupo controle.

Em relação ao consumo de ração destes animais (Tabela 12 e Figura 12), as análises de variância realizadas revelaram haver diferença significante entre os grupos nos $2^{\circ}, 4^{\circ}, 6^{\circ}, 8^{\circ}, 10^{\circ}, 12^{\circ}$ e $14^{\circ}$ dias do experimento $\left(F_{2}=2,994 ; F_{4}=9,856\right.$; 
$F_{6}=14,211 ; \quad F_{8}=124,05 ; \quad F_{10}=177,77 ; \quad F_{12}=19,865 ; \quad F_{14}=288,62 ; \quad d f=3 / 36$, respectivamente, $p<0,05)$, bem como no período total $(F=1460,5$ e $d f=3 / 36)$, quando comparado aos resultados obtidos dos animais pertencentes ao grupo controle, sendo que o consumo dos animais do grupo peer-feeding (PF) foi idêntico àquele dos ratos submetidos à administração de ração contendo $4 \%$ de sementes de S. occidentalis (dados não apresentados). A aplicação do teste de Dunnett apontou diminuição significante $(p<0,05)$ no consumo de ração daqueles ratos pertencentes ao grupo So2\% apenas no $12^{\circ}$ dia de experimento, em relação aos animais do grupo controle. Este mesmo teste revelou haver redução significante $(p<0,05)$ neste parâmetro em todos os dias de tratamento nos animais pertencentes ao grupo So4\%, quando comparado aos ratos do grupo controle. Na avaliação no consumo total de ração, o teste de Dunnett revelou haver diminuição significante $(p<0,05)$ neste parâmetro nos animais tratados com So2\% e So4\%, quando comparados àqueles do grupo controle.

A tabela 13 mostra e a figura 13 ilustra o peso médio destes animais, as análises de variância realizadas revelaram haver diferença significante entre os grupos nos $2^{\circ}, 4^{\circ}, 6^{\circ}, 8^{\circ}, 10^{\circ}, 12^{\circ}$ e $14^{\circ}$ dias do experimento $\left(F_{2}=5,309 ; F_{4}=5,458\right.$; $F_{6}=6,556 ; F_{8}=11,462 ; F_{10}=16,538 ; F_{12}=23,198 ; F_{14}=32,191 ; d f=4 / 45$, respectivamente $p<0,05)$. A aplicação do teste de Dunnett demonstrou haver diminuição significante $(p<0,05)$ no peso médio dos animais tratados com So $2 \%$ em relação àqueles animais pertencentes ao grupo controle nos $4^{\circ}, 6^{\circ}, 8^{\circ}, 10^{\circ}, 12^{\circ}$ e $14^{\circ}$ dias de tratamento. Além disso, este mesmo teste apontou redução significante $(p<0,05)$ no peso médio dos animais tratados com So $4 \%$ em relação àqueles animais pertencentes ao grupo controle nos $2^{\circ}, 4^{\circ}, 6^{\circ}, 8^{\circ}, 10^{\circ}, 12^{\circ}$ e $14^{\circ}$ dias de tratamento. 
O ganho de peso médio semanal e total destes ratos é apresentado na tabela 14 e ilustrado pela figura 14. Assim, a análise de variância realizada revelou haver diferença significante $(p<0,05)$ entre os grupos na $1^{\mathrm{a}}$ e $2^{\mathrm{a}}$ semanas $\left(F_{1}=24,987\right.$; $\left.F_{2}=52,398 ; d f=4 / 45\right)$, bem como no período total $(F=158,91$ e $d f=4 / 45)$ do experimento. A aplicação do teste de Dunnett mostrou diminuição significante $(p<0,05)$ no ganho de peso semanal e no ganho de peso total dos animais tratados com So2\% e So4\%, em relação aos animais do grupo controle. Este mesmo teste apontou redução significante $(p<0,05)$ destes parâmetros nos animais pertencentes ao grupo PF, quando comparado aos animais do grupo controle.

Em relação ás observações clínicas, os seguintes sinais e sintomas, foram observados: letargia, abatimento, prostração, pêlos arrepiados e fezes amolecidas, a partir da segunda semana de tratamento em todos os animais pertencentes ao grupo So $4 \%$.

Quanto à atividade de macrófagos peritoneais (Tabela 15), em ratos tratados durante 14 dias com sementes de $S$. occidentalis na ração, a análise estatística mostrou não haver diferença significante $(p>0,05)$ deste parâmetro entre os animais tratados com a planta e o grupo controle, em relação ao espraiamento de macrófagos, bem como em relação ao número de macrófagos peritoneais que fagocitaram partículas de zymozan.

Em relação à produção das espécies reativas de oxigênio, o teste estatístico revelou haver diferença significante $(p<0,05)$ na produção de água oxigenada $\left(\mathrm{H}_{2} \mathrm{O}_{2}\right)$ sem o estímulo do PMA $(F=3,709$ e df=4/45) entre os grupos (Tabela 16 e Figura 15). A aplicação do teste de Dunnett revelou diminuição significante $(p<0,05)$ deste parâmetro apenas nos animais tratados com So4\% em relação aos animais pertencentes ao grupo controle. O teste estatístico também mostrou haver diferença 
significante $(p<0,05)$ entre os grupos, na produção de $\mathrm{H}_{2} \mathrm{O}_{2}$ quando induzida por PMA $(F=5,168$ e df=4/45). A aplicação do teste de Dunnett mostrou haver redução significante $(p<0,05)$ na produção de $\mathrm{H}_{2} \mathrm{O}_{2}$ dos animais do grupo So4\%, quando comparado aos resultados obtidos dos animais pertencentes ao grupo controle.

Quanto à produção de óxido nítrico (Tabela 17 e Figura 16), a análise de variância mostrou haver diferença significante entre os grupos $(p<0,05)$ na avaliação deste parâmetro $(F=3,800$ e $d f=4 / 45)$, quando comparado aos animais do grupo controle. A aplicação do teste de Dunnett revelou diminuição significante $(p<0,05)$ na produção de óxido nítrico nos animais do grupo So4\%, quando comparado aos resultados obtidos dos animais pertencentes ao grupo controle. 
Tabela 11 - Consumo médio e total de água (em $\mathrm{ml}$ ) pelos ratos tratados durante 14 dias com diferentes concentrações $(0 \%, 1 \%, 2 \%$ e $4 \%)$ de sementes de $S$. occidentalis, na ração e seu grupo peer-feeding. Foram utilizados 10 animais por grupo. São apresentados as médias e os respectivos erros padrões

\begin{tabular}{cccccc}
\hline $\begin{array}{c}\text { Dias de } \\
\text { tratamento }\end{array}$ & $\mathbf{0}$ & $\mathbf{1}$ & $\mathbf{2}$ & $\mathbf{4}$ & PF \\
\cline { 2 - 6 } $\mathbf{2}^{\circ}$ & $74,0 \pm 1,4$ & $73,6 \pm 2,3$ & $71,1 \pm 3,7$ & $60,1 \pm 4,0^{\text {ab }}$ & $71,7 \pm 3,9$ \\
$\mathbf{4}^{\circ}$ & $71,2 \pm 5,8$ & $83,7 \pm 8,8$ & $71,0 \pm 4,3$ & $74,8 \pm 2,1$ & $74,0 \pm 3,1$ \\
$\mathbf{6}^{\circ}$ & $72,0 \pm 4,6$ & $64,4 \pm 3,7$ & $70,0 \pm 2,1$ & $59,0 \pm 2,3^{\text {ab }}$ & $72,2 \pm 3,2$ \\
$\mathbf{8}^{\circ}$ & $68,7 \pm 2,9$ & $69,1 \pm 3,1$ & $68,0 \pm 3,2$ & $66,0 \pm 4,9$ & $75,5 \pm 5,0$ \\
$\mathbf{1 0}^{\circ}$ & $80,0 \pm 4,2$ & $70,0 \pm 3,7$ & $66,0 \pm 2,6^{\mathrm{a}}$ & $63,0 \pm 3,6^{\mathrm{ab}}$ & $77,7 \pm 4,6$ \\
$\mathbf{1 2}^{\circ}$ & $74,4 \pm 1,7$ & $70,0 \pm 2,3$ & $81,1 \pm 6,1$ & $67,7 \pm 4,0$ & $60,0 \pm 1,6$ \\
$\mathbf{1 4}^{\circ}$ & $75,0 \pm 1,6$ & $70,0 \pm 2,8$ & $77,5 \pm 4,1$ & $73,5 \pm 2,5$ & $72,0 \pm 3,8$ \\
$\mathbf{T o t a l}^{\circ}$ & $515,1 \pm 3,1$ & $500,7 \pm 3,8^{\mathrm{a}}$ & $504,1 \pm 3,7^{\mathrm{a}}$ & $464,1 \pm 3,3^{\mathrm{ab}}$ & $503,1 \pm 3,6$
\end{tabular}

a difere significantemente $(p<0,05)$ em relação ao controle (ANOVA, seguida de Dunnett).

b difere significantemente $(p<0,05)$ do grupo PF (Teste "t" Student). 

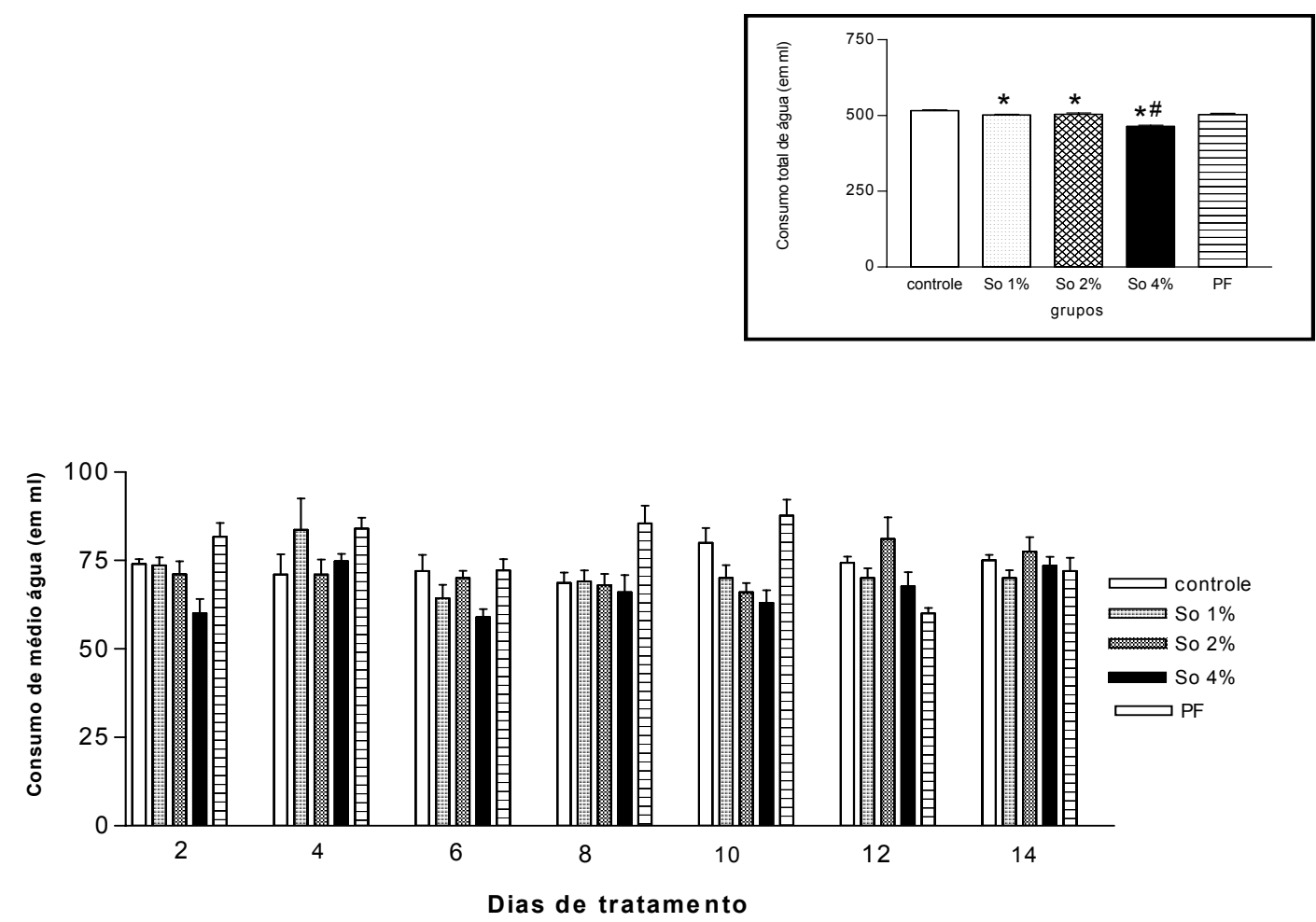

* difere significantemente $(p<0,05)$ em relação ao controle (ANOVA, seguida de Dunnett).

\# difere significantemente $(p<0,05)$ do grupo PF (Teste "t" Student).

OBS: as diferenças estatisticamente significantes no consumo médio estão identificadas na Tabela 11.

Figura 11 - Consumo médio e total de água (em $\mathrm{ml})$ pelos ratos tratados durante 14 dias com diferentes concentrações $(0 \%$, $1 \%, 2 \%$ e $4 \%$ ) de sementes de S. occidentalis, na ração e seu grupo peer-feeding. Foram utilizados 10 animais por grupo. São apresentados as médias e os respectivos erros padrões 
Tabela 12 - Consumo médio e total de ração (em g) pelos ratos tratados durante 14 dias com diferentes concentrações $(0 \%, 1 \%, 2 \%$ e $4 \%)$ de sementes de S. occidentalis, na ração. Foram utilizados 10 animais por grupo. São

\begin{tabular}{|c|c|c|c|c|}
\hline \multirow{2}{*}{$\begin{array}{c}\text { Dias de } \\
\text { tratamento }\end{array}$} & \multicolumn{4}{|c|}{ Senna occidentalis (\%) } \\
\hline & 0 & 1 & 2 & 4 \\
\hline $2^{\circ}$ & $40,6 \pm 2,3$ & $44,6 \pm 1,8$ & $41,7 \pm 2,0$ & $48,0 \pm 1,1^{a}$ \\
\hline $4^{\circ}$ & $47,0 \pm 1,8$ & $48,6 \pm 0,6$ & $47,6 \pm 1,1$ & $38,5 \pm 1,8^{a}$ \\
\hline $6^{\circ}$ & $50,0 \pm 0,7$ & $50,0 \pm 0,6$ & $49,3 \pm 0,5$ & $35,3 \pm 3,7^{a}$ \\
\hline $8^{\circ}$ & $50,9 \pm 0,7$ & $50,3 \pm 0,8$ & $49,3 \pm 0,3$ & $15,3 \pm 3,0^{a}$ \\
\hline $10^{\circ}$ & $48,9 \pm 0,7$ & $47,0 \pm 0,6$ & $41,0 \pm 0,7$ & $17,0 \pm 2,1^{a}$ \\
\hline $12^{\circ}$ & $49,2 \pm 0,4$ & $48,6 \pm 0,6$ & $44,7 \pm 1,6^{a}$ & $37,0 \pm 2,0^{a}$ \\
\hline $14^{\circ}$ & $49,7 \pm 0,3$ & $48,8 \pm 0,5$ & $48,1 \pm 0,7$ & $20,5 \pm 1,3^{a}$ \\
\hline Total & $336,5 \pm 1,7$ & $337,9 \pm 0,6$ & $321,7 \pm 1,0^{a}$ & $211,6 \pm 2,4^{a}$ \\
\hline
\end{tabular}

\footnotetext{
${ }^{a}$ difere significantemente $(p<0,05)$ em relação ao controle (ANOVA, seguida de Dunnett).
} 


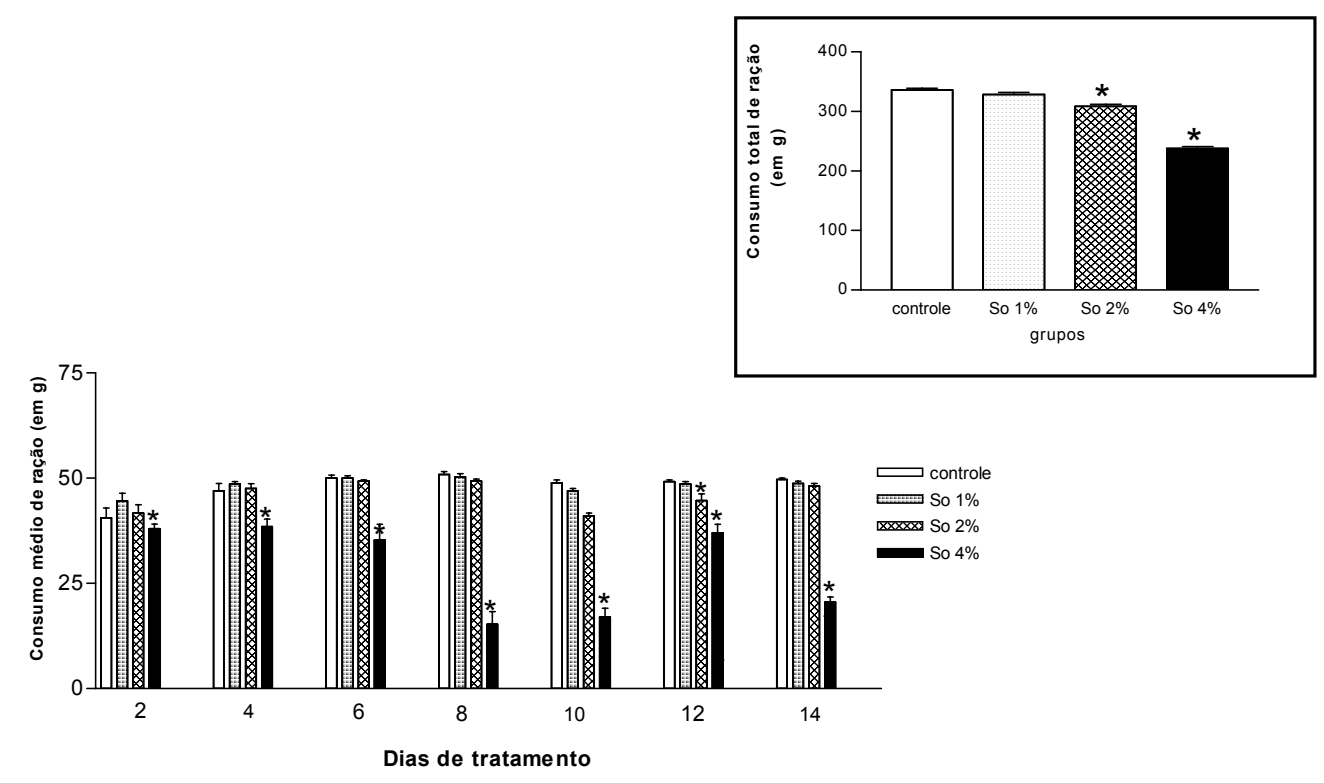

* difere significantemente $(p<0,05)$ em relação ao controle (ANOVA, seguida de Dunnett).

Figura 12 - Consumo médio e total de ração (em g) pelos ratos tratados durante 14 dias com diferentes concentrações $(0 \%, 1 \%, 2 \%$ e $4 \%)$ de sementes de S. occidentalis, na ração. Foram utilizados 10 animais por grupo. São apresentados as médias e os respectivos erros padrões 
Tabela 13 - Peso médio (em g), de ratos tratados durante 14 dias com diferentes concentrações $(0 \%, 1 \%, 2 \%$ e $4 \%$ ) de sementes de $S$. occidentalis, na ração e seu grupo peer-feeding. Foram utilizados 10 animais por grupo. São apresentados as médias e os respectivos erros padrões

\begin{tabular}{cccccc}
\hline $\begin{array}{c}\text { Dias de } \\
\text { tratamento }\end{array}$ & \multicolumn{5}{c}{ Senna occidentalis (\%) } \\
\cline { 2 - 6 } & $\mathbf{0}$ & $\mathbf{1}$ & $\mathbf{2}$ & $\mathbf{4}$ & $\mathbf{P F}$ \\
$\mathbf{2}^{\circ}$ & $166,9 \pm 3,9$ & $162,4 \pm 3,6$ & $152,6 \pm 4,4$ & $143,5 \pm 6,0^{\mathrm{ab}}$ & $168,3 \pm 4,6$ \\
$\mathbf{4}^{\circ}$ & $171,2 \pm 3,6$ & $166,6 \pm 3,6$ & $155,8 \pm 4,0^{\mathrm{a}}$ & $147,9 \pm 5,6^{\mathrm{ab}}$ & $169,1 \pm 4,1$ \\
$\mathbf{6}^{\circ}$ & $177,0 \pm 3,5$ & $168,5 \pm 2,9$ & $161,0 \pm 4,3^{\mathrm{a}}$ & $151,7 \pm 5,4^{\mathrm{ab}}$ & $173,0 \pm 3,0$ \\
$\mathbf{8}^{\circ}$ & $181,0 \pm 3,2$ & $175,0 \pm 3,1$ & $164,0 \pm 4,5^{\mathrm{a}}$ & $147,8 \pm 4,8^{\mathrm{ab}}$ & $177,0 \pm 3,9$ \\
$\mathbf{1 0}^{\circ}$ & $184,9 \pm 3,0$ & $180,9 \pm 2,9$ & $168,0 \pm 4,7^{\mathrm{a}}$ & $144,0 \pm 5,3^{\mathrm{ab}}$ & $180,0 \pm 3,8$ \\
$\mathbf{1 2}^{\circ}$ & $188,0 \pm 3,3$ & $187,2 \pm 2,8$ & $171,3 \pm 4,4^{\mathrm{a}}$ & $139,9 \pm 5,0^{\mathrm{ab}}$ & $182,4 \pm 4,0$ \\
$\mathbf{1 4}^{\circ}$ & $194,5 \pm 2,6$ & $191,5 \pm 3,8$ & $172,0 \pm 4,9^{\mathrm{a}}$ & $136,5 \pm 4,7^{\mathrm{ab}}$ & $186,0 \pm 4,0$
\end{tabular}

\footnotetext{
a difere significantemente $(p<0,05)$ em relação ao controle (ANOVA, seguida de Dunnett).

b difere significantemente $(p<0,05)$ do grupo PF (Teste " $t$ " Student.).
} 


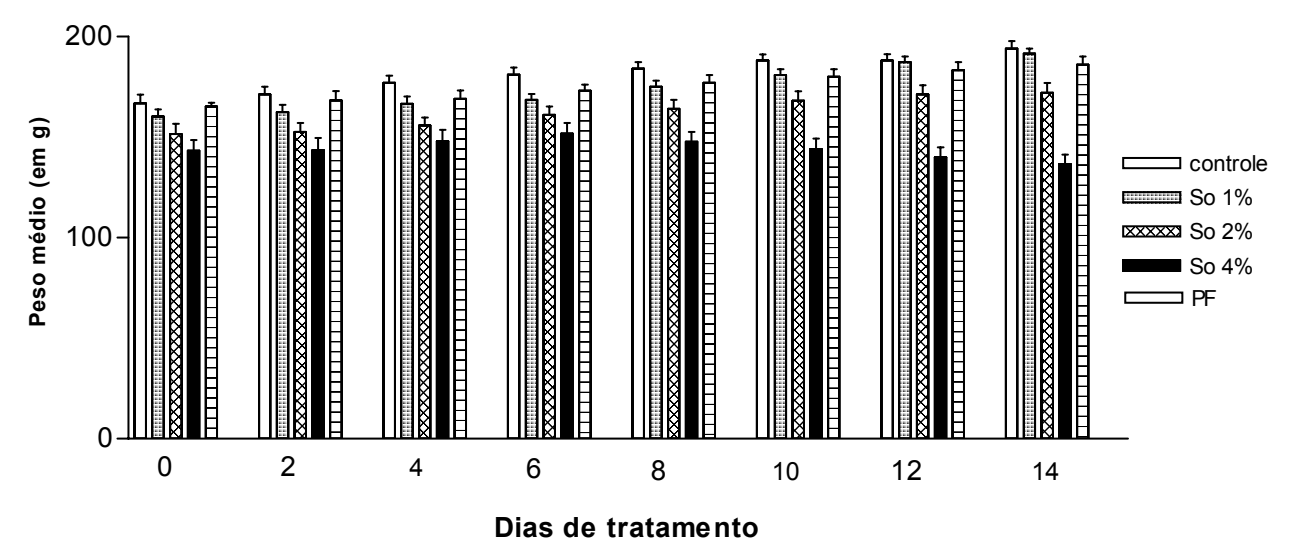

OBS: as diferenças estatisticamente significantes no consumo médio estão identificadas na Tabela 13.

Figura 13 - Peso médio (em g), de ratos tratados durante 14 dias com diferentes concentrações $(0 \%, 1 \%, 2 \%$ e $4 \%$ ) de sementes de $S$. occidentalis, na ração e seu grupo peer-feeding. Foram utilizados 10 animais por grupo. São apresentados as médias e os respectivos erros padrões 
Tabela 14 - Peso semanal e total (em g), de ratos tratados durante 14 dias com diferentes concentrações $(0 \%, 1 \%, 2 \%$ e $4 \%$ ) de sementes de $S$. occidentalis, na ração e seu grupo peer-feeding. Foram utilizados 10 animais por grupo. São apresentados as médias e os respectivos erros padrões

\begin{tabular}{cccccc}
\hline $\begin{array}{c}\text { Semanas de } \\
\text { tratamento }\end{array}$ & $\mathbf{0}$ & $\mathbf{1}$ & $\mathbf{2}$ & $\mathbf{4}$ & Senna occidentalis (\%) \\
\hline S1 & $14,1 \pm 1,4$ & $12,6 \pm 1,5$ & $11,4 \pm 1,7$ & $5,7 \pm 1,8^{\mathrm{ab}}$ & $8,7 \pm 1,6$ \\
S2 & $16,5 \pm 1,3$ & $13,0 \pm 1,4$ & $8,0 \pm 1,6^{\mathrm{a}}$ & $11,3 \pm 1,7^{\mathrm{ab}}$ & $9,0 \pm 1,3^{\mathrm{a}}$ \\
Total & $30,6 \pm 1,3$ & $25,6 \pm 1,4$ & $19,4 \pm 1,6^{\mathrm{a}}$ & $17,0 \pm 1,7^{\mathrm{ab}}$ & $17,7 \pm 1,4^{\mathrm{a}}$ \\
\end{tabular}

a difere significantemente $(p<0,05)$ em relação ao controle, (ANOVA, seguida de Dunnett).

${ }^{b}$ difere significantemente $(p<0,05)$ do grupo PF (Teste "t" Student.). 

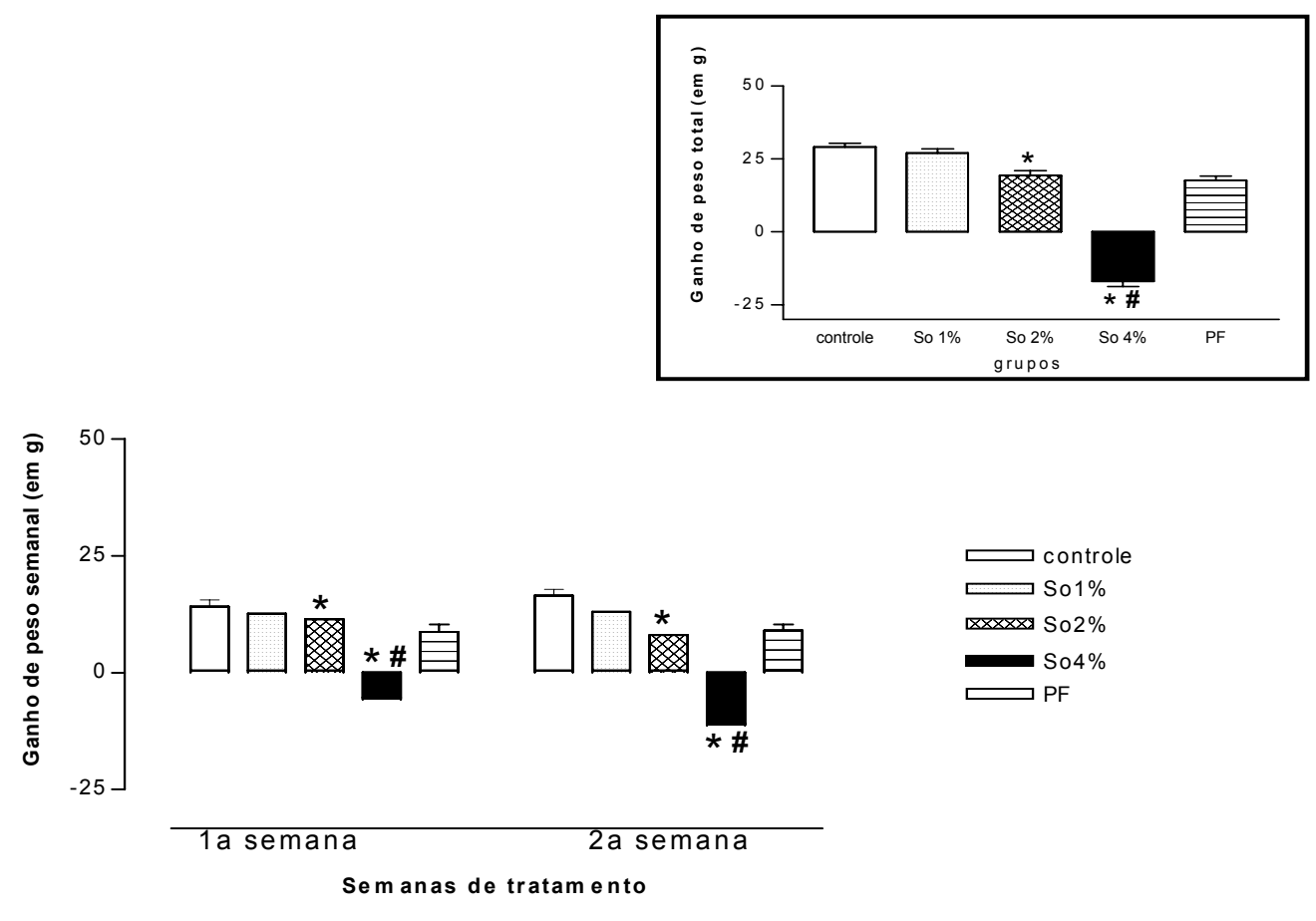

* difere significantemente $(p<0,05)$ em relação ao controle (ANOVA, seguida de Dunnett).

\# difere significantemente $(p<0,05)$ em relação ao PF (Teste "t" Student).

Figura 14 - Peso semanal e total (em g), de ratos tratados durante 14 dias com diferentes concentrações $(0 \%, 1 \%, 2 \%$ e $4 \%$ ) de sementes de $S$. occidentalis, na ração e seu grupo peer-feeding. Foram utilizados 10 animais por grupo. São apresentados as médias e os respectivos erros padrões 
Tabela 15 - Avaliação da atividade de espraiamento e fagocitose de macrófagos peritoneais (\%), de ratos tratados durante 14 dias com diferentes concentrações $(0,1 \%, 2 \%$ e $4 \%)$ de sementes de $S$. occidentalis na ração e seu grupo peer-feeding. Foram utilizados 10 animais por grupo. São apresentados as médias e os respectivos erros padrões

Número de macrófagos em atividade

\begin{tabular}{ccc} 
Grupos & & \\
\cline { 2 - 3 } & Espraiamento & Fagocitose \\
\hline controle & $75,0 \pm 4,2$ & $87,2 \pm 2,5$ \\
So1\% & $79,0 \pm 5,6$ & $73,1 \pm 4,7$ \\
So2\% & $80,7 \pm 5,3$ & $81,1 \pm 5,7$ \\
So4\% & $84,5 \pm 3,2$ & $82,6 \pm 4,8$ \\
PF & $87,1 \pm 5,3$ & $92,2 \pm 2,5$ \\
\hline
\end{tabular}

Não houve diferença significante $(p>0,05)$ entre os grupos. 
Tabela 16 - Liberação por macrófagos peritoneais de água oxigenada $\left(\mathrm{H}_{2} \mathrm{O}_{2}\right)$ espontânea ou induzida por PMA, de ratos tratados durante 14 dias com diferentes concentrações $(0 \%, 1 \%, 2 \%$ e $4 \%)$ de sementes de S. occidentalis, na ração e seu grupo peer-feeding. Foram utilizados 8 animais por grupo.São apresentados as médias e os respectivos erros padrões

\begin{tabular}{ccc}
\hline \multirow{2}{*}{ Grupos } & \multicolumn{2}{c}{ Produção de $\mathrm{H}_{2} \mathrm{O}_{2}$} \\
\cline { 2 - 3 } & espontânea & PMA \\
\hline controle & $2,5 \pm 0,10$ & $4,3 \pm 0,25$ \\
So1\% & $2,7 \pm 0,13$ & $3,9 \pm 0,17$ \\
So2\% & $2,6 \pm 0,17$ & $3,9 \pm 0,17$ \\
So4\% & $2,3 \pm 0,04^{\text {ab }}$ & $3,2 \pm 0,19^{\mathrm{a}}$ \\
PF & $2,9 \pm 0,10$ & $3,1 \pm 0,10$
\end{tabular}

a difere significantemente $(p<0,05)$ em relação ao controle (ANOVA, seguida de Dunnett).

${ }^{b}$ difere significantemente $(p<0,05)$ do grupo PF (Teste "t" Student.). 


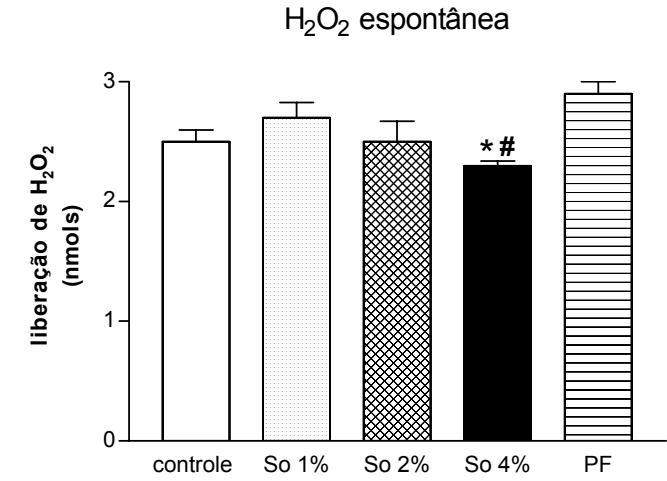

14 dias de tratamento
$\mathrm{H}_{2} \mathrm{O}_{2}$ com PMA

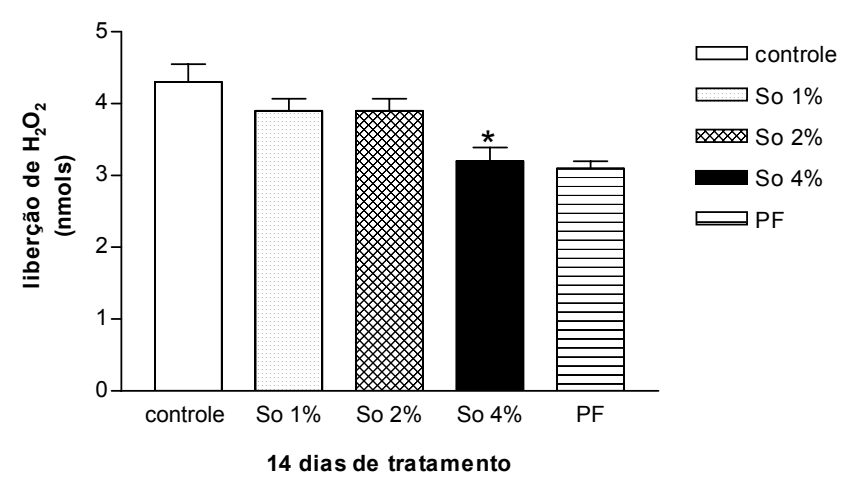

* difere significantemente $(p<0,05)$ em relação ao controle (ANOVA, seguida de Dunnett).

\# difere significantemente $(p<0,05)$ em relação ao PF (Teste " $t$ " Student).

Figura 15 - Liberação por macrófagos peritoneais de $\mathrm{H}_{2} \mathrm{O}_{2}$ espontânea ou induzida por PMA, de ratos tratados durante 14 dias com diferentes concentrações $(0 \%, 1 \%, 2 \%$ e $4 \%)$ de sementes de $S$. occidentalis, na ração e seu grupo peer-feeding. São apresentados as médias e os respectivos erros padrões 
Tabela 17 - Determinação indireta de óxido nítrico via dosagem de seu metabólito (nitrito), por macrófagos peritoneais de ratos tratados durante 14 dias com diferentes concentrações $(0 \%, 1 \%, 2 \%$ e $4 \%)$ de sementes de occidentalis, na ração e seu grupo peer-feeding. São apresentados as médias e os respectivos erros padrões

\begin{tabular}{ccc}
\hline \multirow{2}{*}{ Grupos } & \multicolumn{3}{c}{ Produção de óxido nítrico $^{-}$} \\
\cline { 2 - 3 } Controle & $\mathbf{n}^{*}$ & $\mathbf{n m o l s}^{*} \mathbf{2 \times 1 0 ^ { 6 }}$ células \\
So1\% & 8 & $3,8 \pm 0,17$ \\
So2\% & 8 & $3,8 \pm 0,26$ \\
So4\% & 8 & $4,3 \pm 0,11$ \\
PF & 8 & $3,5 \pm 0,08^{\mathrm{a}}$ \\
\hline
\end{tabular}

${ }^{*}$ Foram utilizados 8 animais por grupo.

${ }^{a}$ difere significantemente $(p<0,05)$ em relação ao controle (ANOVA, seguida de Dunnett). 


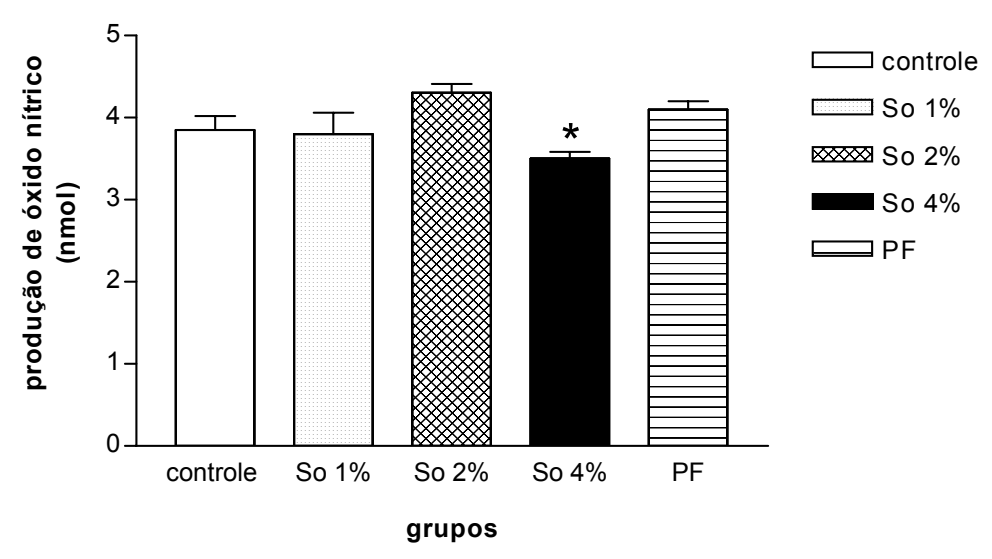

* difere significantemente $(p<0,05)$ em relação ao controle (ANOVA, seguida de Dunnett).

Figura 16 - Determinação indireta de óxido nítrico via dosagem de seu metabólito (nitrito), por macrófagos peritoneais de ratos tratados durante 14 dias com diferentes concentrações $(0 \%, 1 \%, 2 \%$ e $4 \%)$ de sementes de $S$. occidentalis, na ração e seu grupo peer-feeding. São apresentados as médias e os respectivos erros padrões 


\subsection{EXPERIMENTO 3: AVALIAÇÃO DOS EFEITOS DA ADMINISTRAÇÃO PROLONGADA DE SEMENTES DE Senna occidentalis SOBRE A REPOSTA INFLAMATÓRIA AGUDA}

A tabela 18 mostra e a figura 17 ilustra o consumo médio e total de água pelos ratos durante o experimento. Assim, a análise estatística realizada revelou haver diferença significante entre os grupos nos $10^{\circ}, 12^{\circ}$ e $14^{\circ}$ dias do experimento $\left(F_{10}=16,045 ; F_{12}=2,655\right.$ e $F_{14}=1,988 ; d f=4 / 45$, respectivamente, $\left.p<0,05\right)$, bem como no período total $(F=43,148$ e $d f=4 / 45)$. A aplicação do teste de Dunnett apontou diminuição significante $(p<0,05)$ no consumo de água daqueles animais pertencentes ao grupo So4\% em relação àqueles animais do grupo controle nos $10^{\circ}$, $12^{\circ}$ e $14^{\circ}$ dias do experimento. Na avaliação no consumo total de água, o teste de Dunnett revelou haver diminuição significante $(p<0,05)$ neste parâmetro nos animais dos grupos So2\%, So4\% e peer-feeding (PF), quando comparados àqueles do grupo controle.

Em relação ao consumo de ração destes animais (Tabela 19 e Figura 18), as análises de variância realizadas revelaram haver diferença significante entre os grupos nos $4^{\circ}, 6^{\circ}, 8^{\circ}, 10^{\circ}$ e $12^{\circ}$ dias do experimento $\left(F_{4}=8,601 ; F_{6}=2,842 ; F_{8}=9,251\right.$; $F_{10}=3,753 ; F_{12}=7,970 ; d f=3 / 36$, respectivamente, $\left.p<0,05\right)$, bem como no período total $(F=71,599$ e $d f=3 / 36)$, quando comparado aos resultados obtidos dos animais pertencentes ao grupo controle, sendo que o consumo de ração dos animais do grupo PF foi idêntico àquele dos ratos submetidos à administração de ração contendo $4 \%$ de sementes de S. occidentalis (dados não apresentados). A aplicação do teste de Dunnett demonstrou haver diminuição significante $(p<0,05)$ no consumo 
médio de ração dos animais tratados com So4\% em relação àqueles animais pertencentes ao grupo controle, nos $4^{\circ}, 6^{\circ}, 8^{\circ}, 10^{\circ}$ e $12^{\circ}$ dias de tratamento. $\mathrm{Na}$ avaliação no consumo total de ração, o teste de Dunnett revelou haver diminuição significante $(p<0,05)$ deste parâmetro nos animais pertencentes aos grupos So2\% e So4\% em relação ao grupo controle.

A tabela 20 mostra e a figura 19 ilustra o peso médio destes animais, as análises de variância realizadas revelaram haver diferença significante entre os grupos nos $8^{\circ}, 10^{\circ}, 12^{\circ}$ e $14^{\circ}$ dias do experimento $\left(F_{8}=2,991 ; F_{10}=6,135 ; F_{12}=8,764\right.$; $F_{14}=8,439 ; d f=4 / 45$, respectivamente, $\left.p<0,05\right)$. A aplicação do teste de Dunnett demonstrou haver diminuição significante $(p<0,05)$ no peso médio dos animais do grupo experimental So1\% apenas no $12^{\circ}$ dia de tratamento, quando comparado com os animais pertencentes ao grupo controle. Este mesmo teste apontou redução significante $(p<0,05)$ deste parâmetro nos ratos tratados com So2\% no $8^{\circ}, 10^{\circ}, 12^{\circ}$ e $14^{\circ}$ dias de tratamento, em relação ao grupo controle. Quanto aos animais do grupo So4\%, estes apresentaram diminuição significante $(p<0,05)$ no peso médio nos $8^{\circ}$, $10^{\circ}, 12^{\circ}$ e $14^{\circ}$ dias do experimento, quando comparado aos animais do grupo controle.

O ganho de peso semanal e total destes ratos é apresentado na tabela 21 e figura 20. Assim, a análise de variância realizada revelou haver diferença significante entre os grupos na $2^{a}$ semana $\left(F_{2}=3,359\right.$; $\left.d f=4 / 45\right)$, bem como no período total $(F=10,520$ e $d f=4 / 45)$ do experimento. A aplicação do teste de Dunnett mostrou diminuição significante $(p<0,05)$ no ganho de peso semanal dos animais do grupo tratado com So4\%, na $2^{\text {a }}$ semana de tratamento, quando comparados àqueles do grupo controle. A aplicação do teste de Dunnett mostrou diminuição significante 
$(p<0,05)$ no ganho de peso total dos ratos pertencentes aos grupos So2\% e So4\% e PF em relação aos animais pertencentes ao grupo controle.

Em relação ás observações clínicas, os seguintes sinais e sintomas foram observados: letargia, abatimento, prostração, pêlos arrepiados e fezes amolecidas, a partir da segunda semana de tratamento em todos os animais pertencentes ao grupo So4\%.

A tabela 22 apresenta e a figura 21 ilustra o volume do edema inflamatório agudo (em $\mu \mathrm{L}$ ) medido em diferentes momentos (0 - 1 - 2 - 4 - 6 - 8 - 24 horas) após a inoculação de $1 \%$ de carragenina no coxim plantar da pata posterior esquerda de ratos tratados durante 14 dias com diferentes concentrações da planta ou não. As análises de variância realizadas revelaram haver diferença significante entre os grupos nos tempos 1 - 4 e 6 de avaliação $\left(F_{1}=21,502 ; F_{4}=3,109 ; F_{6}=11,393 ; d f=4 / 45\right.$, respectivamente, $p<0,05)$. A aplicação do teste de Dunnett demonstrou haver diminuição significante $(p<0,05)$ na avaliação deste parâmetro na $1^{\text {a }}$ hora de observação, nos animais pertencentes ao grupo So1\%, quando comparado aos animais do grupo controle. Este mesmo teste mostrou haver redução significante $(p<0,05)$ no volume do edema, nos animais pertencentes ao grupo So $2 \%$, nos tempos 1- 4 e 6 de avaliação, em relação aos animais do grupo controle. A análise de variância utilizada revelou ainda, haver diminuição significante $(p<0,05)$ na evolução do volume do edema na $1^{a}, 4^{a}$ e $6^{a}$ horas de avaliação, nos animais pertencentes ao grupo So4\%, quando comparado aos resultados obtidos dos animais do grupo controle. 
Tabela 18 - Consumo médio e total de água (em $\mathrm{ml})$ pelos ratos tratados durante 14 dias com diferentes concentrações $(0 \%$, $1 \%, 2 \%$ e $4 \%$ ) de sementes de $S$. occidentalis, na ração e seu grupo peer-feeding. Foram utilizados 10 animais por grupo. São apresentados as médias e os respectivos erros padrões

\begin{tabular}{|c|c|c|c|c|c|}
\hline \multirow{2}{*}{$\begin{array}{l}\text { Dias de } \\
\text { tratamento }\end{array}$} & \multicolumn{5}{|c|}{ Senna occidentalis (\%) } \\
\hline & 0 & 1 & 2 & 4 & PF \\
\hline $2^{\circ}$ & $78,4 \pm 4,4$ & $75,6 \pm 5,2$ & $75,3 \pm 5,8$ & $69,2 \pm 7,4$ & $76,2 \pm 8,7$ \\
\hline $4^{\circ}$ & $70,8 \pm 2,8$ & $73,7 \pm 2,5$ & $74,7 \pm 4,0$ & $73,1 \pm 8,0$ & $74,4 \pm 0,9$ \\
\hline $6^{\circ}$ & $74,7 \pm 5,7$ & $74,1 \pm 2,4$ & $72,2 \pm 6,1$ & $59,0 \pm 5,1$ & $63,3 \pm 1,2$ \\
\hline $8^{\circ}$ & $70,7 \pm 3,7$ & $68,1 \pm 3,7$ & $65,0 \pm 4,0$ & $60,0 \pm 5,0$ & $71,0 \pm 3,3$ \\
\hline $10^{\circ}$ & $79,3 \pm 3,0$ & $75,8 \pm 2,9$ & $71,7 \pm 2,0$ & $55,8 \pm 2,3^{a b}$ & $76,1 \pm 1,2$ \\
\hline $12^{\circ}$ & $71,1 \pm 5,8$ & $69,9 \pm 5,7$ & $66,7 \pm 3,9$ & $53,6 \pm 5,1^{a b}$ & $66,5 \pm 1,3$ \\
\hline $14^{\circ}$ & $51,9 \pm 2,9$ & $49,0 \pm 3,2$ & $48,7 \pm 2,6$ & $43,2 \pm 1,2^{a b}$ & $50,0 \pm 1,8$ \\
\hline Total & $496,9 \pm 4,0$ & $86,1 \pm 3,6$ & $474,3 \pm 4,7^{\mathrm{a}}$ & $413,9 \pm 3,3^{a b}$ & $447,5 \pm 3,5^{a}$ \\
\hline
\end{tabular}

a difere significantemente $(p<0,05)$ em relação ao controle (ANOVA, seguida de Dunnett).

${ }^{b}$ difere significantemente $(p<0,05)$ do grupo PF (Teste " $t$ " Student). 

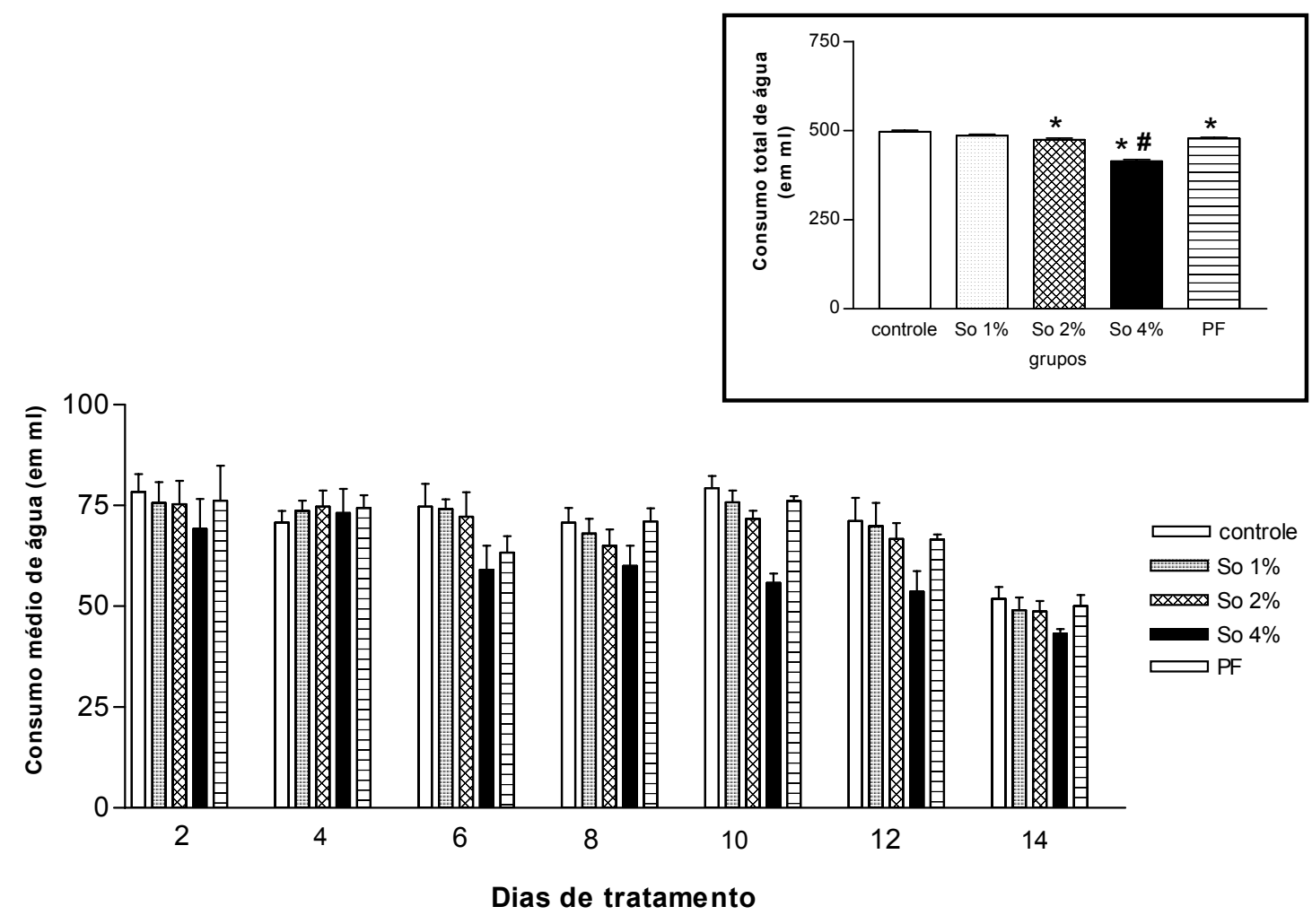

* difere significantemente $(p<0,05)$ em relação ao controle (ANOVA, seguida de Dunnett).

\# difere significantemente $(p<0,05)$ do grupo PF (Teste "t" Student).

OBS: as diferenças estatisticamente significantes no consumo médio estão identificadas na Tabela 18.

Figura 17 - Consumo médio e total de água $(\mathrm{em} \mathrm{ml})$ pelos ratos tratados durante 14 dias com diferentes concentrações $(0 \%$, $1 \%, 2 \%$ e $4 \%$ ) de sementes de $S$. occidentalis, na ração e seu grupo peer-feeding. Foram utilizados 10 animais por grupo. São apresentados as médias e os respectivos erros padrões 
Tabela 19 - Consumo médio e total de ração (em g) pelos ratos tratados durante 14 dias com diferentes concentrações $(0 \%$, $1 \%, 2 \%$ e $4 \%$ ) de sementes de S. occidentalis, na ração. Foram utilizados 10 animais por grupo. São apresentados $\mathrm{s}$ as médias e os respectivos erros padrões

\begin{tabular}{|c|c|c|c|c|}
\hline \multirow{2}{*}{ Dias de tratamento } & \multicolumn{4}{|c|}{ Senna occidentalis (\%) } \\
\hline & 0 & 1 & 2 & 4 \\
\hline $2^{\circ}$ & $51,2 \pm 1,8$ & $52,5 \pm 1,7$ & $51,8 \pm 3,8$ & $41,6 \pm 5,3$ \\
\hline $4^{\circ}$ & $49,5 \pm 1,6$ & $52,9 \pm 2,9$ & $48,0 \pm 2,1$ & $36,6 \pm 2,8^{a}$ \\
\hline $6^{\circ}$ & $47,8 \pm 3,5$ & $52,5 \pm 3,1$ & $46,0 \pm 3,5$ & $38,0 \pm 4,0^{a}$ \\
\hline $8^{\circ}$ & $53,2 \pm 3,7$ & $48,3 \pm 6,8$ & $52,9 \pm 4,3$ & $36,0 \pm 2,9^{a}$ \\
\hline $10^{\circ}$ & $48,8 \pm 3,4$ & $43,7 \pm 2,9$ & $45,6 \pm 3,6$ & $27,0 \pm 3,8^{a}$ \\
\hline $12^{\circ}$ & $48,9 \pm 3,0$ & $45,2 \pm 1,7$ & $41,8 \pm 4,4$ & $31,0 \pm 2,4^{a}$ \\
\hline $14^{\circ}$ & $36,2 \pm 5,0$ & $32,7 \pm 4,7$ & $22,2 \pm 4,3$ & $27,5 \pm 2,7$ \\
\hline Total & $335,6 \pm 3,1$ & $328,3 \pm 3,4$ & $308,3 \pm 3,6^{a}$ & $237,7 \pm 3,4^{a}$ \\
\hline
\end{tabular}

${ }^{a}$ difere significantemente $(p<0,05)$ em relação ao controle (ANOVA, seguida de Dunnett). 

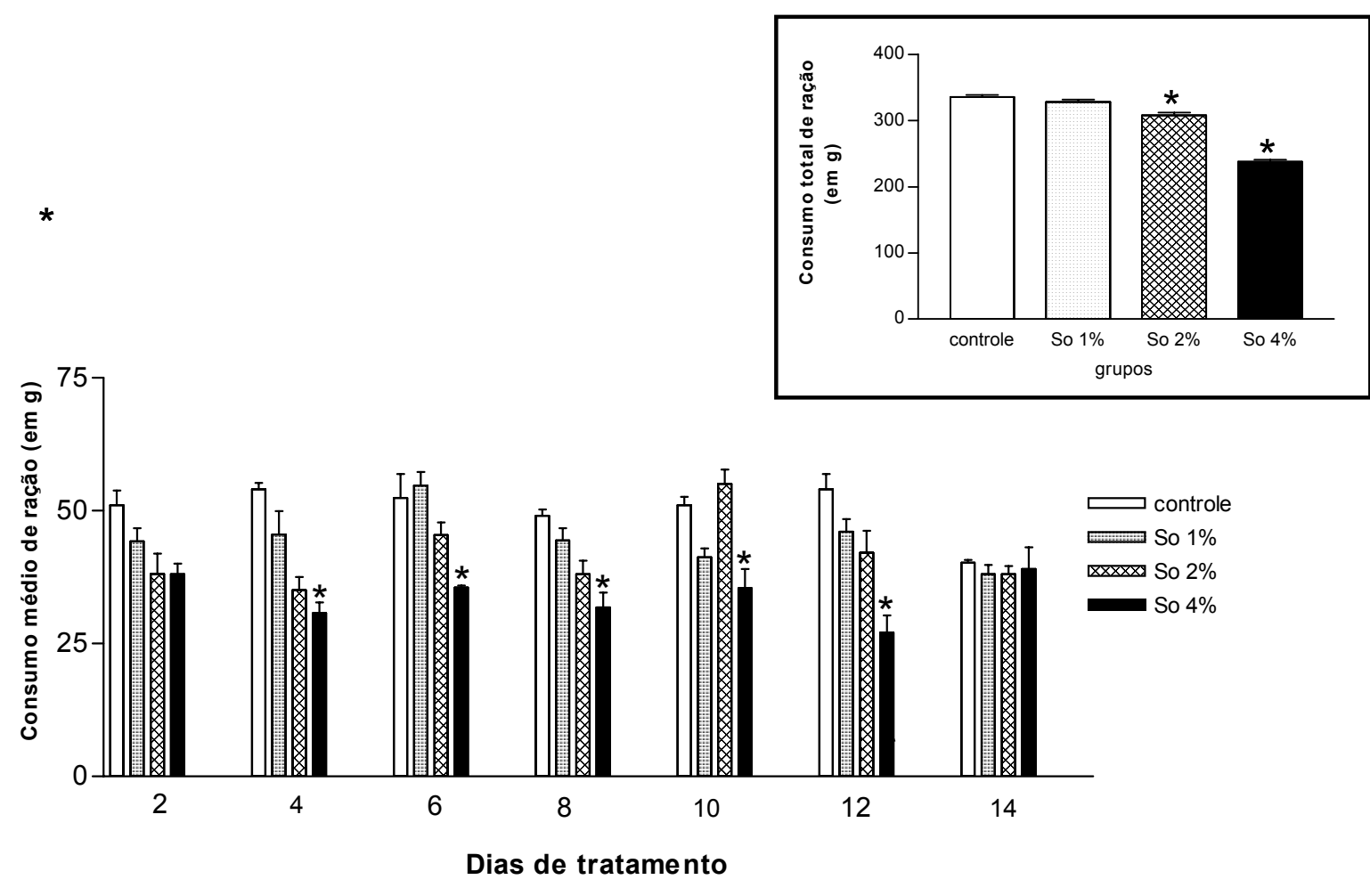

* difere significantemente $(p<0,05)$ em relação ao controle (ANOVA, seguida de Dunnett).

Figura 18 - Consumo médio e total de ração $(\mathrm{em} \mathrm{g})$ pelos ratos tratados durante 14 dias com diferentes concentrações $(0 \%$, $1 \%, 2 \%$ e $4 \%$ ) de sementes de S. occidentalis, na ração. Foram utilizados 10 animais por grupo. São apresentados as médias e os respectivos erros padrões 
Tabela 20 - Peso médio (em g), de ratos tratados durante 14 dias com diferentes concentrações (0\%, 1\%, 2\% e 4\%) de sementes de $S$. occidentalis na ração e seu grupo peer-feeding. Foram utilizados 10 animais por grupo. São apresentados as médias e os respectivos erros padrões

\begin{tabular}{cccccc}
\hline $\begin{array}{c}\text { Dias de } \\
\text { tratamento }\end{array}$ & $\mathbf{0}$ & $\mathbf{1}$ & Senna occidentalis (\%) & \multicolumn{1}{c}{$\mathbf{4}$} & \multicolumn{1}{c}{ PF } \\
\hline $\mathbf{2}^{\circ}$ & $170,7 \pm 4,2$ & $167,3 \pm 4,1$ & $176,1 \pm 3,3$ & $175,4 \pm 2,7$ & $176,5 \pm 4,3$ \\
$\mathbf{4}^{\circ}$ & $176,5 \pm 4,4$ & $170,2 \pm 3,9$ & $177,1 \pm 4,1$ & $173,7 \pm 2,5$ & $177,6 \pm 3,9$ \\
$\mathbf{6}^{\circ}$ & $182,3 \pm 4,6$ & $173,4 \pm 4,2$ & $178,8 \pm 4,9$ & $171,6 \pm 2,7$ & $180,2 \pm 3,3$ \\
$\mathbf{8}^{\circ}$ & $187,4 \pm 4,5$ & $176,0 \pm 4,1$ & $177,3 \pm 5,6^{\mathrm{a}}$ & $166,5 \pm 3,2^{\mathrm{ab}}$ & $179,9 \pm 3,8$ \\
$\mathbf{1 0}^{\circ}$ & $192,5 \pm 4,8$ & $178,7 \pm 4,2$ & $175,7 \pm 5,2^{\mathrm{a}}$ & $161,4 \pm 3,4^{\mathrm{ab}}$ & $180,4 \pm 4,1$ \\
$\mathbf{1 2}^{\circ}$ & $200,4 \pm 4,7$ & $182,3 \pm 4,1^{\mathrm{a}}$ & $175,5 \pm 5,1^{\mathrm{a}}$ & $162,8 \pm 4,6^{\mathrm{ab}}$ & $178,7 \pm 4,4$ \\
$\mathbf{1 4}^{\circ}$ & $200,1 \pm 5,0$ & $184,3 \pm 4,6$ & $174,7 \pm 6,5^{\mathrm{a}}$ & $158,9 \pm 4,1^{\mathrm{ab}}$ & $180,4 \pm 5,0$
\end{tabular}

${ }^{a}$ difere significantemente $(p<0,05)$ em relação ao controle (ANOVA, seguida de Dunnett).

${ }^{b}$ difere significantemente $(p<0,05)$ do grupo PF (Teste "t" Student). 


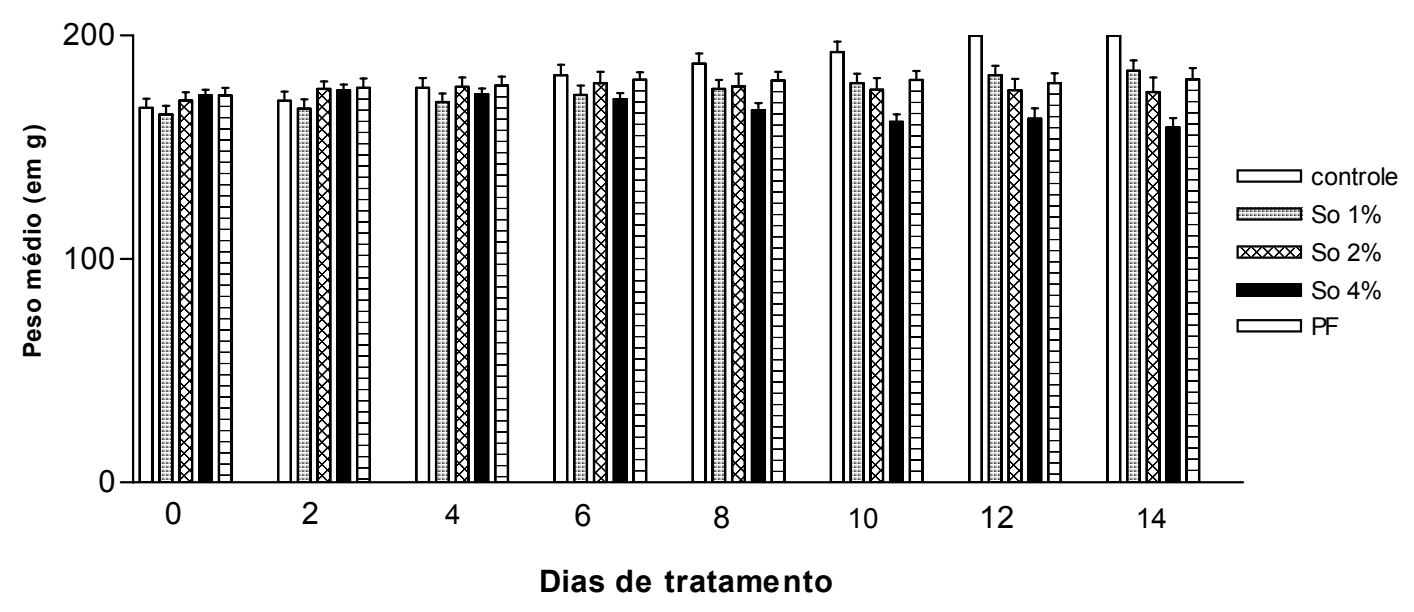

OBS: as diferenças estatisticamente significantes no consumo médio estão identificadas na Tabela 20.

Figura 19 - Peso médio (em g), de ratos tratados durante 14 dias com diferentes concentrações $(0 \%, 1 \%, 2 \%$ e $4 \%$ ) de sementes de $S$. occidentalis, na ração e seu grupo peer-feeding. Foram utilizados 10 animais por grupo. São apresentados as médias e os respectivos erros padrões 
Tabela 21 - Peso semanal e total (em g), de ratos tratados durante 14 dias com diferentes concentrações $(0 \%, 1 \%, 2 \%$ e $4 \%)$ de sementes de $S$. occidentalis, na ração e seu grupo peer-feeding. Foram utilizados 10 animais por grupo. São apresentados as médias e os respectivos erros padrões

\begin{tabular}{|c|c|c|c|c|c|}
\hline \multirow{2}{*}{$\begin{array}{c}\text { Semanas de } \\
\text { tratamento }\end{array}$} & \multicolumn{5}{|c|}{ Senna occidentalis (\%) } \\
\hline & 0 & 1 & 2 & 4 & PF \\
\hline S1 & $14,8 \pm 4,3$ & $8,7 \pm 4,0$ & $7,9 \pm 3,9$ & $1,6 \pm 2,6$ & $6,5 \pm 0,3$ \\
\hline S2 & $13,3 \pm 4,7$ & $8,3 \pm 4,2$ & $-2,5 \pm 5,6$ & $-7,6 \pm 3,3^{a b}$ & $1,0 \pm 4,6$ \\
\hline Total & $28,8 \pm 4,5$ & $17,0 \pm 4,1$ & $5,4 \pm 4,7^{a}$ & $-6,0 \pm 3,2^{a b}$ & $7,5 \pm 3,9^{a}$ \\
\hline
\end{tabular}

a difere significantemente $(p<0,05)$ em relação ao controle (ANOVA, seguida de Dunnett).

${ }^{b}$ difere significantemente $(p<0,05)$ do grupo PF (Teste " $t$ " Student). 

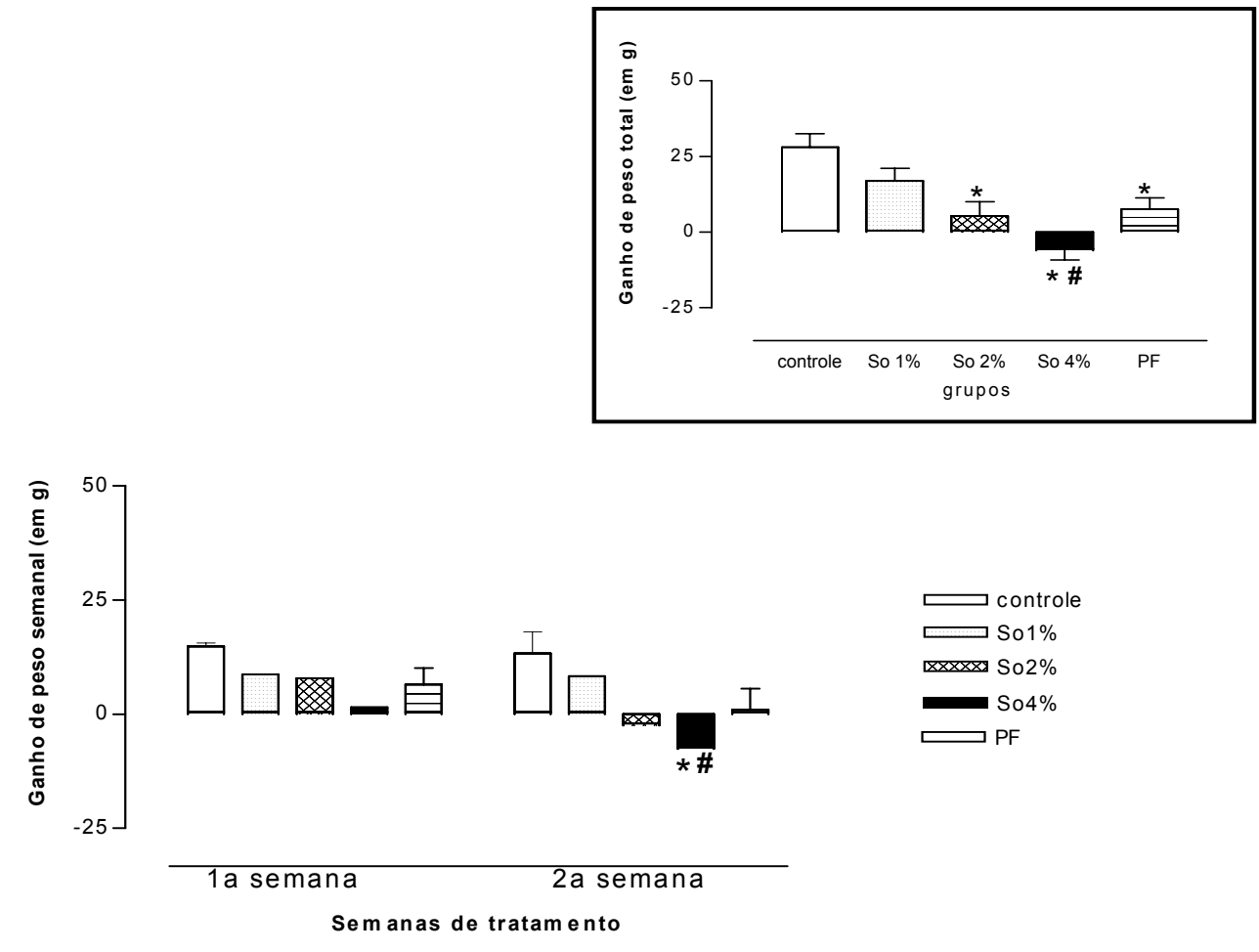

* difere significantemente $(p<0,05)$ em relação ao controle (ANOVA, seguida de Dunnett).

\# difere significantemente $(p<0,05)$ em relação ao PF (Teste " $t$ " Student).

Figura 20 - Peso semanal e total $(\mathrm{em} \mathrm{g})$, de ratos tratados durante 14 dias com diferentes concentrações $(0 \%, 1 \%, 2 \%$ e $4 \%)$ de sementes de $S$. occidentalis, na ração e seu grupo peer-feeding. Foram utilizados 10 animais por grupo. São apresentados as médias e os respectivos erros padrões 
Tabela 22 - Volume do edema inflamatório agudo (em $\mu \mathrm{L}$ ) medido através de pletismografia em diferentes momentos após a inoculação de carragenina $1 \%$ no coxim plantar da pata posterior esquerda de ratos, tratados durante 14 dias com diferentes concentrações $(0 \%, 1 \%, 2 \%$ e $4 \%)$ de sementes de S. occidentalis, na ração e seu grupo peer-feeding. Foram utilizados 10 animais por grupo. São apresentados as médias e os respectivos erros padrões

\begin{tabular}{|c|c|c|c|c|c|}
\hline \multirow{2}{*}{ Tempos } & \multicolumn{5}{|c|}{ Senna occidentalis (\%) } \\
\hline & 0 & 1 & 2 & 4 & PF \\
\hline 0 & $1,25 \pm 0,4$ & $1,23 \pm 0,2$ & $1,24 \pm 0,3$ & $1,11 \pm 0,3$ & $1,30 \pm 0,4$ \\
\hline $1^{a}$ & $43,6 \pm 2,5$ & $38,2 \pm 1,8^{a}$ & $25,3 \pm 1,9^{a}$ & $24,6 \pm 1,6^{a b}$ & $40,4 \pm 1,9$ \\
\hline $2^{a}$ & $76,6 \pm 3,6$ & $70,6 \pm 2,1$ & $66,1 \pm 3,7$ & $61,6 \pm 3,6$ & $70,4 \pm 2,7$ \\
\hline $4^{a}$ & $74,0 \pm 1,7$ & $70,0 \pm 4,4$ & $55,6 \pm 1,0^{a}$ & $53,4 \pm 3,8^{a b}$ & $69,8 \pm 2,2$ \\
\hline $6^{a}$ & $64,5 \pm 1,8$ & $67,7 \pm 2,1$ & $59,7 \pm 1,3^{a}$ & $55,6 \pm 1,0^{\mathrm{ab}}$ & $71,8 \pm 2,1$ \\
\hline $8^{a}$ & $32,6 \pm 3,6$ & $34,5 \pm 1,1$ & $32,1 \pm 3,3$ & $30,8 \pm 1,4$ & $34,8 \pm 1,0$ \\
\hline $24^{a}$ & $18,6 \pm 4,1$ & $15,8 \pm 4,8$ & $15,2 \pm 3,5$ & $12,2 \pm 2,1$ & $14,9 \pm 3,7$ \\
\hline
\end{tabular}

${ }^{a}$ difere significantemente $(p<0,05)$ em relação ao controle (ANOVA, seguida de Dunnett).

${ }^{b}$ difere significantemente $(p<0,05)$ em relação ao PF (Teste "t" Student). 


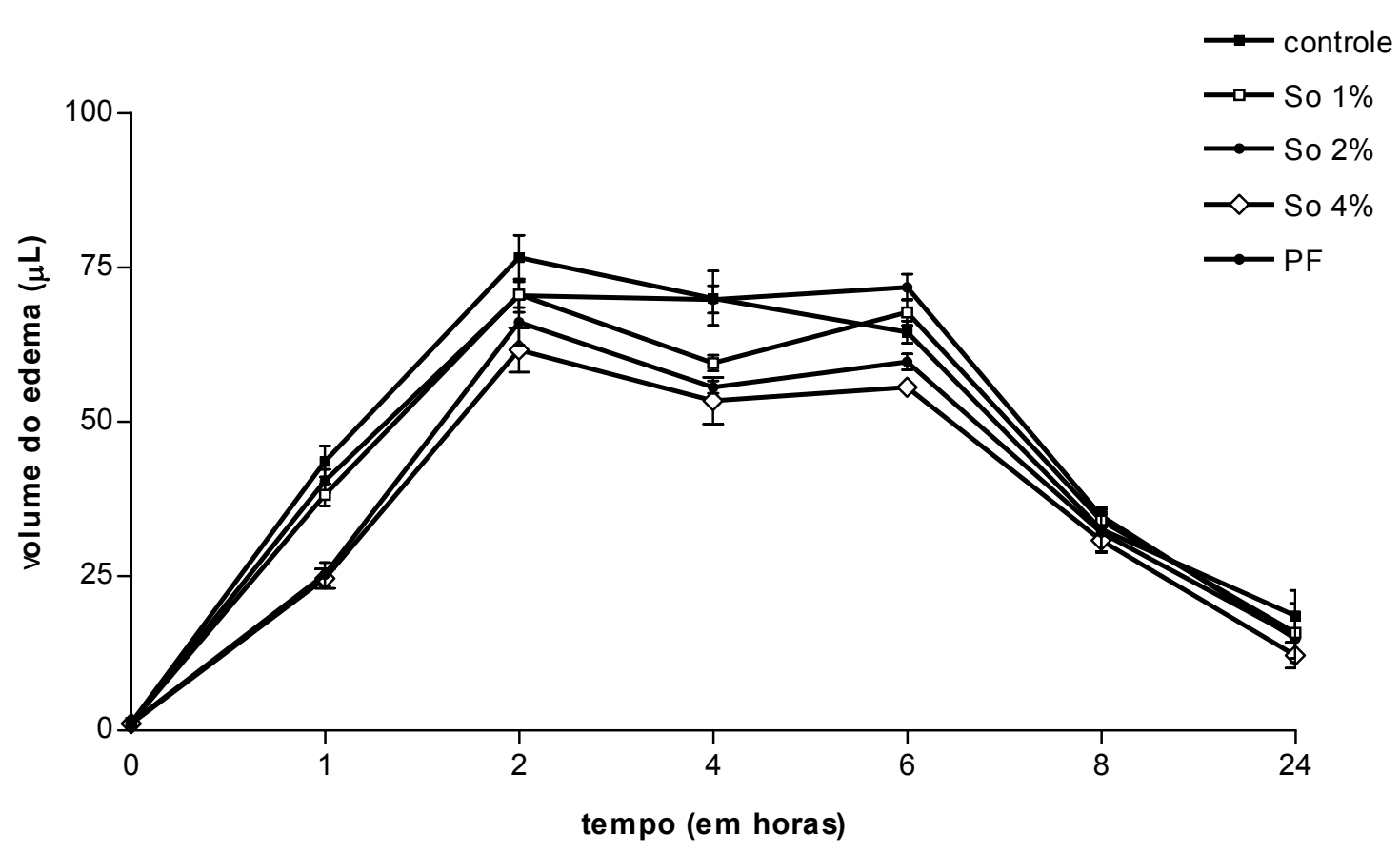

* difere significantemente $(p<0,05)$ em relação ao controle (ANOVA, seguida de Dunnett).

\# difere significantemente $(p<0,05)$ em relação ao PF (Teste " $t$ " Student).

OBS: as diferenças estatisticamente significantes no consumo médio estão identificadas na Tabela 22.

Figura 21 - Volume do edema inflamatório agudo (em $\mu \mathrm{L}$ ) medido através de pletismografia em diferentes momentos após a inoculação de carragenina $1 \%$ no coxim plantar da pata posterior esquerda de ratos, tratados durante 14 dias com diferentes concentrações $(0 \%, 1 \%, 2 \%$ e $4 \%)$ de sementes de S. occidentalis, na ração e seu grupo peer-feeding. Foram utilizados 10 animais por grupo. São apresentados as médias e os respectivos erros padrões 


\subsection{EXPERIMENTO 4: AVALIAÇÃO DOS EFEITOS DA ADMINISTRAÇÃO PROLONGADA DE SEMENTES DE Senna occidentalis SOBRE A RESPOSTA INFLAMATÓRIA CRÔNICA E DO GRANULOMA EXPERIMENTAL EM RATOS}

A tabela 23 mostra e a figura 22 ilustra o consumo médio e total de água pelos ratos durante o experimento. Assim, a análise estatística realizada revelou haver diferença significante entre os grupos nos $4^{\circ}, 6^{\circ}$ e $8^{\circ}$ dias do experimento $\left(F_{4}=5,361 ; F_{6}=4,490\right.$ e $F_{8}=10,836 ; d f=4 / 45$, respectivamente, $\left.p<0,05\right)$, bem como no período total $(F=108,99$ e $d f=4 / 45)$. A aplicação do teste de Dunnett apontou diminuição significante $(p<0,05)$ no consumo de água daqueles animais pertencentes ao grupo So $2 \%$ nos $6^{\circ}$ e $8^{\circ}$ dias de tratamento. Este mesmo teste revelou diminuição significante $(p<0,05)$ nos animais pertencentes ao grupo So4\% nos $4^{\circ}, 6^{\circ}$ e $8^{\circ}$ dias de experimento, quando comparado aos animais do grupo controle. Na avaliação no consumo total de ração, o teste de Dunnett revelou haver diminuição significante $(p<0,05)$ deste parâmetro em todos os grupos experimentais em relação ao grupo controle.

Em relação ao consumo de ração destes animais (Tabela 24 e Figura 23), as análises de variância realizadas revelaram haver diferença significante entre os grupos nos $2^{\circ}, 4^{\circ}, 6^{\circ}, 8^{\circ}$ e $12^{\circ}$ dias do experimento $\left(F_{2}=4,686 ; F_{4}=14,213 ; F_{6}=6,715\right.$; $F_{8}=10,567 ; F_{12}=12,251 ; d f=3 / 36$, respectivamente, $\left.p<0,05\right)$, bem como no período total $(F=337,68$ e $\mathrm{df}=3 / 36)$, quando comparado aos resultados obtidos dos animais pertencentes ao grupo controle, sendo que o consumo dos animais do grupo peerfeeding (PF) foi idêntico àquele dos ratos submetidos à administração de ração contendo $4 \%$ de sementes de S. occidentalis (dados não apresentados). A aplicação do teste de Dunnett demonstrou haver diminuição significante $(p<0,05)$ no consumo 
médio de ração dos animais tratados com So $2 \%$ em relação àqueles animais pertencentes ao grupo controle nos $2^{\circ}, 4^{\circ}, 8^{\circ}$ e $12^{\circ}$ dias de tratamento. Este mesmo teste revelou haver redução significante $(p<0,05)$ neste mesmo parâmetro nos ratos do grupo So $4 \%$ no $2^{\circ}, 4^{\circ}, 6^{\circ}, 8^{\circ}$ e $12^{\circ}$ dias. Na avaliação no consumo total de ração, o teste de Dunnett revelou haver diminuição significante $(p<0,05)$ deste parâmetro em todos os grupos experimentais em relação ao grupo controle.

A tabela 25 mostra e a figura 24 ilustra o peso médio destes animais; as análises de variância realizadas revelaram haver diferença significante entre os grupos nos $4^{\circ}, 8^{\circ}, 10^{\circ}, 12^{\circ}$ e $14^{\circ}$ dias do experimento $\left(F_{4}=2,629 ; F_{8}=11,402\right.$; $F_{10}=24,684 ; F_{12}=22,686 ; F_{14}=21,147 ; d f=4 / 45$, respectivamente, $\left.p<0,05\right)$. A aplicação do teste de Dunnett demonstrou haver diminuição significante $(p<0,05)$ no peso médio dos animais do grupo experimental So $2 \%$ nos $8^{\circ}, 12^{\circ}$ e $14^{\circ}$ dias de tratamento, em relação ao grupo controle. Quanto aos animais do grupo So4\%, estes apresentaram diminuição significante $(p<0,05)$ no peso médio no $4^{\circ}, 8^{\circ}, 10^{\circ}, 12^{\circ}$ e $14^{\circ}$ dias do experimento, quando comparado aos animais do grupo controle.

O ganho de peso semanal e total destes ratos são apresentados na tabela 26 e figura 25. Assim, a análise de variância realizada revelou não haver diferença significante $(p>0.05)$ entre os grupos durante a $1^{a}$ e $2^{a}$ semana de tratamento. Por outro lado, no período total foi verificada redução significante $(F=5,859 ; d f=4 / 45$, respectivamente, $p<0,05)$ deste parâmetro apenas nos animais tratados com So4\%, quando comparado com os animais do grupo controle.

Em relação ás observações clínicas, os seguintes sinais e sintomas foram observados: letargia, abatimento, prostração, pêlos arrepiados e fezes amolecidas, a partir da segunda semana de tratamento em todos os animais pertencentes ao grupo So4\%. 
A tabela 27 mostra e a figura 26 ilustra o volume do edema inflamatório agudo e do granuloma experimental (em $\mu \mathrm{L}$ ) medido em diferentes momentos (1 - 2 - 4 - 6 8 horas e $1-2-3-4-5-6-7-9-11-13-15-17-19-21$ dias) após a inoculação de Onco-BCG $(0,1 \mathrm{ml})$ no coxim plantar da pata posterior esquerda de ratos previamente tratados com diferentes concentrações de $S$. occidentalis na ração, durante 14 dias e seu respectivo grupo controle. A análise estatística dos resultados revelou haver diminuição significante $(p<0,05)$ entre os grupos nos tempos 1- 2 - 4 - 6 - 8 - 24 de observação $\left(F_{1}=5,840 ; F_{2}=7,311 ; \quad F_{4}=8,222\right.$; $F_{6}=13,647 ; F_{8}=5,529 ; F_{24}=4,715 ; d f=4 / 45$, respectivamente $\left.p<0,05\right)$ de observação. A aplicação do teste de Dunnett demonstrou haver diminuição significante $(p<0,05)$ do volume do edema inflamatório agudo de todos os animais dos grupos experimentais, quando comparados àqueles do grupo controle.

Em relação ao volume do granuloma da pata destes animais, a análise de variância realizada revelou haver diferença significante entre os grupos nos tempos 48, 96, 120 e 144 horas $\left(F_{48}=3,870 ; F_{96}=3,381 \quad F_{120}=48,114 ; F_{144}=3,748 ; d f=4 / 45\right.$, respectivamente, $p<0,05)$ de observação. A aplicação do teste de Dunnett demonstrou haver diminuição significante $(p<0,05)$ no volume do granuloma dos animais pertencentes ao grupo experimental So1\% nas 48 horas de observação, em relação aos animais do grupo controle. Este mesmo teste apontou diminuição significante $(p<0,05)$ deste parâmetro nos animais pertencentes ao grupo So $\%$ nos tempos 120 e 144 de observação, quando comparado aos resultados obtidos do grupo controle; bem como diminuição significante $(p<0,05)$ do volume do granuloma experimental, dos ratos do grupo So4\% nos tempos 48, 96, 120 e 144 horas de avaliação, quando comparado aos animais pertencentes ao grupo controle. 
A tabela 28 apresenta os resultados da contagem do número médio de bacilos álcool-ácido resistentes presentes na lesão granulomatosa podal observada no $21^{a}$ dia da inoculação de Onco-BCG $(0,1 \mathrm{~mL} /$ pata) no coxim plantar da pata posterior esquerda de ratos previamente tratados com ração contendo diferentes concentrações de sementes de S. occidentalis durante 14 dias.

A análise estatística dos resultados do tratamento revelou não haver diferenças significantes $(p>0,05)$ entre os grupos tratados e seu respectivo controle. 
Tabela 23 - Consumo médio e total de água $(\mathrm{em} \mathrm{ml})$ pelos ratos tratados durante 14 dias com diferentes concentrações $(0 \%$, $1 \%, 2 \%$ e $4 \%$ ) de sementes de $S$. occidentalis, na ração e seu grupo peer-feeding. Foram utilizados 10 animais por grupo. São apresentados as médias e os respectivos erros padrões

\begin{tabular}{|c|c|c|c|c|c|}
\hline \multirow{2}{*}{$\begin{array}{l}\text { Dias de } \\
\text { tratamento }\end{array}$} & \multicolumn{5}{|c|}{ Senna occidentalis (\%) } \\
\hline & 0 & 1 & 2 & 4 & PF \\
\hline $2^{\circ}$ & $86,8 \pm 5,1$ & $71,7 \pm 2,8^{a}$ & $67,2 \pm 3,9$ & $75,0 \pm 2,8$ & $86,2 \pm 2,7$ \\
\hline $4^{\circ}$ & $82,0 \pm 4,6$ & $78,7 \pm 0,3$ & $78,3 \pm 4,3$ & $63,0 \pm 3,1^{a b}$ & $75,4 \pm 3,4$ \\
\hline $6^{\circ}$ & $87,0 \pm 3,0$ & $74,8 \pm 4,4$ & $62,7 \pm 3,6^{a}$ & $65,1 \pm 4,9^{\mathrm{ab}}$ & $78,7 \pm 4,5$ \\
\hline $8^{\circ}$ & $86,8 \pm 4,4$ & $71,4 \pm 4,9$ & $69,7 \pm 4,2^{a}$ & $46,2 \pm 5,0^{a b}$ & $73,8 \pm 3,7$ \\
\hline $10^{\circ}$ & $66,8 \pm 4,9$ & $65,0 \pm 4,8$ & $61,2 \pm 4,2$ & $62,8 \pm 3,7$ & $66,5 \pm 3,2$ \\
\hline $12^{\circ}$ & $57,4 \pm 4,7$ & $60,0 \pm 4,5$ & $62,8 \pm 5,1$ & $52,8 \pm 3,0$ & $60,5 \pm 5,1$ \\
\hline $14^{\circ}$ & $62,2 \pm 6,0$ & $60,0 \pm 6,7$ & $62,8 \pm 6,3$ & $46,5 \pm 3,9$ & $58,9 \pm 4,7$ \\
\hline Total & $529,0 \pm 4,6$ & $409,9 \pm 4,0^{a}$ & $464,7 \pm 4,5^{a}$ & $411,4 \pm 3,7^{a b}$ & $499,9 \pm 3,9^{a}$ \\
\hline
\end{tabular}

${ }^{a}$ difere significantemente $(p<0,05)$ em relação ao controle (ANOVA, seguida de Dunnett).

${ }^{b}$ difere significantemente $(p<0,05)$ do grupo PF (Teste "t" Student). 

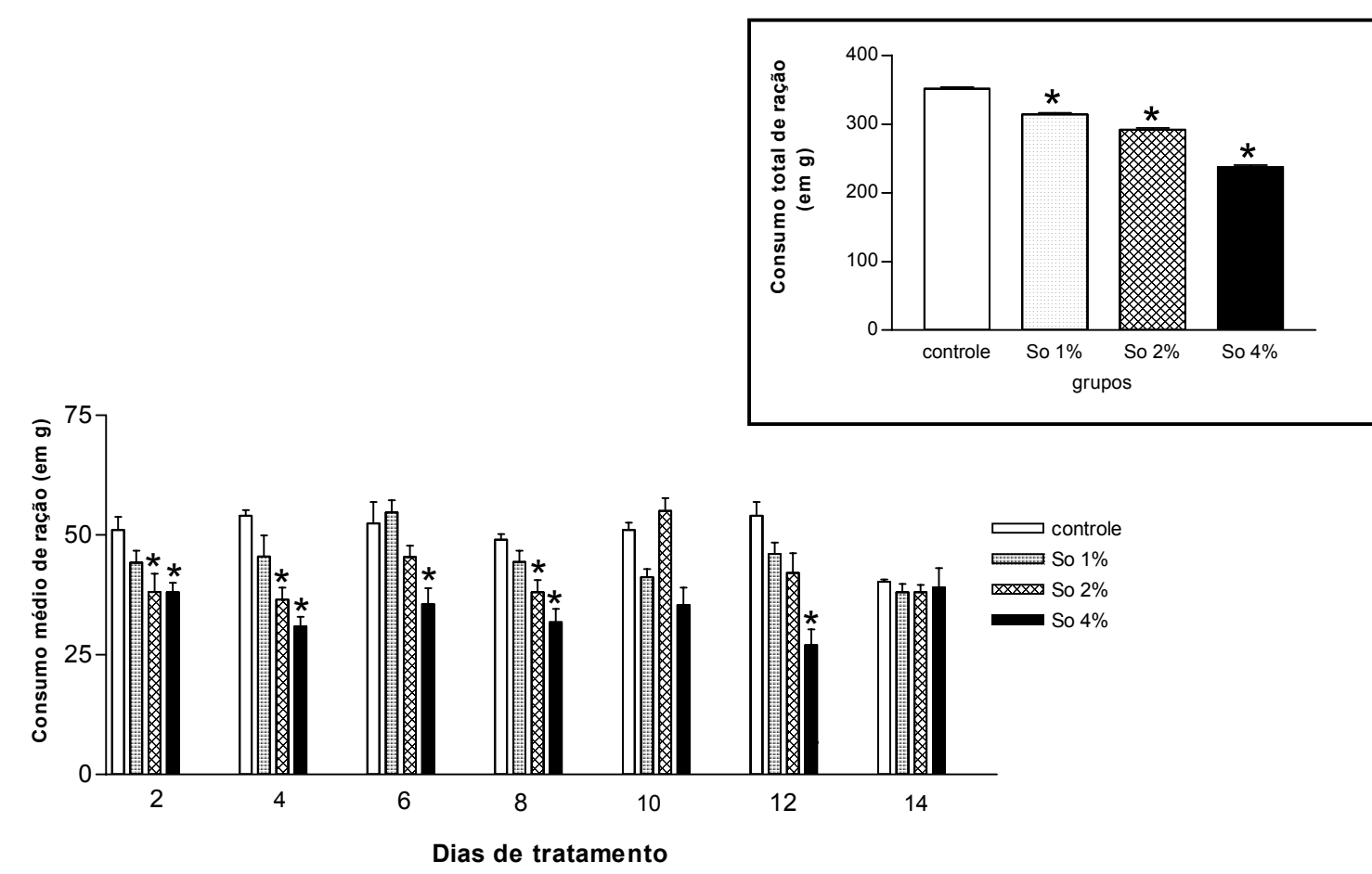

* difere significantemente $(p<0,05)$ em relação ao controle (ANOVA, seguida de Dunnett).

\# difere significantemente $(p<0,05)$ do grupo PF (Teste " $t$ " Student).

OBS: as diferenças estatisticamente significantes no consumo médio estão identificadas na Tabela 23.

Figura 22 - Consumo médio e total de água (em $\mathrm{ml})$ pelos ratos tratados durante 14 dias com diferentes concentrações $(0 \%$, $1 \%$, $2 \%$ e $4 \%$ ) de sementes de S. occidentalis, na ração e seu grupo peer-feeding. Foram utilizados 10 animais por grupo. São apresentados as médias e os respectivos erros padrões 
Tabela 24 - Consumo médio e total de ração (em g) pelos ratos tratados durante 14 dias com diferentes concentrações $(0 \%$, $1 \%, 2 \%$ e $4 \%$ ) de sementes de $S$. occidentalis, na ração. Foram utilizados 10 animais por grupo. São apresentados às médias e os respectivos erros padrões

\begin{tabular}{|c|c|c|c|c|}
\hline \multirow{2}{*}{ Dias de tratamento } & \multicolumn{4}{|c|}{ Senna occidentalis (\%) } \\
\hline & 0 & 1 & 2 & 4 \\
\hline $2^{\circ}$ & $51,0 \pm 2,8$ & $44,2 \pm 2,5$ & $38,1 \pm 3,8^{a}$ & $38,0 \pm 2,0^{a}$ \\
\hline $4^{\circ}$ & $54,0 \pm 1,2$ & $45,5 \pm 4,4$ & $35,0 \pm 2,5^{a}$ & $30,7 \pm 2,0^{a}$ \\
\hline $6^{\circ}$ & $52,4 \pm 4,5$ & $54,7 \pm 2,6$ & $45,4 \pm 2,4$ & $35,5 \pm 3,4^{a}$ \\
\hline $8^{\circ}$ & $49,0 \pm 1,2$ & $44,4 \pm 2,3$ & $38,0 \pm 2,6^{a}$ & $31,8 \pm 2,8^{a}$ \\
\hline $10^{\circ}$ & $51,0 \pm 1,6$ & $41,2 \pm 1,7$ & $55,0 \pm 2,7$ & $35,4 \pm 3,6$ \\
\hline $12^{\circ}$ & $54,0 \pm 2,9$ & $46,0 \pm 2,4$ & $42,1 \pm 4,1^{a}$ & $27,0 \pm 3,3^{a}$ \\
\hline $14^{\circ}$ & $40,2 \pm 0,5$ & $38,0 \pm 1,6$ & $38,0 \pm 1,6$ & $39,0 \pm 4,1$ \\
\hline Total & $351,6 \pm 2,1$ & $314,0 \pm 2,4$ & $291,6 \pm 2,8^{a}$ & $237,7 \pm 3,4^{a}$ \\
\hline
\end{tabular}

\footnotetext{
${ }^{a}$ difere significantemente $(p<0,05)$ em relação ao controle (ANOVA, seguida de Dunnett).
} 


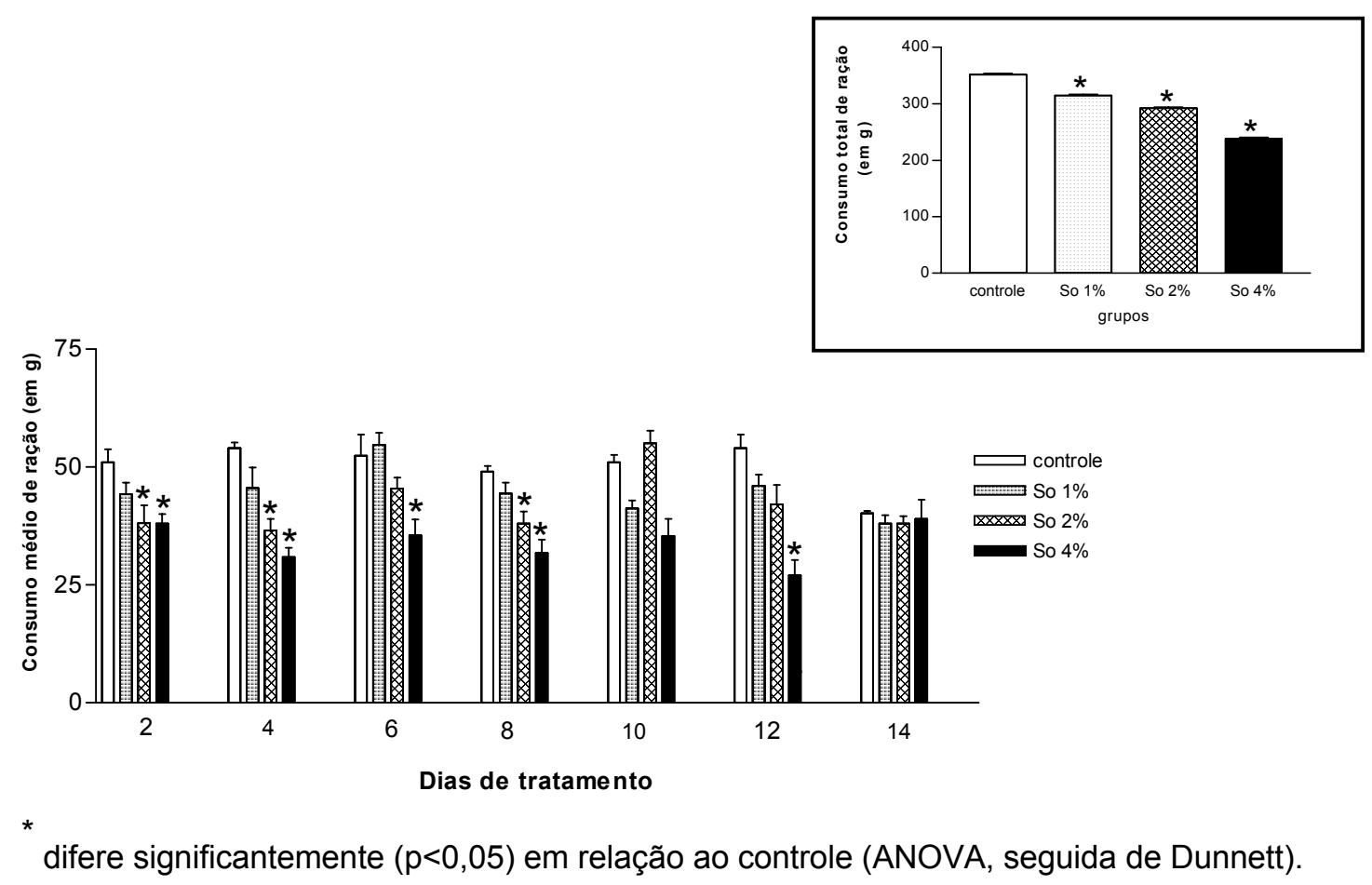

Figura 22- Consumo médio e total de ração (em g) pelos ratos tratados durante 14 dias com diferentes concentrações $(0 \%, 1 \%$, $2 \%$ e $4 \%$ ) de sementes de S. occidentalis, na ração. Foram utilizados 10 animais por grupo. São apresentados as médias e os respectivos erros padrões 
Tabela 25 - Peso médio (em g), de ratos tratados durante 14 dias com diferentes concentrações $(0 \%, 1 \%, 2 \%$ e $4 \%)$ de sementes de S. occidentalis na ração e seu grupo peer-feeding. Foram utilizados 10 animais por grupo. São apresentados as médias e os respectivos erros padrões

\begin{tabular}{|c|c|c|c|c|c|}
\hline \multirow{2}{*}{$\begin{array}{l}\text { Dias de } \\
\text { tratamento }\end{array}$} & \multicolumn{5}{|c|}{ Senna occidentalis (\%) } \\
\hline & 0 & 1 & 2 & 4 & PF \\
\hline $2^{\circ}$ & $152,0 \pm 4,1$ & $160,0 \pm 4,2$ & $164,0 \pm 3,3$ & $155,0 \pm 2,7$ & $161,0 \pm 4,3$ \\
\hline $4^{\circ}$ & $160,0 \pm 3,9$ & $166,0 \pm 4,4$ & $173,0 \pm 4,1$ & $157,0 \pm 2,5^{a b}$ & $166,0 \pm 3,9$ \\
\hline $6^{\circ}$ & $166,0 \pm 3,6$ & $169,0 \pm 3,8$ & $165,0 \pm 4,4$ & $161,6 \pm 5,0$ & $169,0 \pm 4,6$ \\
\hline $8^{\circ}$ & $175,0 \pm 2,9$ & $183,0 \pm 3,5$ & $164,0 \pm 4,3^{a}$ & $149,0 \pm 5,4^{a b}$ & $176,0 \pm 3,0$ \\
\hline $10^{\circ}$ & $182,0 \pm 3,1$ & $190,0 \pm 3,2$ & $158,0 \pm 4,5$ & $144,0 \pm 4,8^{\mathrm{ab}}$ & $184,0 \pm 3,9$ \\
\hline $12^{\circ}$ & $185,0 \pm 2,0$ & $193,0 \pm 3,0$ & $164,0 \pm 4,0^{a}$ & $148,0 \pm 5,2^{a b}$ & $183,0 \pm 4,2$ \\
\hline $14^{\circ}$ & $188,0 \pm 2,8$ & $195,0 \pm 3,3$ & $167,0 \pm 4,4^{a}$ & $150,0 \pm 5,0^{a b}$ & $185,0 \pm 4,0$ \\
\hline
\end{tabular}

\footnotetext{
${ }^{a}$ difere significantemente $(p<0,05)$ em relação ao controle (ANOVA, seguida de Dunnett).
}

${ }^{b}$ difere significantemente $(p<0,05)$ do grupo PF (Teste "t" Student). 


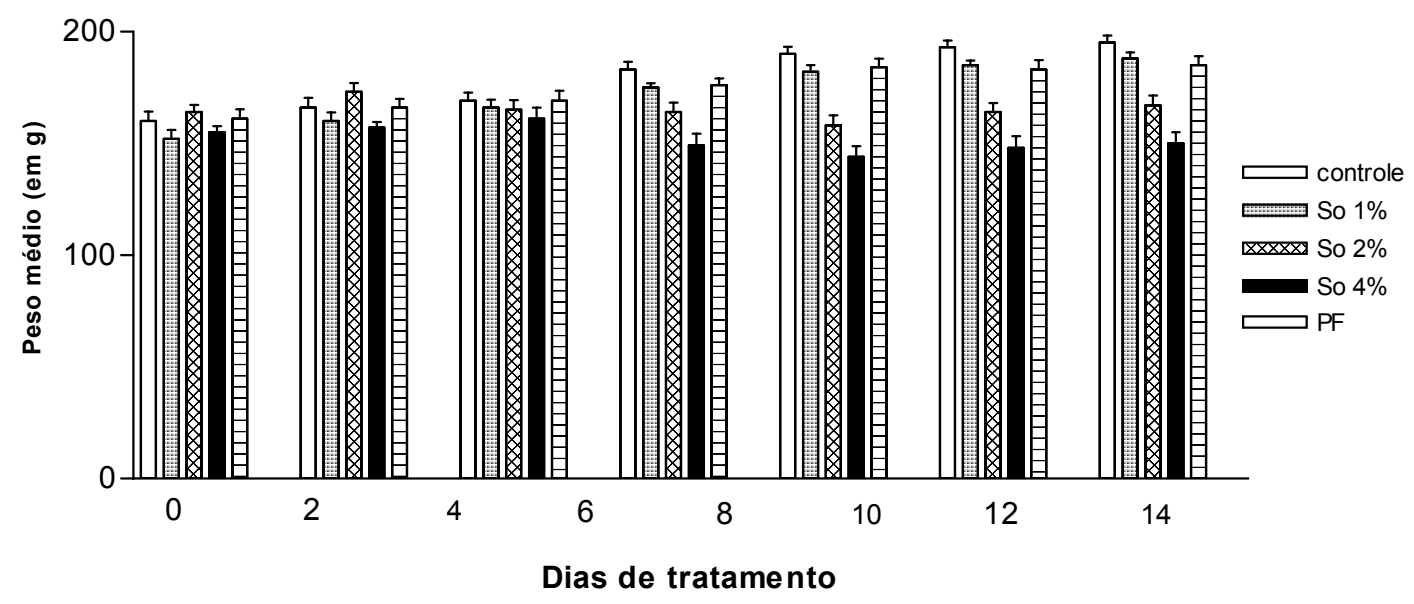

OBS: as diferenças estatisticamente significantes no consumo médio estão identificadas na Tabela 25.

Figura 24 - Peso médio (em g), de ratos tratados durante 14 dias com diferentes concentrações (0\%, 1\%, 2\% e 4\%) de sementes de $S$. occidentalis, na ração e seu grupo peer-feeding. Foram utilizados 10 animais por grupo. São apresentados as médias e os respectivos erros padrões 
Tabela 26 - Peso semanal e total (em g), de ratos tratados durante 14 dias com diferentes concentrações (0\%, 1\%, 2\% e 4\%) de sementes de $S$. occidentalis, na ração e seu grupo peer-feeding. Foram utilizados 10 animais por grupo. São apresentados as médias e os respectivos erros padrões

\begin{tabular}{|c|c|c|c|c|c|}
\hline \multirow{2}{*}{$\begin{array}{l}\text { Semanas de } \\
\text { tratamento }\end{array}$} & \multicolumn{5}{|c|}{ Senna occidentalis (\%) } \\
\hline & 0 & 1 & 2 & 4 & PF \\
\hline S1 & $28,0 \pm 3,6$ & $21,0 \pm 3,9$ & $24,0 \pm 4,0$ & $5,0 \pm 3,9$ & $19,0 \pm 3,9$ \\
\hline S2 & $13,0 \pm 2,6$ & $12,0 \pm 3,1$ & $15,0 \pm 4,3$ & $1,0 \pm 5,0$ & $5,0 \pm 4,0$ \\
\hline Total & $41,0 \pm 3,0$ & $33,0 \pm 3,8$ & $39,0 \pm 4,2$ & $6,0 \pm 4,2^{a b}$ & $24,0 \pm 3,8$ \\
\hline
\end{tabular}

${ }^{a}$ difere significantemente $(p<0,05)$ em relação ao controle (ANOVA, seguida de Dunnett).

${ }^{b}$ difere significantemente $(p<0,05)$ do grupo PF (Teste "t" Student). 

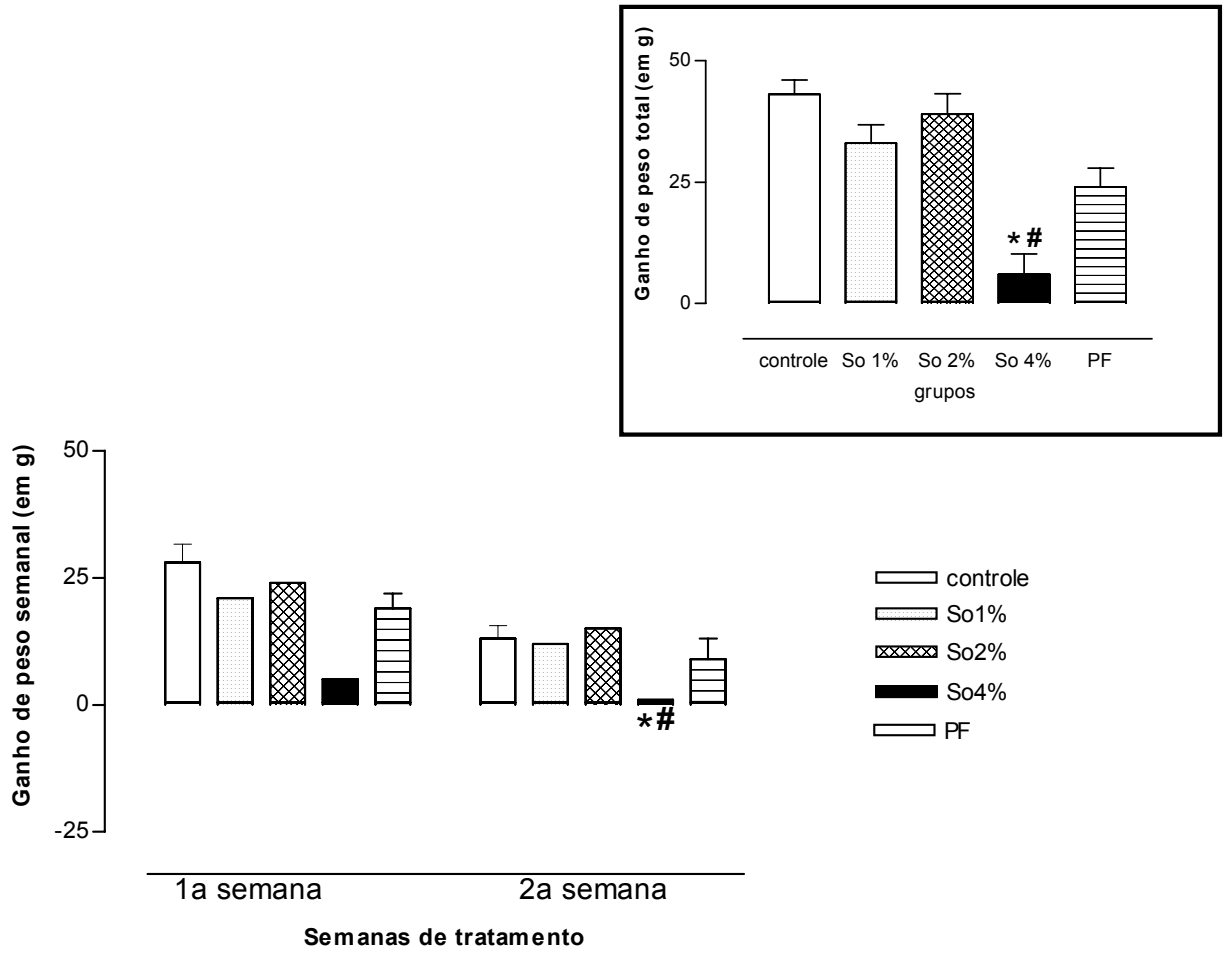

* difere significantemente $(p<0,05)$ em relação ao controle (ANOVA, seguida de Dunnett).

\# difere significantemente $(p<0,05)$ em relação ao PF (Teste " $t$ " Student).

Figura 25 - Peso semanal e total (em g), de ratos tratados durante 14 dias com diferentes concentrações $(0 \%, 1 \%, 2 \%$ e $4 \%)$ de sementes de $S$. occidentalis, na ração e seu grupo peer-feeding. Foram utilizados 10 animais por grupo. São apresentados as médias e os respectivos erros padrões 
Tabela 27 - Volume do edema inflamatório agudo (em $\mu \mathrm{L}$ ) e do granuloma experimental induzido pela inoculação de onco-BCG no coxim plantar da pata posterior esquerda de ratos, tratados durante 14 dias com diferentes concentrações $(0 \%, 1 \%, 2 \%$ e $4 \%)$ de sementes de S. occidentalis, na ração e seu grupo peer-feeding. Foram utilizados 10 animais por grupo. São apresentados as médias e os respectivos erros padrões

\begin{tabular}{cccccc}
\hline Tempos & \multicolumn{5}{c}{ Senna occidentalis (\%) } \\
\cline { 2 - 6 } & $\mathbf{0}$ & $\mathbf{1}$ & $\mathbf{2}$ & $\mathbf{4}$ & $\mathbf{P F}$ \\
\hline $\mathbf{0}$ & $1,48 \pm 0,4$ & $1,46 \pm 0,2$ & $1,48 \pm 0,2$ & $1,46 \pm 0,02$ & $1,48 \pm 0,02$ \\
$\mathbf{1}$ & $33,8 \pm 3,6$ & $18,2 \pm 3,0^{\mathrm{a}}$ & $25,1 \pm 1,7$ & $18,6 \pm 2,8^{\mathrm{ab}}$ & $31,2 \pm 3,8$ \\
$\mathbf{2}$ & $41,8 \pm 2,0$ & $26,7 \pm 3,8^{\mathrm{a}}$ & $28,0 \pm 2,6^{\mathrm{a}}$ & $23,7 \pm 3,1^{\mathrm{ab}}$ & $35,7 \pm 3,3$ \\
$\mathbf{4}$ & $48,7 \pm 2,6$ & $31,5 \pm 3,^{\mathrm{a}}$ & $29,3 \pm 3,4^{\mathrm{a}}$ & $30,2 \pm 3,4^{\mathrm{ab}}$ & $44,3 \pm 3,6$ \\
$\mathbf{6}$ & $89,2 \pm 4,7$ & $56,1 \pm 2,8^{\mathrm{a}}$ & $61,5 \pm 2,7^{\mathrm{a}}$ & $65,3 \pm 4,3^{\mathrm{ab}}$ & $80,6 \pm 3,2$ \\
$\mathbf{8}$ & $87,4 \pm 5,1$ & $67,1 \pm 4,6^{\mathrm{a}}$ & $63,1 \pm 3,3^{\mathrm{a}}$ & $67,1 \pm 4,3^{\mathrm{ab}}$ & $79,2 \pm 3,9$ \\
$\mathbf{2 4}$ & $51,6 \pm 4,8$ & $34,3 \pm 2,9^{\mathrm{a}}$ & $43,8 \pm 3,6$ & $35,1 \pm 3,6^{\mathrm{ab}}$ & $47,2 \pm 3,8$ \\
$\mathbf{4 8}$ & $66,1 \pm 5,5$ & $47,5 \pm 4,5^{\mathrm{a}}$ & $59,1 \pm 5,2$ & $45,5 \pm 4,1^{\mathrm{ab}}$ & $65,4 \pm 3,7$ \\
$\mathbf{7 2}$ & $53,6 \pm 4,0$ & $44,2 \pm 4,3$ & $49,3 \pm 5,6$ & $40,2 \pm 5,0$ & $42,0 \pm 3,5$ \\
$\mathbf{9 6}$ & $42,5 \pm 5,0$ & $39,7 \pm 3,4$ & $38,2 \pm 3,1$ & $33,8 \pm 3,6^{\mathrm{ab}}$ & $45,5 \pm 4,2$ \\
$\mathbf{1 2 0}$ & $68,0 \pm 2,6$ & $62,2 \pm 2,0$ & $56,1 \pm 2,8^{\mathrm{a}}$ & $37,4 \pm 1,9^{\mathrm{ab}}$ & $66,0 \pm 2,6$ \\
$\mathbf{1 4 4}$ & $40,5 \pm 5,2$ & $33,3 \pm 1,8$ & $26,1 \pm 3,3^{\mathrm{a}}$ & $27,5 \pm 1,9^{\mathrm{ab}}$ & $34,4 \pm 2,7$ \\
$\mathbf{1 6 8}$ & $35,5 \pm 4,2$ & $34,6 \pm 5,5$ & $29,1 \pm 4,7$ & $33,3 \pm 3,9$ & $35,5 \pm 3,9$ \\
$\mathbf{2 1 6}$ & $34,4 \pm 4,2$ & $36,0 \pm 5,5$ & $24,5 \pm 4,7$ & $37,7 \pm 3,7$ & $39,6 \pm 3,2$ \\
$\mathbf{2 6 4}$ & $31,0 \pm 3,8$ & $25,8 \pm 3,9$ & $17,1 \pm 5,3$ & $30,7 \pm 5,7$ & $30,0 \pm 3,8$ \\
$\mathbf{3 1 2}$ & $29,1 \pm 3,9$ & $20,3 \pm 3,5$ & $22,5 \pm 3,3$ & $22,4 \pm 3,4$ & $29,1 \pm 4,3$ \\
$\mathbf{3 6 0}$ & $21,5 \pm 3,1$ & $15,8 \pm 4,3$ & $15,7 \pm 5,3$ & $18,3 \pm 3,4$ & $19,4 \pm 3,6$ \\
$\mathbf{4 0 8}$ & $20,8 \pm 4,4$ & $16,7 \pm 3,9$ & $18,2 \pm 2,7$ & $22,9 \pm 3,3$ & $20,4 \pm 3,1$ \\
$\mathbf{4 5 6}$ & $21,8 \pm 5,0$ & $17,5 \pm 3,9$ & $11,3 \pm 4,6$ & $14,5 \pm 4,3$ & $19,1 \pm 4,6$ \\
$\mathbf{5 0 4}$ & $19,4 \pm 3,6$ & $20,1 \pm 2,8$ & $19,2 \pm 4,4$ & $20,4 \pm 4,1$ & $21,8 \pm 3,7$ \\
\hline
\end{tabular}

${ }^{a}$ difere significantemente $(p<0,05)$ em relação ao controle (ANOVA, seguida de Dunnett).

b difere significantemente $(p<0,05)$ do grupo PF (Teste " $t$ 


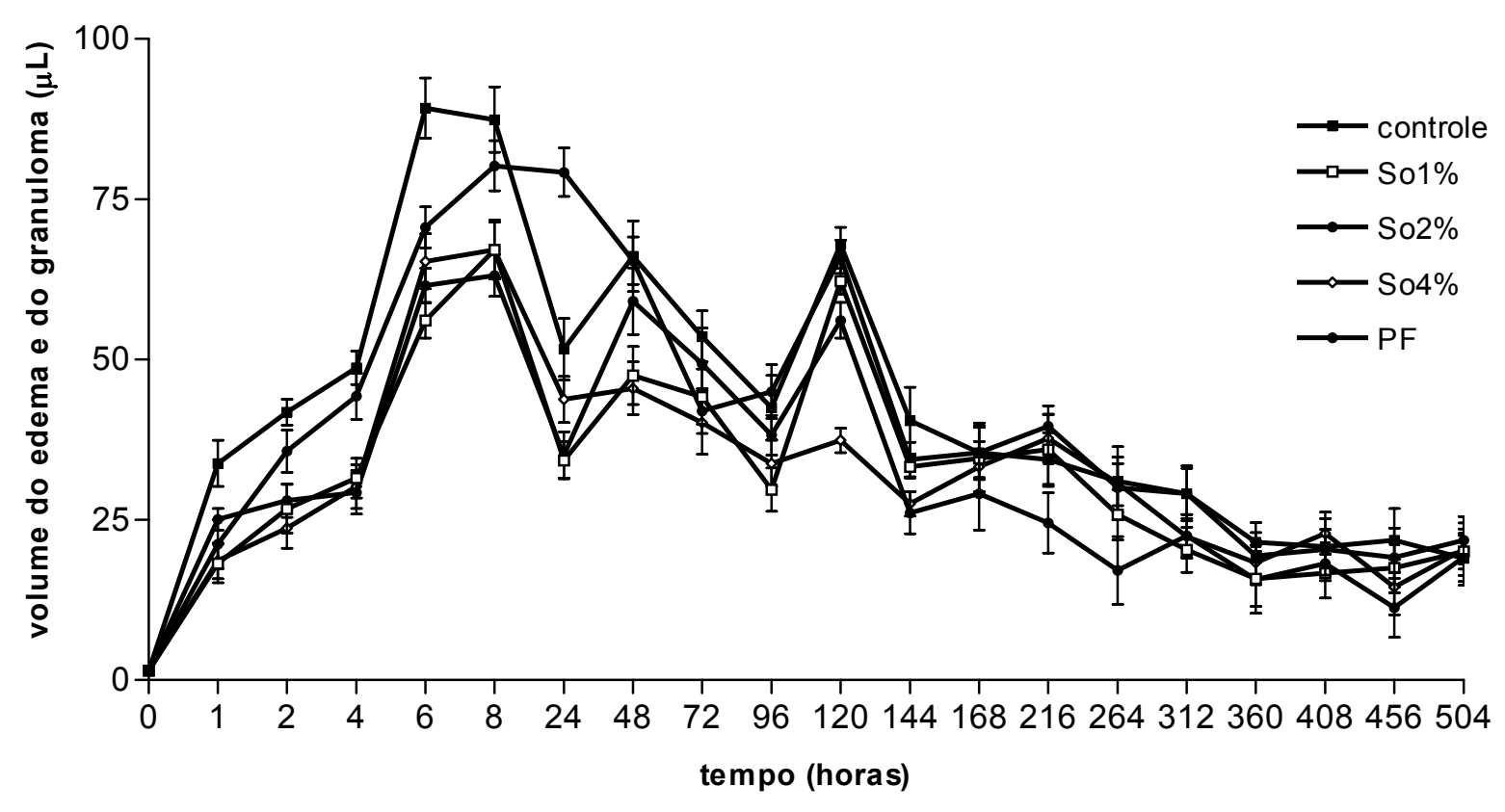

OBS: as diferenças estatisticamente significantes no consumo médio estão identificadas na Tabela 27.

Figura 26 - Volume do edema inflamatório agudo (em $\mu \mathrm{L}$ ) e do granuloma experimental induzido pela inoculação de Onco-BCG no coxim plantar da pata posterior esquerda de ratos, tratados durante 14 dias com diferentes concentrações $(0 \%, 1 \%, 2 \%$ e $4 \%)$ de sementes de S. occidentalis, na ração. São apresentados às médias e os respectivos erros padrões 
Tabela 28 - Número médio de bacilos álcool-ácido resistentes presentes na lesão granulomatosa podal após 21 dias de inoculação de Onco-BCG ( $\left.22^{\circ} \mathrm{dia}\right)$ no coxim plantar da pata posterior esquerda, de ratos tratados durante 14 dias com diferentes concentrações $(0 \%, 1 \%, 2 \%$ e $4 \%)$ de sementes de S. occidentalis, na ração e seu grupo peerfeeding. Foram utilizados 10 animais por grupo.

\begin{tabular}{|c|c|}
\hline & Número de Bacilos \\
\hline Grupos & (média \pm erro padrão) \\
\hline Controle & $45,0 \pm 14,1$ \\
\hline So $1 \%$ & $54,9 \pm 10,8$ \\
\hline So $2 \%$ & $41,7 \pm 14,2$ \\
\hline So $4 \%$ & $36,2 \pm 15,4$ \\
\hline PF & $45,5 \pm 13,2$ \\
\hline
\end{tabular}

Não houve diferença $(p>0,05)$ significante entre os grupos. 
Discussão133

5 DISCUSSÃO 


\section{DISCUSSÃO}

Nas citações da literatura, as perdas econômicas advindas da intoxicação pela S. occidentalis, são bastante significantes, uma vez que os animais intoxicados pela planta desenvolvem anorexia, queda de peso e podem, até mesmo, chegar ao óbito, numa intoxicação aguda (GRAZIANO et al., 1983; HERBERT et al., 1983; SIMPSON et al., 1971).

Tanto as intoxicações naturais como as experimentais vêm reforçando estes achados nas diferentes espécies animais, tais como: bovinos (HENSON et al., 1965), suínos (COLVIN et al., 1986), eqüinos (MARTINS et al., 1986), ovinos (DOLLAHITE; HENSON, 1965), caprinos (BARBOSA-FERREIRA et al., 2005), leporinos (TASAKA et al., 2000), aves (HARAGUCHI et al., 1998) e ratos (WEG, 2001; BARBOSA-FERREIRA et al., 2005).

Além dos achados já descritos, como lesões hepática (IRIGOYEN et al., 1991), muscular (WEG, 2001) e cardíaca (BARROS et al., 1990), recentemente, Silva et al. (2003) mostraram que a ingestão de S. occidentalis por frangos de corte provocou depleção em células linfóides da região medular na bursa de Fabricius, cuja função é a produção de linfócitos $B$, os quais são responsáveis pela síntese de imunoglobulinas (TIZARD, 2000).

Tem sido proposto que a imunodeficiência é uma das principais causas de prejuízos econômicos na criação animal (CHEEKE, 1998; RIET-CORREA et al., 1993); neste sentido, as debilidades físicas causadas pelos efeitos imunotóxicos de plantas podem deixar os animais mais suscetíveis a outras doenças. De fato, cada vez mais se observa que estudos experimentais vêm se ocupando em avaliar os 
efeitos de plantas tóxicas sobre a resposta imune específica e inespecífica (DUGAN; GUBMANN, 1990; HUEZA et al., 2003; VOSS; BRENNECKE, 1991). Deve-se ainda considerar que o sistema imunológico pode estar sendo comprometido mesmo na ausência de qualquer sinal de toxicidade em outro órgão ou sistema (BURNS-NASS et al., 2000).

Assim, o presente estudo objetivou verificar os efeitos da intoxicação pela S. occidentalis em ratos, utilizando metodologias capazes de avaliar parâmetros das respostas inflamatórias e/ou imunológica não-específica, ou seja, da atividade de macrófagos e das espécies reativas de oxigênio e nitrogênio, com a finalidade de verificar se, em mamíferos, ocorreriam modificações semelhantes àquelas encontradas por Silva et al. (2003) em frangos de corte.

Embora várias espécies de mamíferos possam ser utilizadas em ensaios toxicológicos, os ratos são os animais de escolha devido a muitos fatores, entre os quais, destacam-se: sua anatomia e fisiologia bem conhecidas, sua capacidade de desenvolver prole numerosa, a facilidade no seu manuseio e por apresentarem curto ciclo de vida (MUTAI, 2000). Neste sentido, verifica-se que os poucos trabalhos de pesquisa, utilizando-se ratos como sujeitos experimentais, vêm reproduzindo satisfatoriamente alguns sinais clássicos da intoxicação por $S$. occidentalis em animais de criação (BARBOSA-FERREIRA, 2003; CALORE et al., 1997; CALORE et al., 1998; WEG, 2001).

No presente estudo, a escolha das porcentagens de sementes de S. occidentalis $(1 \%, 2 \%$ e $4 \%)$, foi alicerçada no trabalho conduzido, neste mesmo laboratório, em roedores, por Barbosa-Ferreira et al. (2005) e, da mesma maneira, os resultados mostraram que estes ratos, quando submetidos às maiores 
concentrações de sementes desta planta na ração ( $2 \%$ e $4 \%$ ), foram os que apresentaram queda no consumo de ração e água e, conseqüentemente, diminuição do seu peso corporal. Estes achados também corroboram com aqueles descritos por Tasaka et al. (2000), em coelhos, os quais revelaram tais alterações nestes parâmetros com estas mesmas concentrações das sementes da planta.

Um dos fatores que poderiam interferir no consumo de ração e ganho de peso dos animais seria a baixa palatabilidade da planta, verificada por Mercer et al. (1967) e ratificada por outros pesquisadores (CALORE et al., 1998; TASAKA et al., 2000; TOKARNIA et al., 2000). Por outro lado, recente estudo conduzido por BarbosaFerreira (2003), em ratos, que receberam ração comercial e experimental com palatabilizante, demonstrou que a baixa palatabilidade da planta não seria a única responsável pela queda no consumo de ração e sim principalmente devido ao seu efeito tóxico, uma vez que aqueles ratos tratados com a planta associada ao palatabilizante apresentavam, na $2^{\mathrm{a}}$ semana de exposição, queda significante no consumo de ração.

Outro fator que deve ser considerado, no que se refere à queda de peso dos animais expostos à $S$. occidentalis, seria a possibilidade dos ratos apresentarem síndrome de má-absorção intestinal, já que foram observadas fezes pastosas naqueles animais tratados com a maior concentração da planta, o que poderia ser um indicativo desta afecção (BOTSARIS et al., 1995; DUKE, 1929; MULLERLISSNER, 1993). Contudo, o estudo histopatológico da mucosa intestinal dos ratos que receberam a $S$. occidentalis nas diferentes concentrações não mostrou quaisquer alterações sugestivas de injúria intestinal. Da mesma maneira, Brusick e Mengs (1997) administrando, tanto a planta in natura como seus derivados a ratos, 
não encontraram lesões intestinais nos animais submetidos a nenhum destes tratamentos.

Desta forma, com o objetivo de verificar se a diminuição no ganho de peso estaria somente relacionada à queda do consumo de ração ou se isso ocorreria também devido ao efeito tóxico da planta, realizou-se um experimento denominado de peer-feeding, no qual os animais de um grupo recebiam a mesma quantidade de ração que aqueles do grupo tratado com a maior concentração da planta na ração (So4\%); no entanto, esta se apresentava isenta de sementes de S. occidentalis.

Como houve maior ganho de peso dos animais pertencentes ao grupo peerfeeding, quando comparado com aquele obtido dos ratos do grupo So $4 \%$, pode-se sugerir enfaticamente que a alteração nesse parâmetro não está relacionada à desnutrição e sim, provavelmente, ao fato de que o princípio ativo tóxico da S. occidentalis estaria interferindo negativamente no metabolismo animal. Entretanto, com os dados aqui obtidos, não seria possível sugerir qual seria a fisiopatologia deste processo.

A inclusão deste grupo peer-feeding serviu, também, para a melhor interpretação dos dados relativos à avaliação hematológica, imunológica e inflamatória dos efeitos tóxicos da S. occidentalis nos animais, pois, pode-se supor que distúrbios na alimentação devam levar ao comprometimento destas funções. De fato, Borelli et al. (1995) demonstraram que a má-nutrição ou desnutrição interfere em parâmetros hematopoéticos e, secundariamente, na celularidade e na estrutura dos tecidos hemato-linfopoéticos. Além disso, sabe-se que a não absorção de nutrientes modifica a resposta imune tanto especifica como inespecífica (SOUZA et al., 2001). 
Nesta direção, como os animais que foram tratados com a maior dose de sementes da S. occidentalis apresentaram anemia microcítica e hipocrômica, mas não os ratos do grupo peer-feeding, pode-se sugerir que este efeito sobre o sistema hematológico ocorra por ação da toxina presente nesta planta. Portanto, a anemia descrita em ratos e em frangos de corte por Adam et al. (2001) e Nakage et al. (2000), talvez não estivesse relacionada à alteração do estado nutricional destes animais e sim ao efeito tóxico direto da planta no tecido sangüíneo. Reforça esta suposição o fato de que, neste trabalho, ratos expostos à dieta com $4 \%$ de S. occidentalis não apresentaram modificações nos níveis séricos de proteínas totais, albumina e glicose.

De forma similar, é amplamente conhecido que a má-nutrição tem grande importância no tamanho dos órgãos linfóides, particularmente no timo (GOLDEN et al., 1977; PRENTICE, 1999; SAVINO, 2002). Como se verificou nesta pesquisa diminuição do consumo de ração dos ratos submetidos ao tratamento com a planta, assim como naqueles frangos de corte, também tratados com a $S$. occidentalis (SILVA et al., 2003), utilizou-se também o grupo peer-feeding, neste experimento para se descartar ou não a possibilidade da influência do estado nutricional sobre o peso e a funcionalidade desses órgãos e, mais uma vez, verificou-se que os animais do grupo peer-feeding não apresentaram diminuição no peso, tamanho e celularidade destes tecidos.

Por outro lado, este trabalho mostrou que os ratos submetidos à ração com So4\%, tiveram redução tanto no peso relativo, como no tamanho do timo, além de depleção do estroma medular e cortical deste órgão. Neste sentido, os animais tratados com So2\% e So4\%, embora não tenham apresentado diminuição no peso relativo do baço, apresentaram redução na região cortical deste órgão. Em relação a 
este aspecto, sabe-se que a atrofia cortical do timo está diretamente relacionada com a sensibilidade dos linfócitos $\mathrm{T}$, quando expostos a fatores intrínsecos e extrínsecos, os quais podem inibir o recrutamento, a diferenciação e o crescimento dos progenitores de células T na medula óssea (BERTHIAUME et al., 1999). Tais resultados podem sugerir que a $S$. occidentalis seja capaz de comprometer a resposta imune específica de indivíduos expostos a esta planta. Entretanto, quanto ao baço, no presente momento não se pode sugerir, se esta redução estaria relacionada ao efeito direto do(s) princípio(s) tóxico(s) da planta sobre este órgão ou se seria devido à depleção do timo que, conseqüentemente, teria causado a redução da população de células $B$.

É sabido que a medula óssea apresenta padrões de celularidade que são relativamente independentes das flutuações fisiológicas e, por esta razão, as metodologias utilizadas para se quantificar as células do tecido hematopoético são consideradas sensíveis e confiáveis (HARVEY, 1996). Neste sentido, a contagem de células totais deste tecido realizada neste trabalho revelou um aumento do número das mesmas em ratos tratados com So $1 \%$ e So2\%; embora paradoxal, estes dados concordam com aqueles obtidos por Bin-Hafeez et al. (2001) e Voss e Brennecke (1991), que utilizaram, respectivamente, sementes de Cassia obtusifolia e extrato aquoso de S. occidentalis. Contudo, a fisiopatologia deste fenômeno até o momento é desconhecida e, portanto, não se sabe se estes efeitos estariam relacionados à ação específica da S. occidentalis sobre a eritropoese ou se a anemia ocorreria como uma resposta secundária ao aumento das outras linhagens precursoras da medula óssea. Todavia, esta última hipótese deve ser considerada com cautela, uma vez que ensaios para a avaliação de progenitores celulares da medula óssea não foram realizados em nenhuma pesquisa desta natureza; além disso, estes dados 
também são sugestivos de que baixas concentrações de sementes de S. occidentalis seriam capazes de induzir a hematopoese.

Outro aspecto que este estudo procurou abordar foi o efeito da S. occidentalis sobre os processos inflamatório agudo e crônico, já que várias espécies de Senna têm sido amplamente utilizadas em medicina humana, particularmente na medicina tradicional indiana (NADKARNI, 1982), devido as suas várias propriedades farmacológicas (LEMLI, 1988), dentre elas o combate a processos inflamatórios, como o reumatismo (KIRTHIKAR et al., 1969).

Vários são os métodos utilizados para a avaliação experimental da resposta inflamatória; optou-se por utilizar, neste estudo, o edema agudo de pata induzido pela carragenina (BILLINGHAM; DAVIES, 1979; VAN ARMAN et al., 1979; WINTER et al., 1962) e o edema crônico desencadeado pelo BCG (PAULINO, 1997), já que estas metodologias são aquelas de eleição para avaliação de novas agentes antiflogísticos (SADIQUE et al., 1987; WINTER et al., 1962); além disto, estes protocolos já estão muito bem estabelecidos neste laboratório.

Na presente pesquisa, observou-se a redução do volume de edema agudo e crônico em todos os animais experimentais, sendo estes dados concordantes com aqueles encontrados por Sadique et al. (1987), os quais verificaram estes mesmos efeitos, também em ratos, tratados com o extrato aquoso desta planta. Estes mesmos autores aventaram duas hipóteses: a primeira foi a de que a S. occidentalis possui ação inibitória sobre a fosfolipase $A_{2}$, resultando na redução da síntese do ácido araquidônico, um precursor para a síntese de prostaglandinas, as quais sabidamente estão diretamente relacionadas à manutenção do edema inflamatório (MARTINEZ; BOLÃNOS, 1979); a segunda possibilidade levantada pelos autores, 
seria a indução da estabilização da membrana lisossomal, acarretando no impedimento da liberação de lisoenzimas. Entretanto, nenhum outro estudo pode, até o momento, comprovar estas teorias. Além disso, será ainda necessário saber, qual(s) o(s) princípio(s) ativo(s) presente(s) na planta que estaria(m) envolvido(s) neste efeito antiinflamatório; assim, propõe-se, futuramente, pesquisar os possíveis mecanismos desta ação desencadeada pela S. occidentalis.

Em adição, um outro parâmetro ligado à resposta imune e inflamatória que pode ser comprometido por uma injúria tóxica é a atividade de macrófagos. Assim, os macrófagos residentes distribuídos por muitos órgãos são responsáveis pelos sinais de origem inflamatória ou imunológica, os quais estimulam funções complexas destas células, como o processamento e apresentação de antígenos, a fagocitose e a destruição de células tumorais (COSTA ROSA et al., 1994). Estas células são largamente distribuídas em vários tecidos, na forma de fagócitos mononucleares residentes, desenvolvendo funções imunológicas, fisiológicas e homeostáticas (MILLER; HUNT, 1996). Os macrófagos representam um modelo muito útil para estudos relativos ao espraiamento de células, pela rapidez que desencadeiam este processo. Além disso, estas células também são muito competentes para a fagocitose, que pode ser modulada in vitro e in vivo por diferentes estados ligados à sua ativação, o que afeta de forma considerável a sua taxa de espraiamento e outras propriedades biológicas (RABINOVITCH, 1973; RABINOVITCH; DeSTEFANO, 1973).

Conforme descrição de Miller e Hunt (1996), os macrófagos também são conhecidos por produzirem grande variedade de outros produtos biológicos, tais como: lisozimas, proteases, lipases e outras enzimas, vários componentes do sistema complemento, fatores de coagulação sangüínea, proteínas de ligação e 
adesão, subprodutos reativos do oxigênio (como radicais superóxido e peróxido de hidrogênio), óxido nítrico, eicosanóides (como prostaglandinas, tromboxanos e leucotrienos), o que Ihes confere excelente capacidade multifuncional. Ainda, segundo Crocker e Milon (1991), estas células são reconhecidas pelo seu potencial na regulação da hematopoese.

Ressalte-se que naqueles experimentos para a avaliação da atividade de macrófagos, administrou-se tioglicolato para elicitação das células peritoneais (REIKO; WERB et al., 1984) e, em seguida, inoculou-se LPS para ativação das mesmas (KUMAR et al., 1997), com a finalidade de se obter um maior número possível de células ativadas. O objetivo destes procedimentos foi a realização de ensaios mais precisos, não só para avaliação do espraiamento e fagocitose, como também para a produção de água oxigenada e óxido nítrico pelos macrófagos.

Deste modo, no presente estudo, as medidas da concentração de água oxigenada e óxido nítrico mostraram redução significante naqueles ratos tratados com a maior concentração da S. occidentalis.

Analisando em conjunto, os dados relativos aos efeitos da S. occidentalis na atividade de macrófagos, pouco poderia ser especulado neste momento. Contudo, no que se refere à redução da produção de água oxigenada e óxido nítrico, uma possível explicação seria a de que haveria uma alteração da função mitocondrial, diminuindo, assim, a produção destas espécies reativas de oxigênio e nitrogênio; de fato, é sabido que a $S$. occidentalis promove o desacoplamento da fosforilação oxidativa e a desestabilização das mitocôndrias (CAVALIERI et al., 1997; GRAZIANO et al., 1983). 
Concluindo, o presente trabalho mostrou que, também em mamíferos, a S. occidentalis pode comprometer o sistema imunológico, haja vista as alterações encontradas no timo e baço dos ratos expostos à planta. Além disso, este estudo revelou que a $S$. occidentalis também promove efeitos tóxicos sobre eritrócitos e alterações na resposta inflamatória. Ressalte-se, ainda, que tais achados não se devem a possíveis alterações nutricionais promovidas pela queda do consumo de alimento pelos animais, e sim ao efeito direto da $S$. occidentalis, o que reforça a necessidade de se incluir um grupo peer-feeding em protocolos para estudos imunotoxicológicos. Assim, em continuidade a esta pesquisa, são objetivos futuros verificar o(s) mecanismo(s) envolvido(s) nestes processos fisiopatológicos, bem como o(s) princípio(s) ativo(s) responsável(eis) por tais ações produzidas pela planta. 
Conclusão 144

6 CONCLUSÃO 


\section{CONCLUSÕES}

- A queda no consumo de água e ração pelos ratos, estaria diretamente relacionada aos efeitos tóxicos da S. occidentalis e não somente devido à sua baixa palatabilidade;

- A diminuição no ganho de peso dos ratos tratados com as diferentes concentrações de S. occidentalis não estaria relacionada exclusivamente com a desnutrição, mas também devido à ação do(s) princípio(s) ativo(s) tóxico(s) desta planta em interferir(em) negativamente no metabolismo animal;

- A S. occidentalis foi capaz de interferir no sistema hematológico dos ratos tratados com a maior concentração de sementes da planta, induzindo a anemia microcítica e hipocrômica;

- A intoxicação por S. occidentalis foi capaz de promover alterações nos órgãos linfóides de ratos intoxicados com a planta, causando redução no peso relativo e tamanho do timo; além de depleção do estroma medular e cortical deste órgão e redução na região cortical do baço

- Ratos tratados com S. occidentalis, nas concentrações mais baixas $(1 \%$ e $2 \%$ ), apresentaram maior número total de células da medula óssea. 
- A S. occidentalis foi capaz de reduzir o edema inflamatório agudo e crônico, em ratos tratados com as diferentes concentrações da planta na ração;

- A administração de $S$. occidentalis reduziu a produção de água oxigenada e de óxido nítrico em ratos tratados com a maior concentração da planta;

- A adição de um grupo peer-feeding mostrou ser fundamental para se descartar a influência do estado nutricional sobre todos os parâmetros aqui avaliados. 


\section{REFERÊNCIAS}

ADAM, S. E .I.; AL-YAHYA, M. A.; AL-FARHAN, A. H. Combined toxicity of Cassia occidentalis and Citrullus colocynthis in rats. Veterinary and Human Toxicology, v. 43, n. 2, p. 70-72, 2001.

ADAMS, D. O.; HAMILTON, T. A. The cell biology of macrophage activation. Annual Reviews of Immunology, v. 2, n. 2, p. 283-291, 1984.

AGARWAL, R.; DIWANAY, S.; PATKI, P.; PATWARDHAN, B. Studies on immunomodulatory activity of Withania somnifera (Ashwagandha) extracts in experimental immune inflammation. Journal of Ethnopharmacology, v. 67, n. 1, p.27-35, 1999.

BAILEY, L. H.(Ed.). Manual of cultivated plants. New York: Macmilan, 1977. p. 17.

BAKER, L. A.; CAMPBELL, P. A. Thioglycollate medium decreases resistance to bacterial infection in mice. Infectology and Immunology, v.27, n. 3, p. 455-460.

BARBOSA-FERREIRA, M.; DAGLI, M. L. Z.; MAIORKA, P. C.; GÓRNIAK, S. L. Long-Term Intoxication by Senna occidentalis seeds in rats. Food and Chemical Toxicology, 2005. (no prelo).

BARBOSA-FERREIRA, M. Estudo dos efeitos tóxicos produzidos pela administração prolongada de sementes de Senna occidentalis. Avaliação em ratos e caprinos. 2003. 139 f. Dissertação (Mestrado em Ciências) - Faculdade de Medicina Veterinária e Zootecnia, Universidade de São Paulo, São Paulo, 2003.

BARROS, C. S. L. Intoxicação por plantas que afetam o sistema muscular intoxicação por Senna occidentalis. In: RIET-CORREA, F.; MENDEZ, M. C.; SCHILD, A. IL. (Eds.). Intoxicação por plantas e micotoxicoses em animais domésticos. Pelotas: Hemisfério Sul do Brasil, 1991. p. 201-223. 
BARROS, C. S. L.; ILHA, M. R. S.; BEZERRA J.R., P. S.; LANGOHR, I. M.; KOMMERS, G. D. Intoxicação por Senna occidentalis (Leg. Caesalpinoideae) em bovinos em pastoreiro. Pesquisa Veterinária Brasileira, v. 19, n. 3/4, p. 68-70, 1999.

BARROS, C. S. L.; PILATI, C.; ANDUJAR, M. B.; GRAÇA, D. L.; IRIGOYEN, L. F.; LOPES, S. T.; SANTOS, C. F. Intoxicação por Cassia occidentalis (Leg Caesalpinoideae) em bovinos. Pesquisa Veterinária Brasileira, v. 10, n. 1, p. 47-58, 1990.

BERTHIAUME, F.; APARICIO, C. L.; EUNGDAMRONG, J.; YARMUSH, M. L. Age and disease-related decline in immune function: an opportunity for "thymus-boosting" therapies. Tissue Engineering, v. 5, n. 6, p. 499-514, 1999.

BILLINGHAM, M. E. J.; DAVIES, J. E. Experimental mode of arthritis in animal as screening test for drugs to treat arthritis in man. In: VANE, J. R.; FERREIRA, S. H. (Ed.). Anti-inflammatory Drugs, New York: Springer-Verlag, 1979. p. 109.

BIN-HAFEEZ, B.; AHMAD, I.; HAQUE, R.; RAISUDDIN, S. Protective effect of Cassia occidentalis $\mathrm{L}$. on cyclophosphamide-induced suppresion of humoral immunity in mice. Journal of Ethnopharmacology, v. 75, n. 1, p. 13-18, 2001.

BIRGEL, E. H. Hematologia clínica veterinária. In: BIRGEL, E. H.; BENESI, F. J. (Ed.). Patologia clínica veterinária. São Paulo: Sociedade Paulista de Medicina Veterinária, 1982. p. 2-34.

BORELLI, P.; MARIANO, M.; BOROJEVIC, R. Protein malnutrition: effect on myeloid cell production and mobilization into inflammatory reactions in mice. Nutrition Research, v. 15, n. 10, p. 1477-1485, 1995.

BOTSARIS, A. S.; BOORHEM, R. L.; CORREAA, C. B. V. Fitoterapia chinesa e plantas brasileiras. São Paulo: Cone, 1995. 700 p.

BRUSICK, D.; MENGS, U. Assessment of the genotoxic risk from laxative Senna products. Environmental and Molecular Mutagenesis, v. 29, n. 1, p. 1-9, 1997. 
BURNS-NASS, L. A.; MEADE, J.; MUNSON, A. E. Toxic responses of the immune system. In KLAASSEN, C.D. (Ed.). Casarett and Doull's toxicology: the basic science of poisons. 6th ed. New York: Mc Graw-Hill, 2000. p. 419.

CALORE, E. E.; CAVALIERE, M. J.; HARAGUCHI, M.; GÓRNIAK, S. L.; DAGLI, M. L. Z.; RASPANTINI, P. C. F.; CALORE, N. M. P. Experimental mitochondrial myopathy induced by chronic intoxication by Senna occidentalis seeds. Journal of Neurological Sciences, v. 146, n. 1, p. 1-6, 1997.

CALORE, E. E.; CAVALIERE, M. J.; HARAGUCHI, M.; GÓRNIAK. S. L.; DAGLI, M. L. Z.; RASPANTINI, P. C. F.; CALORE, N. M. P.; WEG, R. Toxic peripheral neuropathy of chicks feed Senna occidentalis seeds. Ecotoxicology and Environmental Safety, v. 39, n. 1, p. 27-30, 1998.

CAVALIERE, M. J.; CALORE, E. E.; HARAGUCHI, M.; GÓRNIAK, S. L.; DAGLI, M. L. Z.; RASPANTINI, P. C. F.; CALORE, N. M.; WEG, R. Mitochondrial myopathy in Senna occidentalis feed chicken. Ecotoxicology and Environmental Safety, v. 37, n. 2, p. 181-185, 1997.

CHEEKE, P. R. Natural toxicants in feeds, forages and poisonous plants. Danville: Interstate, 1998. 479 p.

COLVIN, B. M.; HARRISON, L. R.; SANGSTER, L. T.; GOSSER, H. S. Cassia occidentalis toxicosis in growing pigs. Journal of American Veterinary Medical Association, v. 189, n. 4, p. 423-426, 1986.

COSTA ROSA, L. F. B. P.; SAFI, D. A.; CURI, R. Effect of thioglycollate and BCG stimuli on glucose and glutamine metabolism in rat macrophages. Journal of Leukocyte Biology, v. 56, n.1, p. 10-14, 1994.

CROCKER, P. R.; MILON, G. Macrophages in control of hematopoiesis. In: LEWIS, C. E.; McGEE, J. O'. (Ed.). The Macrophages: the natural imunne system. New York: Oxford University Press, 1991, p. 117.

DHULEY, J. N. Effect of some Indian herbs on macrophage functions in ochratoxin A tretated mice. Journal of Ethonopharmacology, v. 58, n. 1, p. 15-20,1997. 
DING, A. H.; NATHAN, C. F.; STUEHS, D. J. Release of reactive nitrogen intermediates and reactive oxygen intermediates from mouse peritoneal macrophages. Journal of Immunological Methods, v. 141, n. 7, p. 2407-2412. 1988.

DOLLAHITE, J. W.; HENSON, J. B. Toxic plants as the etiologic agent of myophaties in animals. American Journal of Veterinary Research, v. 26, n. 112, p. 749-752, 1965.

DUGAN, G. M.; GUMBMANN, M. R. Toxicological evaluation of sicklepod and black nightshade seeds in short-term feeding studies in rats. Food and Chemical Toxicology, v. 28, n. 2, p. 101-107, 1990.

DUKE, A. J. Handbook of medical herbs. Florida: CRC Press, 1929. p. 102-103.

DWYER. D. D. Effects of poisonous plants on livestock In: KEELER, R. F.; VAN KAMPEN, K. R.; JAMES, L. F. Effects of poisonous plants on livestock. Nova York: Academic Press, 1978. p.13-21.

EL-SAYED, N. Y.; ABDELBARI, E. M.; MAHMOUD, O. M.; ADAM, S. E. I. The toxicity of Cassia senna in Nubian goats. The Veterinary Quarterly, v. 45, n. 2, p. 80-85, 1993.

GAD, S. C.; WEIL, C. S. Statistics for toxicologists. In: HAYES, A. W. (Ed.). Principles and methods of toxicology. New York: Raven Press, 1989. p. 435-483.

GALE, R. P. Myelosuppressive effects of antineoplastic chemotherapy. In: TESTA, N. G.; GALE, R. P. (Eds.). Hematopoesis. Long-term effects of chemotherapy. New York: Marcel Dekker, 1988. p. 63-73.

GEMSA, D.; STEGGEMANN, L.; MENZEL, J.; TILL, G. Release of cyclic AMP from macrophages by stimulation with prostaglandins. Journal of Immunology, v. 114, n. 4, p. 1422-1424, 1975. 
GOLDEN, M. H.; JACKSON, A. A.; GOLDEN, B. E. Effect of zinc on thymus of recently malnourished children. Lancet, v. 19, n. 2, p. 1057-1059, 1977.

GRAPHPAD INSTAT. Instat guide to choosing and interpreting statistical tests, version 3.00. San Diego, 1998. Disponível em: <http://www.graphpad.com>. Acesso em: 23 mar. 2004.

GRAPHPAD PRISM. Graphpad software. Version 3.00. San Diego, 1999. Disponível em: < http://www.graphpad.com>. Acesso em 23 mar. 2004.

GRAZIANO, M. J.; FLORY, W.; SEGER, C. L.; HERBERT, C. D. Effects of Cassia occidentalis extract in the domestic chicken (Gallus domesticus). American Journal of Veterinary Research, v. 44, n. 7, p. 1238-1244, 1983.

GUEST, I.; UETRECHT. J. Drugs toxic to the bone marrow that target the stromal cells. Immunopharmacology, v. 46, n. 2, p. 103-112, 2000,

HARAGUCHI, M.; GÓRNIAK, S. L.; CALORE, E. E.; CAVALIERE, M. J.; RASPANTINI, P. C. F.; CALORE, N. M. P.; DAGLI, M. L. Z. Muscle degeneration in chickens caused by Senna occidentalis seeds. Avian Pathology, v. 27, n. 4, p. 346351, 1998.

HARAGUCHI, M.; GÓRNIAK, S. L.; DAGLI, M. L. Z.; FORMIGONE, F.; RASPANTINI, P. C. F. Determinação dos constituintes químicos das frações tóxicas de fedegoso (Senna occidentalis (L.)). In: Reunião Anual da Sociedade Brasileira de Química, 19., 1996, Poços de Caldas, MG. Anais... v.1, p.096.

HARVEY, J. W. The erythrocyte: Physiology, metabolism, and biochemical disorders. In: KANEKO, J. J. Clinical biochemistry of domestic animals. San Diego: Academic Press, 1996.

HENSON, J. B.; DOLLAHITE, J. W.; BRIDGES, C. H.; RAO, R. R. Myodegeneration in cattle grazing Cassia specie. Journal of American Veterinary Medical Association, v. 147, n. 2, p. 142-145, 1965. 
HERBERT, C. D.; FLORY, W.; SEGER, C.; BLANCHARD, R. E. Preliminary isolation of a myodegenerative toxic principle from Cassia occidentalis. American Journal of Veterinary Research, v. 44, n. 7, p. 1370-1374, 1983.

HOAGLAND, H. C. Hematologic complications of câncer chemotherapy. Seminary of Oncology, v. 9, n. 1, p. 95-102, 1982.

HOEHNE, F. C. Plantas e substâncias vegetais tóxicas e medicinais. São Paulo: Departamento de Botânica do Estado de São Paulo, 1939. p. 140-149.

HOPPER, K. E. Kinetics of macrophage recruitment and turnover in peritoneal inflammatory exudate induced by Salmonella or thioglycollate broth. Journal of Leukocyte Biology, v. 39, n. 4, p. 435-446, 1986.

HUEZA, I. M.; FONSECA, E. S. M.; PAULINO, C. A.; HARAGUCHI, M.; GÓRNIAK, S. L. Evaluation of immunomodulatory activity of Ipomoea carnea on peritoneal cells of rats. Journal of Ethnopharmacology, v. 87, n. 2, p. 181-186, 2003.

IRIGOYEN, L. F.; GRAÇA, D. L.; BARROS, C. S. L. Intoxicação experimental por Cassia occidentalis (leg. Caesalpinoideae) em eqüinos. Pesquisa Veterinária Brasileira, v. 11, n. 1/2, p. 35-44, 1991.

JOLY, A. B. Botânica: introdução à taxonomia vegetal. São Paulo: Editora Nacional, 1977. $777 \mathrm{p}$.

JOO, J. S.; EHRENPEIS, E. D.; GONZALEZ, L.; KAYE, M.; BRENO, S.; WEXNER, S. D.; ZAITMAN, D. Secrets K. alterations in colonic anatomy induced by chronic stimulant laxatives: the cathartic colon revised. Journal Clinical Gastroenterology, v. 4, n. 2, p. 283-286, 1998.

KARNOVSKY, M. L.; LAZDINS, J. K. The biochemical criteria for activated macrophages. Journal of Immunology, v. 121, n. 3, p. 808-813, 1978. 
KIM, H. L.; CAMP, B. J.; GRIGSBY, R. D. Isolation of N-metimorpholine from the seeds of Cassia occidentalis L. (Coffee Senna). Journal of Agricultural Food Chemistry, v. 19, n.1, p. 198-199, 1971.

KIRTHIKAR, K. R.; BASU, B. D.; AN, I. C. S. (Ed.). Indian Medicinal Plants, New Delhi: Periodical Experts, 1969. p. 623.

KUBY, J. Cells and organs of the immunology system. In: KUBY, J. (Ed.). Immunology, New York: WH Freeman and Co. 1997. p. 47-83.

KUMAR, V.; COTRAN, R. S.; ROBBINS, S. L. Patologia Básica. Rio de Janeiro: Guanabara Koogan, 1997. 608 p.

LANNING, L. L. Toxicological Pathology Assessment. In: HASCHEK, W. M.; ROSSEAUX, C. G. (Eds.). Fundamental of Toxicology Pathology. Canada: Academic Press.,1998. p. 315-324.

LAWRENCE, D. A.; KIM, D. Central/peripheral nervous system and immune response. Toxicology, v. 142, n. 3, p. 189-291, 2000.

LEMLI, J. Senna an old drug in modern research. Pharmacology, v. 36, p. 3-6, 1988, supplement 1.

LORENZI, H. Plantas daninhas do Brasil: terrestres, aquáticas, parasitas, tóxicas e medicinais. Nova Odessa: Plantarum, 1991. 273 p.

LYDYARD, P.; GROSSI, C. Sistema Linfóide. In: ROITT, I.; BROSTOFF, J.; MALE, D. Imunologia, São Paulo: Manole. 1999. p. 31-38.

MARTIN, B. W.; TERRY, M. K.; BRIDGES, E. M.; BAILEY, J. R. Toxicity of Cassia occidentalis in the horse. Veterinary and Human Toxicology, v. 23, n. 6, p. 416-417, 1981. 
MARTÍNEZ, M.; BOLAÑOS, R. Antiinflmatorios esteroides y no esteroideos. In: BAZERQUE, P. M.; MARTíNEZ, M.; MAGGI, N. D.; CERASO, O. L.; BOLANÕS, R. Farmacologia de la inflamación y del dolor. Buenos Aires: Ediciones Toray Argentina. 1979. p. 57-85.

MARTINS, E.; MARTINS, V. M. V.; RIET-CORREA, F.; SONCINI, R. A.; PARABONI, S. V. Intoxicação por Cassia occidentalis (Leguminoseae) em suínos. Pesquisa Veterinária Brasileira, v. 6, n. 2, p. 35-38, 1986.

MERCER, H. D.; NEAL, F. C.; HIMES, J. A.; EDDS, G. T. Cassia occidentalis toxicosis in cattle. Journal of American Veterinary Medical Association, v. 151, n. 6, p. 735-741, 1967.

MILLER, L.; HUNT, J. S. Sex steroid hormones and macrophage function. Life Sciences, v. 59, n. 1, p. 1-14, 1996.

MIZEL, S. B.; DAYER. J. M.; KRANE, S. M.; MERGEN-HAGEN, S. E. Stimulation of rheumatoid synovial cell collagenase and prostaglandin production by partially purified lymphocyte activing factor (Irterleukin - 1). Proceedings of the National Academy of Science of the United States of America, v. 78, n. 4, p. 2474-2477, 1981.

MULLER-LISSNER, S. A. Adverse effects of laxatives: fact and fiction. Pharmacology, v. 47, n. 1, p. 138-145, 1993.

MUTAI, M. National and international guidelines for the conduct of chemical safety studies: choice of strains. In. KRINKE, G. J. The laboratory rat. San Diego: Academic Press. 2000. p. 17-27.

NADKARNI, K. M. Indian Materia Medica. Bombay: Popular Pirakhasam. 1982. p. 271-292. 
NAKAGE, A. P. M.; MACARI, M.; NAKAGHI, L. S.; MALHEIROS, E. B.; VASQUES, L. H.; SECATO, E. R. Haematological and hormonal studies from broiler chickens fed with corn contaminants: Crotalaria spectabilis and Senna occidentalis. Brazilian Journal Veterinary Research Animal Science, v. 37, n. 5, p. 377-381, 2000.

O'HARA, P. J.; PIERCE, K. R. A toxic cardiomyopathy caused by Cassia occidentalis. II. Biochemical studies in poisoned rabbits. Veterinary Pathology, v. 11, n. 12, p. 110-124, 1974a.

O'HARA, P. J.; PIERCE, K. R; READ, W. K. A toxic cardiomyopathy caused by Cassia occidentalis I. Morphlogical studies in poisened rabbits. Veterinary Pathology. v. 11, n. 2, p. 97-109, 1974b.

O'HARA, P. J.; PIERCE, K. R.; READ, W. K. Degenerative myopathy associated with the ingestion of Cassia occidentalis $\mathrm{L}$. Clinical and pathologic features of the experimental disease. American Journal of Veterinary Research, v. 30, n. 12, p. 2173-2180, 1969.

PAGE, R. K.; VEZEY, S.; CHARLES, O. W.; HOLLIFIELD, D. T. Effects on feed consumption and egg production of coffee bean seed (Cassia occidentalis) fed to white Leghorn hens. Avian diseases, v. 21, n. 1, p. 90-96, 1977.

PAN, L. C.; WILSON, D. W.; SEAL, H. L. Strain differences in the response of Fischer 344 and spague-Dawley rats to monocrotaline induced vascular disease. Toxicology, v. 79, n. 1, p. 21-35, 1993.

PASSETI, T. A. Regulação genética de atividades funcionais de macrófagos inflamatórios. Influência na resistência à infecção experimental pelo Toxoplasma gondii. 1993. 87 f. Dissertação (Mestrado em Ciências). Faculdade de Ciências Farmacêuticas da Universidade de São Paulo, São Paulo, 1993.

PAULINO, C. A. Influência do diazepam sobre parâmetros das respostas inflamatórias aguda e crônica de ratos submetidos ou não ao estresse pelo frio. 1997. $152 \mathrm{f}$. Tese (Doutorado em Ciências). Faculdade de Medicina Veterinária e Zootecnia da Universidade de São Paulo, São Paulo, 1997. 
PICK, E.; KEISARI, Y. A simple colorimetric method for the mesaurement of hydrgen peroxide produce by cell in culture. Journal of Immunological Methods, v. 38, n. 2, p.161-170, 1980.

PICK, E.; MIZEL, D. Rapid microssays for the measurement of superoxide and hydrogen peroxide production by macrophages in culture sing and automatic enzyme immunossay. Journal of Immunological Methods, v. 46, n. 2, p. 211-226. 1981.

PIMENTEL, F.G. (Ed.). Curso de estatística experimental. Piracicaba: Nobel, 1981. $430 \mathrm{p}$.

PRENTICE, A. M. The thymus: a barometer of malnutrition. British Journal of Nutrition, v. 81, n. 5, p. 345-347, 1999.

RABINOVITCH, M. Macrophage spreading in vitro. In: VAN FURTH, R. (Ed.). Mononuclear Phagocytes in Immunity Infection and Phatology. Oxford: Blackwell Scientific Pub, p. 369-385, 1973.

RABINOVITCH, M.; De STEFANO, M. J. Macrophage spreading in vitro I. Induces of spreading. Experimental Cell Research, v. 77, n. 3, p. 323-334, 1973.

RAISUDDIN, S.; SINGH, K. P.; ZAIDI, S. I. A; SAXENA, A. K.; RAY, P. K.; Effects of aflatoxin on lymphoid cells of weanling rats. Journal of Applied Toxicology, v. 10, n. 4 , p. $245-250,1990$.

REIKO, T.; WERB, Z. Secretory products of macrophages and their physiological functions. American Journal of Physiology, v. 246, n. 15, p. 1-9, 1984.

RIET-CORREA, F.; MENDEZ, M. C.; SCHILD, A. L. Intoxicações por plantas e micotoxicoses em animais domésticos. Pelotas: Hemisfério Sul do Brasil, 1993. $340 \mathrm{p}$.

RODRIGUES, U.; RIET-CORREA, F.; MORAES, N. Intoxicação experimental em suínos com baixas concentrações de Senna occidentalis (Leg. Caesalpinoideae) na ração. Pesquisa Veterinária Brasileira, v. 13, n. 3/4, p. 57-66, 1993. 
ROGERS, R. J.; GIBSON, J.; REICHMANN, K. G. The toxicity of Cassia occidentalis for cattle. Australian Veterinary Journal, v. 55, n. 9, p. 408-412, 1979.

RUSSO, M.; TEIXEIRA, H. C.; MARCONDES, M. C. G.; BARBUTO, J. A. N.. Superoxide impendent hydrogen peroxide release by activated macrophages. Brazilian Journal Biology Research, v. 22, n. 10, p. 1271-1273, 1989.

SADIQUE, J.; CHANDRA, T.; THENMOZHI, V.; ELANGO, V. Biochemical modes of action of Cassia occidentalis and Cardiosperum halicacabum in inflammation. Journal of Ethnopharmacology, v. 19, n. 2, p. 201-212, 1987.

SANDERSON, B. J. S.; CLARK, A. M. Micronuclei in adult and foetal mice exposed in vivo heliotrine, urethane, monocrotaline and benzidine. Mutation Research, v. 285, n. 1, p. 27-33, 1993.

SAVINO, W. The thymus gland is a target in malnutrition. European Journal of Clinical Nutrition, v. 56, n. 1, p. S46-S49, 2002.

SILVA, T. C.; GÓRNIAK, S. L.; OLORIS, S. C. S.; RASPANTINI, P. C.; HARAGUCHI, M.; DAGLI, M. L. Z. Effects of Senna occidentalis on chick bursa of Fabricius. Avian pathology, v. 32, n. 6, p. 633-637, 2003.

SIMPSON, C. F.; DAMRON, B. L.; HARMS, R. H. Toxic myopathy of chickens fed Cassia occidentalis seed. Avian Disease, v. 15, n. 2, p. 284-290, 1971.

SNEDCOR, G. W. Statistical methods. Ames: College Press, 1946. 324 p.

SOUZA, I. P.; KANG, H. C.; NARDINELLI, L.; BORELLI, P. Desnutrição proteica: efeito sobre o espraiamento, fagocitose e atividade fungicida de macrófagos peritoneais. Revista Brasileira de Ciências Farmacêuticas, v. 37, n. 2, p. 143-151, 2001. 
TASAKA, A. C. Estudo da toxicidade da Senna occidentalis em coelhos. I Avaliação em animais durante a fase de crescimento. II - Efeitos perinatais. São Paulo. 2000. 120 f. Tese (Doutorado em Ciências). Faculdade de Medicina Veterinária e Zootecnia da Universidade de São Paulo, São Paulo, 2000.

TASAKA, A. C.; CALORE, E. E.; CAVALIERE, M. J.; DAGLI, M. L. Z.; HARAGUCHI, M.; GÓRNIAK, S. L. Experimental poisoning in rabbits fed with Senna occidentalis seeds. Veterinary Research Communications, v. 24, n. 8, p. 573-582, 2000.

TIZARD, I. R. Veterinary immunology: an introduction. 6th ed. Philadelphia: W.B. Saunders, 2000. $482 p$

TOKARNIA, C. H.; DÖBEREINER, J.; PEIXOTO, P. V. Plantas tóxicas do Brasil. Rio de Janeiro: Helianthus, 2000. $310 \mathrm{p}$.

VAN ARMAN, C. G.; BEGANY, A. J.; MILLER, L. M.; PLESS, H. H. Some details of the inflammations caused by yeast and carrageenan. Journal of Pharmacology and Experimental Therapeutics, v. 150, n. 3, p. 328-334, 1965.

VAN FURTH, R. (Ed.). Mononuclear phagocytes: functional aspects. The Hague. The Netherlands: Nijhoff, 1980. p. 11-31.

VOSS, K. A.; BRENNECKE, L. H. Toxicological and hematological effects of sicklepod (Cassia obstusifolia) seeds in Sprague- Dawley rats: a subchronic feeding study. Toxicon, v. 29, n. 11, p. 1319-1336, 1991.

WEG, R. Indução de miopatia tóxica em ratos tratados com sementes de Senna occidentalis. 2001. 70 f. Tese (Doutorado em Ciências). Faculdade de Medicina Veterinária e Zootecnia da Universidade de São Paulo, São Paulo, 2001.

WINTER, C. A.; RISLEY, E. A.; NUSS, G. W. Carrageenin-induced edema in the hind paw of the rat as an assay for anti-inflammatory drugs. Proceedings of the Society for Experimental Biology and Medicine. Society for Experimental Biology and Medicine., v. 111, n. 3, p. 544-547, 1962. 
WITTE, P. Metabolism and pharmacokinectics of anthranoids. Pharmacology, v. 1, n. 47, p. $86-97,1993$. 